\title{
2 Widersprüche eines Entwicklungsstaates: Tansania in der Ujamaa-Ära
}

Der tansanische Entwicklungsstaat war zutiefst widersprüchlich und hatte historische Vorläufer: zuerst das omanische Sultanat, dessen Herrschaftsbereich sich auf Sansibar und einen schmalen Küstenstreifen am Festland ausdehnte, sowie in der Folge die deutsche und britische Kolonialverwaltung über weitere Teile des Festlandes. Die Anfang des 19. Jahrhunderts eingeführte Gewürznelken- und Sklavenökonomie leitete Sansibars Aufstieg zum zentralen Handelsstützpunkt an der ostafrikanischen Küste ein. In den 1860er-Jahren setzte Sultan Majid (18561870) Maßnahmen, um ein politisches, administratives und wirtschaftliches Machtzentrum auf dem Festland zu etablieren - das spätere Dar es Salaam. Majid und sein Nachfolger Bargash (1870 - 1888) betrieben eine Modernisierungspolitik, die von internationalen Beispielen in Indien oder Ägypten inspiriert war. Aus dem Jemen und aus Indien warb Majid Händler an und ermutigte sie, in Kokosnussplantagen und Karawanenhandel $\mathrm{zu}$ investieren, weiterhin verpflichtete er europäische und US-amerikanische Berater. ${ }^{1}$ Bargash zeigte sich 1875 von einem Besuch beim Khediven in Kairo beeindruckt und versuchte, die ägyptische Politik auf Sansibar zu übertragen; Wasserleitungen, ein Kanalisationssystem und Beleuchtung waren sichtbare Zeichen urbaner Modernisierung. ${ }^{2}$

Im Zuge der europäischen imperialen Expansion Ende des 19. Jahrhunderts kam Sansibar unter britischen Einfluss. Für das Festland bekam die private Deutsch-Ostafrikanische Gesellschaft 1885 einen „Schutzbrief“ des Deutschen Reiches ausgestellt. Angesichts des anhaltenden Widerstands vonseiten afrikanischer Gesellschaften und der Schwäche dieser Privatgesellschaft intervenierte die deutsche Regierung mit militärischen Mitteln und übernahm die Verwaltung 1891 selbst. Den kolonialen Eliten dienten die Entwicklungsinterventionen in erster Linie dazu, die Herrschaft auf neue Räume auszuweiten und abzusichern sowie die Ausbeutung von Rohstoffen und Arbeitskraft $\mathrm{zu}$ intensivieren. Die deutsche Kolonialherrschaft (1885-1918) über das Festland blieb vorerst ein

1 James R. Brennan/Andrew Burton, The Emerging Metropolis: A History of Dar es Salaam circa 1862-2000, in: James R. Brennan u.a., Hg., Dar es Salaam: Histories from an Emerging African Metropolis, Dar es Salaam 2007, S.13-75, hier: S. 14-19; Jürgen Becher, Dar es Salaam, Tanga und Tabora. Stadtentwicklung in Tansania unter deutscher Kolonialherrschaft (1885-1914). Stuttgart 1997, S. 28-29; Eric Burton, Development Concepts of Peasants, Poets and Dancers in German East Africa ca. 1870 -1918, Diplomarbeit, Wien 2013, Kap. 3.3.

2 Roman Loimeier, Eine Zeitlandschaft in der Globalisierung. Das islamische Sansibar im 19. und 20. Jahrhundert, Bielefeld 2012, S. 24-26.

Ә OpenAccess. ( 2021 Eric Burton, publiziert von De Gruyter. (cc)BY Dieses Werk ist lizenziert unter der Creative Commons Attribution 4.0 International Lizenz. https://doi.org/10.1515/9783110705621-005 
„militärischer Despotismus“, der mit Gewalt den Widerstand lokaler Bevölkerungen brechen sollte. ${ }^{3}$ Zwischen 1888 und 1905 wurden 84 bewaffnete Konflikte gezählt, der verhängnisvollste davon der Maji Maji-Krieg (1905-1907), in dem die Kolonialtruppen auch die Taktik der verbrannten Erde anwandten. Geschätzte 300.000 Menschen fielen den militärischen Disziplinierungsmaßnahmen im Süden Tansanias zum Opfer. ${ }^{4}$ Erst nach 1907 etablierte sich eine zivile Kolonialverwaltung, deren Einfluss aber weiterhin auf „Inseln der Herrschaft“ beschränkt blieb. ${ }^{5}$ Investitionen in die Infrastruktur (u.a. der Bau von Eisenbahnstrecken), geologische Erkundungen, Bildung und Gesundheit standen ganz im Zeichen einer kolonialen Inwertsetzung des Territoriums als Rohstoffquelle und Absatzmarkt. ${ }^{6}$ Sozioökonomische Transformationen durch Landnahme, die Ausweitung der Plantagenwirtschaft, Arbeitsmigration oder die Ausweitung christlicher Mission waren regional höchst ungleichmäßig verteilt.

Nach der Niederlage im Ersten Weltkrieg musste das Deutsche Reich sämtliche Kolonien an die Siegermächte abtreten. Unter britischer Herrschaft (19221961), erst unter Völkerbundmandat und nach dem Zweiten Weltkrieg in Form eines UN-Treuhandgebiets, war das nunmehr Tanganjika genannte Territorium Experimentierraum für die „indirekte Herrschaft“. Mit der Einbeziehung lokaler Eliten sollte der soziale Wandel zugunsten politischer Stabilität minimiert und die vermeintlich traditionellen, tribalen Organisationsstrukturen gestärkt werden was bisweilen einer Erfindung von „Stämmen“ und ihren Traditionen gleichkam. ${ }^{7}$ Die Herrschaft wurde mit rassistischen Strukturen abgesichert, in denen sich die dreistufige Hierarchie von „Europäern“, „Indern“ und „Afrikanern“ weiter verfestigte.

Nach dem Zweiten Weltkrieg versuchte das hoch verschuldete Großbritannien höhere Einkünfte in den abhängigen Territorien zu generieren. Der neue Kurs des „Entwicklungskolonialismus“ - in der Literatur auch als „zweite koloniale Eroberung “ bezeichnet, umfasste eine Reihe kostspieliger Ordnungs- und Interventionstechniken, darunter die Planung von Entwicklungsprojekten, Maßnah-

3 Albert Wirz, Einleitung. Körper, Raum und Zeit der Herrschaft, in: Katrin Bromber u.a., Hg., Alles unter Kontrolle! Disziplinierungsprozesse im kolonialen Tansania (1850 - 1960), Köln 2003, S. 5-36, hier: S. 12.

4 Walter Schicho, Handbuch Afrika. Band 3: Nord- und Ostafrika. Frankfurt/Main 2004, S. 313. 5 Michael Pesek, Koloniale Herrschaft in Deutsch-Ostafrika. Expeditionen, Militär und Verwaltung seit 1880, Frankfurt/Main 2005, S. 190.

6 Juhani Koponen, Development for Exploitation. German Colonial Policies in Mainland Tanzania, 1884-1914, Helsinki/Hamburg 1994; Rainer Tetzlaff, Koloniale Entwicklung und Ausbeutung: Wirtschafts- und Sozialgeschichte Deutsch-Ostafrikas 1885-1914, Berlin 1970.

7 „Europeans believed Africans belonged to tribes; Africans built tribes to belong to“ heißt es dazu pointiert bei Iliffe, Modern History, S. 324. 
men zur Verbesserung der Produktivität in der Landwirtschaft, Investitionen in Bildung und Verwaltungsreformen. ${ }^{8}$ Zunehmend griff der koloniale Staat nun auch auf Expertise und wissenschaftliches Spezialwissen zurück. ${ }^{9}$ Die kolonialen Entwicklungspläne ab 1938 blieben allerdings weitgehend Makulatur, und zwar nicht nur aufgrund der zunehmenden Verschuldung Großbritanniens im Zuge des Zweiten Weltkriegs. ${ }^{10}$ Wie tansanische Politiker im Rahmen von Verhandlungen nach der Unabhängigkeit immer wieder betonten (Armut und „Rückständigkeit“ waren stichhaltige Argumente für entwicklungspolitische Ressourcentransfers), hatte Tanganjika aufgrund des Mandatsstatus deutlich weniger Investitionen als z.B. Uganda oder Kenia erhalten und verfügte dementsprechend nur über ein rudimentäres Bildungssystem und keinerlei nennenswerte industrielle Kapazitäten. ${ }^{11}$

Die nationalistische Befreiungsbewegung Tanganyika African National Union (TANU), die sich 1954 unter der Führung des in Uganda und Schottland ausgebildeten Lehrers Julius Kambarage Nyerere formiert hatte, gewann nicht zuletzt aufgrund weithin unbeliebter kolonialer Entwicklungsinterventionen schnell eine Massenbasis. ${ }^{12}$ Der Rückhalt der TANU lag gerade in den Regionen, wo die Verwaltung massiv in landwirtschaftliche Praktiken mit Argumenten der Erosionskontrolle, Produktionssteigerung und Modernisierung eingegriffen hatte. ${ }^{13} \mathrm{Hinzu}$ kam die allgemeine Abneigung gegen die rassistische Hierarchie, in der AfrikanerInnen Aufstiegsmöglichkeiten und Rechte verwehrt blieben, während Politik und Wirtschaft von europäischen und asiatischen Gruppen dominiert wurden. Nach Wahlsiegen 1954 und 1958 konnte Nyerere 1960 eine Regierung bilden, die dann die Bedingungen für die Unabhängigkeit von Großbritannien ohne größere

8 Iliffe, Modern History, S. 436.

9 Hodge/Hödl, Introduction, S. 15-16.

10 Juhani Koponen, From Dead End to New Lease of Life: Development in South-Eastern Tanganyika from the late 1930s to the 1950s, in: Joseph Morgan Hodge u.a., Hg., Developing Africa: Concepts and Practices in Twentieth-Century Colonialism, Manchester 2014, S. 37-62, hier: S. 51-52.

11 Volkmar Köhler, Zum Stellenwert Tanzanias in der deutschen Entwicklungszusammenarbeit, in: Ulf Engel u. a., Hg., Tanzania Revisited: Political Stability, Aid Dependency, and Development Constraints 2000, S. 21-30, hier: S. 30.

12 Zur Biographie Nyereres siehe Tom Molony, Nyerere. The Early Years, Woodbridge 2014. Die TANU ging aus der 1929 gegründeten Tanganyika African Association hervor, deren Mitglieder ausschließlich Beamte waren.

13 Iliffe, Modern History, S. 523. 
Konfrontationen aushandelte. Tanganjika war damit 1961 das erste unabhängige Territorium von Britisch-Ostafrika. ${ }^{14}$

Ujamaa, als eine Variante afrikanischer Sozialismen, wie sie zu dieser Zeit auch in Mali, Ghana oder Senegal formuliert wurden, entstand in diesen Jahren als eine politische Philosophie und wurde erst im Laufe der 1960er-Jahre zur Partei- und Staatsdoktrin und Grundlage der Entwicklungspolitik Tansanias. ${ }^{15}$ Einen ersten programmatischen Text zu Ujamaa veröffentliche Nyerere 1962, also im Jahr nach der Unabhängigkeit, um dem jungen Staat eine eigene Nationalethik $\mathrm{zu}$ verleihen. $\mathrm{Zu}$ diesem Zeitpunkt verstand Nyerere den (Afrikanischen) Sozialismus nicht als sozioökonomische Formation, sondern als eine menschzentrierte „Geisteshaltung“, die sich durch „Respekt und Anerkennung für die anderen, gemeinschaftliche[n] Besitz an wichtigen Gütern wie Land [und] die Verpflichtung zur Arbeit“ auszeichnete und die Ausbeutung vom Menschen durch den Menschen verhinderte. ${ }^{16}$ Den zentralen Bezugspunkt bildete dabei eine idealisierte afrikanische Gesellschaft (im Singular), deren Geisteshaltung es wiederzubeleben galt. In ideologischer Hinsicht hatte Ujamaa Schnittmengen mit panafrikanistischen Ideen und anderen peripheren Sozialismen der 1950er und 1960er-Jahre, die unter dem Primat der Blockfreiheit zum sowjetischen Machtbereich und einem doktrinären, marxistisch-leninistischen Sozialismusverständnis auf Distanz gingen. Nyerere, selbst Sohn eines chief der kleineren Ethnie der Zanaki, griff aber auch auf afrikanische Traditionen, die katholische Soziallehre und den Sozialdemokratismus der Fabier zurück, den er während seines Studiums in Großbritannien näher kennengelernt hatte. ${ }^{17}$ Wie „Entwicklung“ wurde Ujamaa in den folgenden Jahren zu einem einflussreichen, aber stets umkämpften Schlagwort,

14 Großbritannien bevorzugte nach einer Kosten-Nutzen-Rechnung 1957 die Desintegration des Imperiums und versuchte, die Transition zum eigenen Vorteil zu gestalten. Zu den britischen Strategien zu dieser Zeit (,rapid disengagement from East Africa“, „moving rapidly from institutionalized multi-racialism to African majority rule") siehe David Birmingham, The Decolonization of Africa, London 1995, S. 211; L. J. Butler/Sarah Stockwell, Hg., The Wind of Change, London 2013.

15 Das Swahili-Substantiv jamaa bedeutet (Groß-)Familie, die Vorsilbe $u$ - abstrahiert es. Dementsprechend ließe sich der Begriff wörtlich als familyhood oder Familiensinn übertragen, oft wird er aber auch als Sozialismus übersetzt - wobei es hierfür auch den Begriff usoshialisti gibt und Ujamaa in der Regel den spezifisch tansanischen Sozialismus meint. Der Ujamaa-Begriff ist ein von Nyerere angeeigneter Neologismus, der bereits in einem Werk von Petro Itosi Marella in den 1940er Jahren geprägt wurde und dort eine harmonische Gesellschaft beschreibt. Zur politischen Terminologie siehe Emma Hunter, Political Thought and the Public Sphere in Tanzania. Freedom, Democracy, and Citizenship in the Era of Decolonization, New York 2015, S. 221.

16 Eckert, Herrschen und Verwalten, S. 223

17 Siehe hierzu Molony, Nyerere; Bjerk, Julius Nyerere 
das mit verschiedenen Inhalten gefüllt und für verschiedene Interessen angeeignet wurde.

Auf die Phase der Etablierung politischer Souveränität bis Mitte der 1960er Jahre folgte eine zweite Phase, in welcher die Regierung den Staat zunehmend als Motor sozialen Wandels positionierte und andere Akteure in die entwicklungspolitischen Transformationsstrategien integrierte. Erst die weitgehend von Nyerere verfasste Deklaration von Arusha, die 1967 vom Nationalen Exekutiv-Komitee der TANU verabschiedet wurde, ließ aus Ujamaa Partei- und Staatsdoktrin werden. Spätestens zu diesem Zeitpunkt ging das Bekenntnis zum Sozialismus in Tansania über den weitgehend rhetorischen Charakter manch anderer afrikanischer Sozialismen weit hinaus. Mit der Betonung von self-reliance, also dem Bauen auf die eigene Kraft statt auf äußere Unterstützung, war die Deklaration eine Reaktion auf außenpolitische Krisen und den Wegfall von Entwicklungshilfe (siehe unten), aber auch auf innere Probleme wie die wachsende Ungleichheit. Sie führte zur Verstaatlichung der Banken und zahlreicher Unternehmen und läutete damit die aktivste Phase des Entwicklungsstaates ein, die von 1967 bis 1975 andauerte. In dieser Phase wurde Tansania zum genuinen „Entwicklungsstaat“, ${ }^{18}$ band interne wie externe Akteure - darunter Kirchen, Moscheen und westliche Entwicklungshilfeorganisationen und staatliche Geberagenturen - in eine „Entwicklungsfront“ ein, intervenierte stärker in die Wirtschaft und begrenzte die politische Teilhabe der Gesellschaft, während diese gleichzeitig stärker in die Entwicklungsvorhaben einbezogen wurde, wie Michael Jennings festhält:

\footnotetext{
The country was to be a developmental state, with every ounce of its energy and attention, its intellectual and material resources, dedicated to raising standards of living. The dominant discourse that emerged in this period was one in which socioeconomic advancement, the nation state, and the articulation of national citizenship revolved around the fulcrum of national development. A "citizen" was one who shared these developmental aims and objectives, participated actively in projects, and accepted the responsibilities of self-reliance and community advancement. ${ }^{19}$
}

18 James C. Scott, Seeing like a State. How Certain Schemes to Improve the Human Condition Have Failed, New Haven 1998. Für eine Unterscheidung - die sich im Deutschen schwer treffen lässt - zwischen ökonomisch erfolgreichen „developmental states“ wie China oder Malaysia und geberabhängigen „development states“ wie Tansania siehe Maia Green, The Development State. Aid, Culture and Civil Society in Tanzania, Woodbridge, Suffolk 2014, S. 16. Manche Autoren sehen den Wandel zum „Etatismus“ (statism, also die stärkere Intervention in wirtschaftliche Belange, während gleichzeitig die Möglichkeiten politischer Teilhabe eingeschränkt werden) in Tansania 1967, andere erst 1969 oder 1972. Siehe Jennings, Surrogates of the State, S. 60 -64.

19 Michael Jennings, "Very Real War": Popular Participation in Development in Tanzania During the 1950s \& 1960s, in: International Journal of African Historical Studies 40/1 (2007), 
Ab Ende der 1970er-Jahre gerieten die Allianzen zunehmend unter Druck; die Hegemonie des Entwicklungsstaates wurde von mehreren Seiten herausgefordert, als Brüche zwischen der tansanischen Regierung und westlichen Gebern, aber auch in Parteikreisen selbst auftraten. 1985 trat Nyerere vom Präsidentenamt zurück und machte damit den Weg frei für die vom IWF und westlichen Gebern geforderten Strukturanpassungsprogramme. Die 1991 von der CCM verabschiedete Deklaration von Sansibar stellte dann den mehr oder minder offiziell eingestandenen Abschied vom sozialistischen Entwicklungsweg dar.

Dieser grobe chronologische Überblick darf nicht darüber hinwegtäuschen, dass der tansanische Staat - wie jeder Staat - immer ein Ensemble widerstreitender Interessen und miteinander konkurrierender Felder blieb und die Transformationsstrategie Ujamaa dadurch zwangsläufig Kompromisse, Spannungen und Gegensätze beinhalten musste. Das tansanische Experiment war, so Priya Lal, dadurch gekennzeichnet, dass es zugleich „utopisch und pragmatisch, antimodern und modernistisch, populistisch und etatistisch“ war. ${ }^{20}$ Es beinhaltete Tendenzen zur Zentralisierung und Planung ebenso wie Impulse in Richtung Dezentralisierung und Improvisation. Die Bedeutung dieser Widersprüche geht laut Lal über den Fall Tansanias hinaus, repräsentieren sie doch „die dialektische Spannung im Kern von Staatsbildungsprozessen, Sozialismus und nationaler Entwicklung in postkolonialen Kontexten“.21 Ein Fokus auf Spannungen und Antagonismen offenbart, „wie nicht-monolithisch der Staat tatsächlich war“.22

Vier Spannungen werden in diesem Kapitel skizziert, um Ansprüche und Praktiken von Ujamaa zu umreißen und die Handlungsspielräume sozialer Gruppen in einer Verschränkung von nationalen und globalen Perspektiven auszuloten. Eine erste Spannung bestand zwischen Befreiung und Autoritarismus: Auf der politischen Ebene wurde Befreiung gleichermaßen mit (meist diffusen) Hoffnungen auf eine vollständige Dekolonisierung wie auch oft (ungleich konkreteren) Vorstellungen von Entwicklung verknüpft. Wie verhielt sich „Befreiungsdiplomatie“ auf internationaler Ebene und das Bekenntnis zur Überwindung sämtlicher Ausbeutungsverhältnisse zu den zunehmend autoritären, aber keineswegs gänzlich erfolgreichen Disziplinierungspraktiken der eigenen Bevölkerung gegenüber? Daran knüpft der Gegensatz von Abhängigkeit und self-reliance an: Wie lässt sich erklären, dass sich Tansania trotz des proklamierten Ziels der

S. 71-95, hier: S. 71. Zum Begriff development front siehe Jennings, Surrogates of the State, S. $60-64$.

20 Priya Lal, African Socialism in Postcolonial Tanzania, Cambridge 2015, 11; Übersetzung E. B.

21 Ebd.; Übersetzung E. B.

22 Leander Schneider, Government of Development. Peasants and Politicians in Postcolonial Tanzania, Bloomington 2014, S. 17; Übersetzung E. B. 
Eigenständigkeit zunehmend verschuldete und in eine vertiefte Abhängigkeit vom Westen geriet? Drittens bestand eine Spannung zwischen Egalitarismus und Elitenbildung: Wie sollte eine egalitäre Gesellschaft eingeführt werden, wenn ein „pyramidales“ Bildungssystem und Vorstellungen sozialer Aufwärtsmobilität weiterhin existierten und Statusunterschiede reproduzierten? Schließlich wird auch die Frage von Einheit und Antagonismen behandelt: Wie lassen sich Grabenkämpfe und strukturelle Spannungen in der politischen und sozialen Landschaft Tansanias verstehen, wenn man annimmt, dass sich Ujamaa zeitweise als hegemoniale Ideologie im Land durchsetzen und sogar darüber hinaus ausstrahlen konnte? Alle diese Fragen betreffen das entwicklungspolitische Feld und Strategien der Extraversion, also die Mobilisierung externer Ressourcen in asymmetrischen Verhältnissen - und sind in dieser Hinsicht auch über Tansania hinaus relevant. Ein Hauptziel dieses Kapitels ist, entwicklungspolitische Interventionen nicht als externe Eingriffe in einem statischen Kontext zu verstehen, sondern diese in multiplen und teils gegenläufigen Dynamiken zu verorten. Die Ausführungen auf den folgenden Seiten bilden damit nicht nur ein Plädoyer für ein Verständnis des tansanischen Sozialismus in all seinen Widersprüchen, sondern auch gleichzeitig eine Grundlage für eine bessere Einordnung der räumlich wie zeitlich stärker fokussierten Fallstudien in den restlichen Kapiteln.

\subsection{Befreiung und Autoritarismus: Disziplinierung im Zeichen der Dekolonisierung}

Außenpolitisch war die tansanische Regierung eine prinzipienfeste Vertreterin von Antikolonialismus, Antirassismus und Antiimperialismus. Nyereres Befreiungsdiplomatie ${ }^{23}$ auf globaler Ebene brachte ein antiimperialistisches Prestige ein, das sich in politischem Einfluss niederschlug. Im Inneren hingegen setzte der Staat der Emanzipation bald Grenzen. ${ }^{24}$ Durchaus ernsthafte Bestrebungen, Entwicklung und demokratische Partizipation in einem Einparteiensystem zu vereinen, mündeten in den frühen 1970er-Jahren in zunehmend autoritären und exklusiven Herrschaftsformen. ${ }^{25}$ Nyerere war es schon in den Jahren 1961-64

23 Zum Begriff „liberation diplomacy“ siehe Ng'wanza Kamata, The Economic Diplomacy of Tanzania. Accumulation by Dispossession in a Peripheral State, in: Agrarian South. Journal of Political Economy 1/3 (2013), S. 291-313.

$24 \mathrm{Zu}$ den vielschichtigen Aneignungen des Freiheitsbegriffs (uhuru) in Tansania, siehe Hunter, Political Thought, Kap. 5.

25 Die Rolle Tansanias im Befreiungskampf im sub-saharischen Afrika ist aus historischer Sicht bisher noch nicht adäquat aufgearbeitet worden. Einige Publikationen, die sich mit diesem 
gelungen, Oppositionsparteien auszuschalten, traditionelle Autoritäten (chiefs) sowie Vereinigungen auf ethnischer oder religiöser Basis zu entmachten, die Gewerkschaften gleichzuschalten und damit dem Verbund von Partei und Regierung zu einem Machtmonopol zu verhelfen ${ }^{26}$ Trotzdem waren die staatlichen Disziplinierungsversuche gegenüber der Bevölkerung in der interventionistischen Phase ab 1967 nur bedingt erfolgreich - im Gegensatz zum langfristigen und international anerkannten Engagement für die Befreiungsbewegungen.

\section{Befreiung als Außen- und Innenpolitik}

Schon vor der Unabhängigkeit hatte sich die TANU dem panafrikanischen Gedanken verschrieben, dass die eigene Freiheit erst erreicht sein würde, wenn der gesamte afrikanische Kontinent den Kolonialismus besiegt hatte. Die PAFMECA (Pan-African Freedom Movement of East and Central Africa), in der sich diese Bestrebungen institutionalisierten, wurde 1958 von der TANU mitgegründet und hauptsächlich von ihr finanziert. ${ }^{27}$ Nach der Unabhängigkeit wurde Tansania ${ }^{28} \mathrm{zu}$ einem Drehkreuz des antikolonialen Befreiungskampfes, zur Exilheimat afrikanischer Befreiungsbewegungen und deren Sprungbrett zu Militärausbildungen in Algerien, China, Osteuropa oder Kuba. In den folgenden Jahren erlaubte Tansania dem ANC und PAC aus Südafrika, der angolanischen MPLA, der mosambikani-

Thema befasst haben, greifen kaum auf Archivmaterialien oder Interviews mit ZeitzeugInnen zurück und neigen zur Glorifizierung Nyereres und Tansanias: Shubi L. Ishemo, „A symbol that cannot be substituted": The role of Mwalimu J K Nyerere in the liberation of Southern Africa, 1955-1990, in: Review of African Political Economy 27/83 (2000), S. 81-94; Annar Cassam/ Chambi Chachage, Hg., Africa's Liberation. The Legacy of Nyerere, Nairobi 2010. Die bisher gründlichste Einführung ist Arnold Temu u. a., Tanzania and the Liberation Struggle of Southern Africa, 1961 to 1994, in: Arnold J. Temu/Joel das Neves Tembe, Hg., Southern African Liberation Struggles: Contemporaneous Documents, 1960 -1994, Volume 6 (Frontline States - Continued), Dar es Salaam 2014, S. 5-78; siehe auch Arrigo Pallotti, Post-Colonial Nation-Building and Southern African Liberation: Tanzania and the Break of Diplomatic Relations with the United Kingdom, 1965-1968, African Historical Review, 41/2 (2009), S. 60 - 84.

26 Henry Bienen, Tanzania: Party Transformation and Economic Development, Expanded Edition, Princeton 1970, S. 26; Steven Feierman, Peasant Intellectuals. Anthropology and History in Tanzania, Madison, Wisconsin 1990, S. 230; Iliffe, Modern History, S. 569; Mahmood Mamdani, Citizen and Subject. Contemporary Africa and the Legacy of Late Colonialism, Princeton 1996, S. 287.

27 Paul Bjerk, Building a Peaceful Nation. Julius Nyerere and the Establishment of Sovereignty in Tanzania, 1960 - 1964. Woodbridge 2015, S. 185.

28 Im Sinne der Einheitlichkeit und Lesbarkeit ist im Folgenden mit Tansania auch Tanganjika vor 1964 gemeint. 
schen FRELIMO, der namibischen SWAPO, der ZAPU und ZANU aus Simbabwe und anderen Befreiungsbewegungen, die gegen Kolonialherrschaft und weiße Minderheitsregime kämpften, die Einrichtung von Büros, den Empfang von Waffenlieferungen aus kommunistischen Ländern und die Errichtung von Flüchtlings- und Trainingscamps sowie Bildungsinstitutionen. ${ }^{29}$ In Anerkennung dieses Engagements eröffnete das Befreiungskomitee der Organisation für Afrikanische Einheit sein Hauptquartier 1963 in Dar es Salaam. Nyerere galt weithin manchen noch vor Kwame Nkrumah, Gamal Abdel Nasser, Ben Bella oder Sékou Touré - als ein entscheidender Unterstützer des bewaffneten Befreiungskampfes in Afrika. ${ }^{30}$

Die Unterstützung für die Befreiungsbewegungen brachte Prestige, machte aus Tansania aber auch einen Brennpunkt geopolitischer Rivalitäten und einen Schauplatz des Gerangels der großen Mächte um politischen Einfluss. Mit der Entfaltung des sino-sowjetischen Konflikts diskreditierten sich kommunistische Solidaritätskomitees gegenseitig. China warnte die afrikanischen Staaten vor der Sowjetunion und ihrem ,sham support but real betrayal, sham unity but real split in the Afro-Asian peoples' solidarity movement"“. ${ }^{31}$ Die Botschaften Chinas, der Sowjetunion und der USA lieferten sich einen Wettlauf darin, die akademisch aussichtsreichsten Flüchtlinge aus Südafrika mit Stipendien auszustatten. ${ }^{32}$ Auch die DDR hatte bereits einzelne KandidatInnen aufgenommen; die BRD zog 1963 nach und zeigte sich - ohne freilich die Befreiungsbewegungen in irgendeiner Weise politisch anzuerkennen - in einigen Fällen bereit, „den Flüchtlingen aus den noch nicht ,befreiten' Gebieten zu helfen, ihre akademische Ausbildung in Deutschland zu beenden“.33

Die tansanische Befreiungsdiplomatie war zwar prinzipiengeleitet, aber auch realistisch und pragmatisch. ${ }^{34}$ Der tansanische Einfluss setzte den weißen Minderheitsregimen im südlichen Afrika Widerstand entgegen und entzog ihnen

29 Temu u.a., Tanzania and the Liberation Struggle.

30 Piero Gleijeses, Conflicting Missions. Havana, Washington, and Africa, 1959-1976, Chapel Hill 2002, S. $85-92$; S. $243-248$.

31 Chama cha Mapinduzi Archiv (CCMA), ADM/449, Statement by the Chinese Committee for Afro-Asian Solidarity on the So-Called Council Session of the Afro-Asian Peoples' Solidarity Organization to be Held in Cyprus in February 1967.

32 BArch Koblenz, B 212/26037, Hauck (DAAD) an BRD-Botschaft Dar es Salaam, o.O., 16.4.1963; ebd., Götz (BRD-Botschaft) an DAAD-Generalsekretär Scheibe, Dar es Salaam, 2.11.1962; Schoeller (BRD-Botschaft) an AA, Dar es Salaam, 13.7.1962.

33 BArch Koblenz, B 212/26037, Götz (BRD-Botschaft) an Scheibe (DAAD), Dar es Salaam, 2.11. 1962; ebd., Scheibe (DAAD) an BRD-Botschaft Dar es Salaam, o.O., 16.10.1962.

34 Bjerk, Building a Peaceful Nation, 183-184, 205; George Roberts, Politics, Decolonisation, and the Cold War in Dar es Salaam c. 1965-72, PhD Thesis, Warwick 2016, S. 112. 
Legitimität; er verschaffte Tansania auch mehr Manövrierfähigkeit auf dem internationalen Parkett. Wie Julian Go festhält, stellte ein antikolonialer Standpunkt in der zweiten Hälfte des 20. Jahrhunderts wichtiges symbolisches Kapital im globalen politischen Feld dar. ${ }^{35}$ Tansania konnte dieses Prestige und den regionalen Einfluss für andere politische oder wirtschaftliche Ziele einsetzen. Die USBotschaft schätzte etwa 1978 ein, dass Tansania allein aus strategischer und handelspolitischer Sicht für die USA unbedeutend war, aber Nyerere aufgrund seines Einflusses in der UN und bei den Frontlinienstaaten ${ }^{36}$ unbedingt als Verbündeter gewonnen werden musste, um die Konflikte in und um Rhodesien, Namibia und Südafrika im US-Interesse möglichst auf nichtmilitärischem Wege zu lösen. ${ }^{37}$ Im Rahmen der Blockfreienbewegung forderte Nyerere die Neustrukturierung der Handelsbeziehungen zwischen dem globalen Norden und dem globalen Süden und positionierte sich als „Gewerkschafter der Armen“. ${ }^{38}$ Das symbolische Kapital Tansanias und Nyereres Einfluss in politischen Fragen blieben über Jahrzehnte (trotz einiger umstrittener Parteinahmen, z. B. für die Sezession Biafras 1967-1970) beträchtlich, obwohl ab Mitte der 1970er-Jahre Luanda und Lusaka zu neuen Zentren des Befreiungskampfs wurden und die Eskalation des globalen „Kalten Krieges“ in mehreren heißen Kriegen in den 1980er-Jahren die Einflusssphären zum Nachteil Tansanias verschob. ${ }^{39}$ Damit verringerte sich einerseits der diplomatische Spielraum, andererseits wurden Tansanias sozialistischer Entwicklungsweg und die blockfreie Position in den USA und anderen westlichen Ländern im Rahmen der wieder verschärften Systemkonkurrenz und Polarisierung zunehmend negativ bewertet. ${ }^{40}$

35 Julian Go, Global Fields and Imperial Forms: Field Theory and the British and American Empires, in: Sociological Theory 26/3 (2008), S. 201-229.

36 Die Gruppe der Frontline States wurde 1974 gegründet und bestand bis zum Ende der Apartheid 1994. Die Organisation vereinte jene souveränen Länder des südlichen Afrika, die geographisch an die noch von weißen Minderheitsregimen beherrschten Staaten angrenzten und den bewaffneten Befreiungskampf unterstützten. Die Gruppe war zeitweise ein wichtiger Akteur im Dekolonisierungsprozess und in Friedensverhandlungen.

37 Wikileaks, US-Botschaft an Secretary of State, Dar es Salaam, 8.12.1978. wikileaks.org/plusd/cables/1978DARES05351_d.html (Zugriff: 27.7.2016).

38 Priya Lal, African Socialism and the Limits of Global Familyhood. Tanzania and the New International Economic Order in Sub-Saharan Africa, in: Humanity: An International Journal of Human Rights, Humanitarianism, and Development 6/1 (2015), S. 17-31.

39 Andrew Coulson, Tanzania. A Political Economy, 2. Aufl., Oxford 2013, S. 354--356; Roberts, Politics, S. 207.

40 Joel Samoff, Theory and Practice in the Analysis of Tanzanian Liberalization: A Comment, in: Horace Campbell/Howard Stein, Hg., Tanzania and the IMF: The Dynamics of Liberalization, Boulder 1992, S. 171-188, hier: S. 178. 
Länder, die Befreiungsbewegungen unterstützten, waren imperialistischen Angriffen ausgesetzt und riskierten auch die Austragung von Fraktionskämpfen auf eigenem Boden. Portugiesische Truppen und Flugzeuge intervenierten wiederholt auf tansanischem Boden. 1969 wurde FRELIMO-Anführer Eduardo Mondlane durch eine Briefbombe 1969 in Dar es Salaam ermordet. ${ }^{41} 1970$ fiel Nyereres Freund und Präsident Ugandas Milton Obote einem Putsch durch Idi Amin zum Opfer. Im Oktober 1970 drang eine portugiesische Söldnertruppe aus Guinea-Bissau in Sékou Tourés Guinea ein und versuchte im Zuge eines letztlich erfolglosen Putschversuchs, portugiesische Kriegsgefangene zu befreien und die Befreiungsbewegung für die Unabhängigkeit Guineas und Kap Verdes auszuschalten. ${ }^{42}$ Die letzten zwei Ereignisse fielen in eine Zeit, als in Tansania gerade ein Prozess wegen „Hochverrats“ gegen mehrere hochrangige tansanische PolitikerInnen geführt wurde. Das schaffte ein Klima der Bedrohung von innen und außen, das sich auf die Innenpolitik auswirkte. Die neuen Parteirichtlinien (Mwongozo), die das National Executive Council der TANU 1971 in einer Notfallsitzung nach dem Coup in Uganda verabschiedete, gingen explizit auf die Ereignisse im Nachbarland und in Guinea ein. Sie warnten vor Neokolonialismus und der kapitalistischen Penetration Afrikas und forderten mehr „Wachsamkeit“ in der Bevölkerung gegen Eindringlinge. ${ }^{43}$ Die neuen Richtlinien läuteten vier Jahre nach der Deklaration von Arusha die Militarisierung der Gesellschaft ein. Angestellte, Arbeiter, Studenten und Sekundarschüler (da „nationale Sicherheit“ als männliche Aufgabe gesehen wurde, handelte es sich größtenteils um Männer) wurden zu mehrmonatigen paramilitärischen Ausbildungen eingezogen, um die Nation gegen innere und äußere Feinde zu verteidigen; im ganzen Land wurden Milizen (mgambo) gebildet, eine bis heute existierende Institution. Nationalisierungsanstrengungen in allen Sphären der Gesellschaft - Wirtschaft, Verwaltung, Bildung, Kultur - waren mit dem Aufruf zur „Wachsamkeit“ gegenüber imperialistischer Subversion verbunden. ${ }^{44}$

Der Befreiungskampf war also nicht nur in diplomatischen Kreisen, sondern auch in der tansanischen Gesellschaft sehr präsent. Beinah täglich füllten Schlagzeilen über den Fortgang der Befreiungskämpfe im südlichen Afrika und im Rest der Welt die Titelseiten der Zeitungen. Die mithilfe von Ujamaa und der lingua franca Swahili neu konstruierte, nationale tansanische Identität, verbreitet

41 George Roberts, The Assassination of Eduardo Mondlane. FRELIMO, Tanzania, and the Politics of Exile in Dar es Salaam, in: Cold War History 17/1 (2016), S. 1-19.

42 Rui Lopes, West Germany and the Portuguese Dictatorship, 1968-1974: Between Cold War and Colonialism, Houndmills 2014; S. 25; Roberts, Politics, S. 174-175.

43 Aminzade, Race, S. 198-199.

44 Lal, African Socialism, Kap. 2. 
über die ideologischen Staatsapparate (das Bildungssystem und die Medien), war mit Stolz für die eigene Rolle im geschichtsträchtigen Befreiungsprozess verbunden. ${ }^{45}$ Hatte Nyerere Anfang der 1960er-Jahre noch auf eine „traditionell afrikanische“ Disposition zu Fleiß und gerechter Verteilung gesetzt, sah er politische Bildung als zunehmend unverzichtbar an, um der Bevölkerung eine sozialistische Geisteshaltung anzuerziehen. Die Jugendorganisation der Partei, die TANU Youth League (TYL), sowie der 1963 eingerichtete National Service, ${ }^{46}$ den alle SekundarschulabsolventInnen zu durchlaufen hatten, impften Patriotismus (uzalendo), Disziplin, Loyalität, Pflichtbewusstsein und Selbstaufopferung als anstrebenswerte Werte ein. ${ }^{47}$ Junge Männer und Frauen marschierten im National Service, der auch „Nation-Building Army“ (Jeshi la kujenga Taifa) hieß, und sangen dabei blutrünstige Lieder gegen die weißen Minderheitsregime in Südrhodesien und Südafrika. Das vermittelte ein progressives Selbstbild, denn die Lieder - so erinnert sich der Journalist Godfrey Mwakikagile - machten aus jungen StaatsbürgerInnen internationalistische BefreiungskämpferInnen, die über die Landesgrenzen hinaus eine geschichtswirksame Rolle einnahmen:

[W]e were on the frontline of the African liberation struggle and should be ready to defend our country, anytime and at any cost, and be prepared to fight alongside our brothers and sisters still suffering under colonialism and racial oppression anywhere on the continent. ${ }^{48}$

Nicht nur Mwakikagile sah sich an der Spitze des globalen Widerstands gegen Imperialismus, Apartheid und Kapitalismus. SekundarschülerInnen spendeten, um den Kauf von Waffen für Befreiungsbewegungen zu finanzieren, Mitglieder der TANU Youth League meldeten sich freiwillig für Kampfeinsätze gegen die portugiesische Kolonialmacht in Guinea-Bissau und zahlreiche BürgerInnen spendeten Blut für die mosambikanische FRELIMO. ${ }^{49}$ Der Antiimperialismus of-

$45 \mathrm{Zu}$ den Parteitageszeitungen siehe William Tordoff/Ali A. Mazrui, The Left and the Super-Left in Tanzania, in: The Journal of Modern African Studies 10/3 (1972), S. 427-445, hier: S. 437-438. 46 In Tansania war Delegations- und Personalaustausch mit Israel und Jugoslawien zentral für die Einrichtung des National Service. Inspirationen kamen aber auch aus Delegationsbesuchen nach Ghana. Siehe Lal, African Socialism, 50 - 51.

47 Issa Mruma, Tanga Work for Youth, in: Uhuru, 17.2.1978; G. Thomas Burgess, To Differentiate Rice from Grass. Youth Labor Camps in Revolutionary Zanzibar, in: Andrew Burton/Hélène Charton-Bigot, Hg., Generations Past: Youth in East African History, Athens 2010, S. 221-236. 48 Godfrey Mwakikagile, Tanzania Under Mwalimu Nyerere: Reflections on an African Statesman, Dar es Salaam 2006, S. 135.

49 CCMA, THQ/C.50/11, T. J. Yamboboto (TANU-Sektion Mpanda) an TANU-Generalsekretär, Mpanda, 14. 2.1973, Bl. 9; ebd., Gwaponile Akim Mwanjabala (TYL-Vorsitzender Mkwawa High School) an Secretary Liberation Committee, Iringa, 5.6.1968, Bl. 8; Aminzade, Race, S. 196-197. 


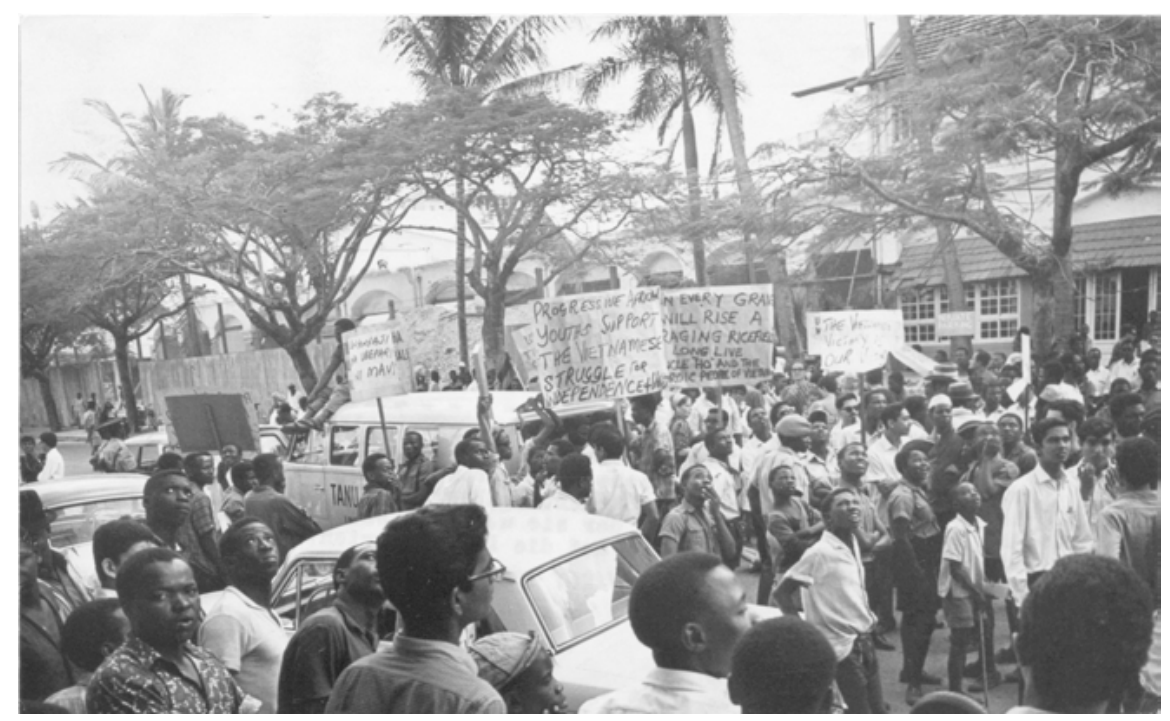

Abbildung 2.1: Proteste im Sinne des antiimperialistischen Entwicklungsstaates: Studierende und Jugendliche protestieren vor der US-Botschaft gegen den Vietnam-Krieg und Kapitalismus. Fotografie, Dar es Salaam, 31.7.1968 (Quelle: UAL, Fotosammlung UZ 146_N0017)

fenbarte sich in Demonstrationen gegen die USA und den Vietnamkrieg (Abbildung 2.1) ebenso wie in Protesten gegen den Einmarsch der Sowjetunion in die ČSSR. Die Partei versuchte, den Aktivismus der Jugend zu kanalisieren. Viele Proteste wurden von der TANU oder der Jugendorganisation initiiert oder unterstützt (siehe das Fahrzeug mit der Aufschrift „TANU“ in der Abbildung) und von entsprechenden Stellungnahmen in den Medien flankiert. ${ }^{50}$ Regierung und Massenorganisationen zielten darauf ab, das politische Potenzial der Jugend $\mathrm{zu}$ monopolisieren. Die jugendliche Avantgarde sollte ihre Energie in Übereinstimmung mit nationalstaatlichen Interessen einsetzen. Erscheinungen der „Dekadenz“, des eigennützigen Materialismus und Karrierismus galten der Führungsschicht als moralische und nationsgefährdende Übel; ebenso die radikalen linken Strömungen an der Universität, die wiederholt die Legitimität der Elite infrage stellten. ${ }^{.1}$

50 Roberts, Politics, S. 161.

51 Andrew Michael Ivaska, Cultured States. Youth, Gender, and Modern Style in 1960s Dar es Salaam, Durham 2011, S. 20, 146. 


\section{Grenzen der Emanzipation von unten}

Die Kehrseite der Wahrnehmung äußerer Bedrohungen war die Uniformierung und Einschränkung des öffentlichen Lebens in Tansania. Die globalen Spannungen von Kaltem Krieg und Dekolonisierung boten - wie anderswo auf der Welt - Anlass für generalisiertes Misstrauen sowie einen erhöhten Grad der Militarisierung der Gesellschaft und staatlicher Repression..$^{52}$ Mit der Gerinnung von Ujamaa zur Staatsdoktrin, der Ausschaltung der politischen Opposition und der verfassungsmäßigen Festschreibung der „Einparteidemokratie“ 1964/65 wurden bürgerliche Rechte sukzessive eingeschränkt; Kritik und Debatte waren bis Mitte der 1980er-Jahre nur noch in wenigen geschützten Räumen möglich..53 Die Bedrohungsszenarien imperialistischer Invasion und neokolonialer Einflussnahme leisteten der Beschwörung von „Feinden der Nation“ Vorschub. Das Misstrauen äußerte sich gegenüber allen möglichen Kategorien von „Fremden“ wie Flüchtlingen, „Indern“ oder expatriates.

Einige Gruppen in Tansania interpretierten den Anspruch der self-reliance als Aufruf, die Verwestlichung abzuwehren und zur „afrikanischen Tradition“ zurückzukehren. Gerade junge Männer im urbanen Raum - die „Grünen Garden“ griffen dazu auch auf Aktivismusformen und Organisationsmuster aus Fernost zurück. ${ }^{54}$ Ab Mitte der 1960er befürworteten mehrere ranghohe TANU-PolitikerInnen die Annäherung an das chinesische Entwicklungsmodell und priesen chinesische ArbeiterInnen, die in Tansania u.a. zu Tausenden an der Eisenbahnverbindung nach Sambia arbeiteten, für ihre vorbildliche Selbstdisziplin und

52 Dass Nyerere vor allem aufgrund des verringerten Spielraums auf internationaler Ebene zunehmend zu autoritären Mitteln im Inneren griff ist eine zentrale These von Roberts, Politics. Den Vergleich mit der Cold War culture in den USA zieht Lal, African Socialism, S. 60-69, S. 95. Lal bezieht sich u.a. auf Xenophobie, Geschlechterrollen und Familienbilder sowie die Militarisierung der Gesellschaft.

53 „Criticism has been limited to that produced by the President himself, the writings of the University based Marxist left and complaints about lost postal orders and examination certificates in the letter pages of the daily press. “John Arnold, The Internal Debate, in: Tanzanian Affairs, 14 (1982), S. 14-16, hier: S. 14. Siehe auch James R. Brennan, Julius Rex. Nyerere through the Eyes of his Critics, 1953-2013, in: Journal of Eastern African Studies 8/3 (2014), S. 459-477. Zur „Einparteidemokratie“ und Ujamaa als Konzept, das bestehende Diskurse effektiv miteinander verband, siehe Hunter, Political Thought, Kap. 7.

54 G. Thomas Burgess, Cinema, Bell Bottoms, and Miniskirts: Struggles over Youth and Citizenship in Revolutionary Zanzibar, in: International Journal of African Historical Studies 35/2-3 (2002); Kelly M. Askew, Performing the Nation. Swahili Music and Cultural Politics in Tanzania, Chicago 2002, S. 159-169; Ivaska, Cultured States. 
Genügsamkeit. ${ }^{55}$ Der neue Mensch sollte auch im tansanischen Sozialismus „materialistisch produzieren“, also möglichst viel Output erzeugen, aber „nichtmaterialistisch konsumieren“, also möglichst wenig selbst begehren. ${ }^{56}$

Disziplin und harte Arbeit galten zugleich als Voraussetzungen für Entwicklung und als Symbole postkolonialer Modernität. ${ }^{57}$ Uhuru na jasho („Freiheit und Schweiß“) und Uhuru na kazi („Freiheit und Arbeit“) waren die Wahlsprüche der TANU als Befreiungsbewegung sowie der jungen Nation, als deren größten Feind die Partei die Faulheit bezeichnete. ${ }^{58}$ „Feinde der Nation“ waren im weiteren Sinne all jene, die nicht zur „Entwicklung“ (im Sinne der politischen Ebene) beitrugen und die offizielle Autorität unterliefen, darunter auch „Gammler“ (wazembe) und „Faulpelze“ (wavivu), die als „Parasiten“ bzw. „Ausbeuter“ (wanyonyaji) und „Blutsauger“ (kupe mrija) galten. ${ }^{59}$ Ein Schlüsselmoment war hier die Verkündung der bereits erwähnten Parteirichtlinien im Jahr 1971. Diese hatten die Arbeiterschaft zur Mitbestimmung und dem Kampf gegen Ausbeutung und koloniale Attitüden auch am eigenen Arbeitsplatz aufgerufen, Anweisungen sollten nicht länger einfach nur um der Autorität willen hingenommen werden. Tatsächlich nahmen viele ArbeiterInnen, mit der Unterstützung der neu eingerichteten betrieblichen Parteizellen und Arbeiterräte, die Parteirichtlinien als Grundlage für die Denunziation korrupter und arroganter Manager (Tansanier wie expatriates), da sie besagten: „For a Tanzanian leader it must be forbidden to be arrogant, extravagant, contemptuous and oppressive." ${ }^{\text {60 }}$ Die Parteirichtlinie vertrat nun einen explizit machtkritischen Entwicklungsbegriff, der Fortschritt mit Befreiung gleichsetzte: „For people who have been slaves or have been oppressed, exploited and disregarded by colonialism or capitalism, ,development means ,liberation““. ${ }^{61}$ War der populäre Widerstand gegen Korruption und Selbstberei-

55 Monson, Africa's Freedom Railway, S. 7-10, S. 37; Priya Lal, Maoism in Tanzania: Material Connections and Shared Imaginaries, in: Alexander C. Cook, Hg., Mao’s Little Red Book: A Global History, Cambridge 2014, S. 96-116.

56 G. Thomas Burgess, A Socialist Diaspora: Ali Sultan Issa, the Soviet Union and the Zanzibari Revolution, in: Maxim Matusevich, Hg., Africa in Russia, Russia in Africa: Three Centuries of Encounters, Trenton, NJ 2007, S. 263-291, hier: S. 284.

57 Monson, Africa's Freedom Railway, S. 9; Andreas Eckert, „We Must Run While Others Walk“: African Civil Servants, State Ideologies and Bureaucratic Practices in Tanzania, from the 1950s to the 1970s, in: Thomas Bierschenk/Olivier de Sardan, Jean-Pierre, Hg., States at Work: Dynamics of African Bureaucracies, Leiden 2014, S. 205-219, hier: S. 216.

58 Bjerk, Building a Peaceful Nation, S. 66-67.

59 Göran Hydén, Beyond Ujamaa in Tanzania. Underdevelopment and an Uncaptured Peasantry, London 1980, S. 167.

60 Zit. nach Issa G. Shivji, Class Struggles in Tanzania, London 1978, S. 121.

61 The Standard, The Dar Declaration, 22.2.1971, 3, zit. nach Aminzade, Race, S. 176. 
cherung noch im Sinne der Parteiführung, so entsprachen die zahlreichen wilden Streiks, Fabrikübernahmen und der Zusammenbruch der Arbeitsdisziplin nicht mehr ihren Intentionen. Marxistische Autoren in Tansania begrüßten die Ereignisse als Ausbruch des revolutionären Klassenkampfs, Regierung und Bürokratie hingegen sorgten sich um einbrechende Produktionszahlen und die Gefährdung staatlich-sozialistischer Ordnung und Autorität. ${ }^{62}$

Polizeieinsätze, Entlassungen und „Repatriierungen“ sollten die Disziplin wiederherstellen. Anfangs unentschlossen im Umgang mit den Konflikten ging die politische Führung ab 1973/74 entschiedener vor, um Arbeitsdisziplin herzustellen und in die Produktionsbeziehungen einzugreifen. Streiks waren praktisch schon 1962 zur illegalen Praxis erklärt und durch die Kooptierung der Gewerkschaften weiter entschärft worden, zusätzlich wurden nun eine Reihe „disziplinarischer Vergehen“ zu legitimen Gründen für eine Entlassung ohne vorherige Verwarnung erklärt. ${ }^{63}$ In den Tageszeitungen der Partei wurde die „Faulheit“ am Arbeitsplatz in Leserbriefen und Gedichten verdammt und zur Sünde stilisiert. ${ }^{64}$ Tabitha Siwale, Ministerin des Ressorts Housing and Lands, erinnerte die ArbeiterInnen 1975 an ihre Pflicht, „den Befreiungskampf der Arbeit“ wie den Befreiungskampf gegen den Kolonialismus zu führen. ${ }^{65}$ Dieser von oben ausgerufene „Kampf“ zielte allerdings auf die Erhöhung der Produktivität, nicht auf bessere Arbeitsbedingungen. Gleichzeitig wies Siwale nämlich Forderungen nach Gehaltserhöhungen mit dem Argument zurück, es seien ohnehin immer die „Faulen“, die zuerst nach mehr Geld „schreien“ würden. Die Gewerkschaftsunion NUTA (ab 1977 JUWATA) solle Schritte gegen die „Gammler“ und „großen Ausbeuter“ einleiten. Das weist darauf hin, dass die Rolle der Gewerkschaft sich nach der Ausschaltung der unabhängigen Gewerkschaftsbewegung 1964 gewandelt hatte. NUTA sollte die Pflichten, nicht die Rechte von Angestellten und ArbeiterInnen durchsetzen; sie sollte erziehen, nicht emanzipieren. Das Thema der Arbeitsdisziplin wurde selbst in den Karikaturen der Gewerkschaftszeitung thematisiert; gerade jungen Frauen, die im urbanen Raum der Lohnarbeit nachgingen,

62 Aminzade, Race, S. 158-161; Shivji, Class Struggles, Kap. 13; kritisch auch: Hydén, Beyond Ujamaa, S. 168.

63 Wilbert B. L. Kapinga, State Control of the Working Class through Labour Legislation, in: Issa G. Shivji, Hg., The State and the Working People in Tanzania, Dakar 1986, S. 87-106.

64 Uhuru, Tatizo la uzembe na uvivu kazini ni la siku nyingi, 31.12.1975, S. 6; Uhuru, Wapingao Ujamaa / Kazi, 13.12.1976, S. 8.

65 Uhuru, Nuta ikomeshe uzembe kazini, 30.12.1975: „[...] kupigana vita vya ukombozi wa kazi ambavyo wakati wa ukoloni vilikuwa ni adhabu“. 


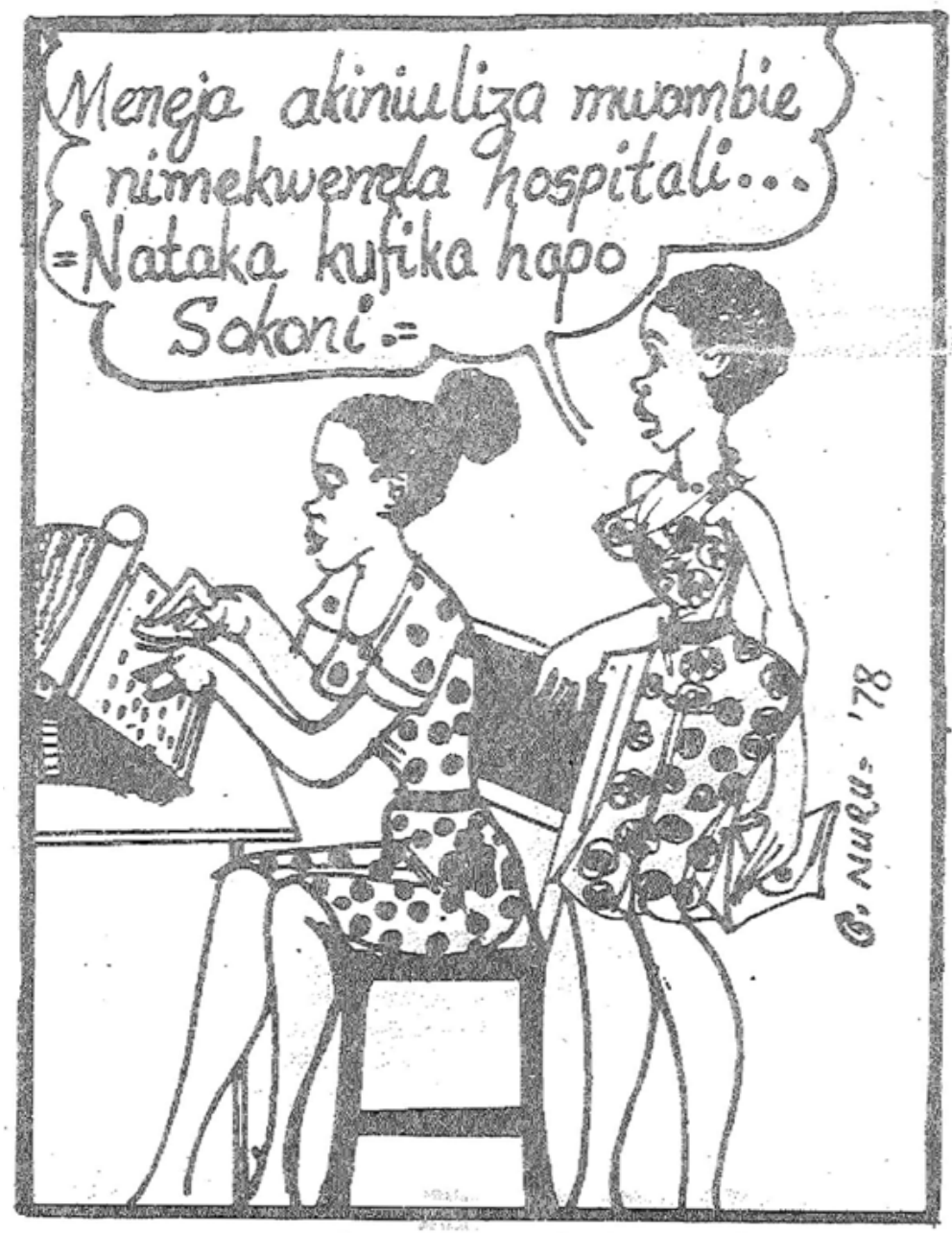

Abbildung 2.2: Karikatur zum Thema Arbeitsdisziplin aus dem Organ der Einheitsgewerkschaft JUWATA. Der Sprechblasentext: „Wenn der Chef (/die Chefin) nach mir fragt, sag ihm (/ihr) ich bin ins Krankenhaus gegangen... Ich will zum Markt.“ (Quelle: Mfanyakazi 686, 5.8.1978, S. 8)

wurde in Karikaturen unmoralisches Verhalten unterstellt (Abbildung 2.2). ${ }^{66}$ Auch die Frauenorganisation der Partei, die UWT, trat mit Disziplinierungsrhetorik in

66 Detailliert zu den Geschlechterbildern: Ivaska, Cultured States, Kap. 2; Priya Lal, Militants, 
Erscheinung. Moralisierende Schlagzeilen wie „UWT Won’t Defend Lazy Women“, „UWT Chief Castigates Loiterers“ oder „UWT Won’t Protect Dishonest Women“ waren in den späten 1970er-Jahren gang und gäbe und verlagerten die Erklärung für bestimmte Verhaltensweisen von strukturellen Faktoren in die individuelle Verantwortung. ${ }^{67}$

\section{Grenzen der Disziplinierung von oben}

Die Rhetorik eines „fordernden“ statt nur „gebenden“ Entwicklungsstaates hatte sich schon zuvor in Praktiken übersetzt. Insbesondere die ländliche Bevölkerung wurde zunehmend unter Druck gesetzt, ihren „Beitrag“ zur nationalen Entwicklung zu leisten, bis es im Rahmen der anfangs auf Freiwilligkeit basierenden Kampagne zur „Verdörflichung“ (villagization) von 1973 bis 1975 zu Zwangsumsiedlungen kam. Folgend einer Feststellung, dass „die Bauern“ noch nichts zur sozialistischen Umgestaltung des Landes beigetragen, aber schon viel von ihr profitiert hätten, verkündete Nyerere: „To live in villages is an order“. ${ }^{68}$ Versuche, die verstreut lebende ländliche Bevölkerung in übersichtlichen, administrierbaren Dörfern anzusiedeln, hatte es seit der spätkolonialen Zeit gegeben. Noch 1973 waren nur zwei Millionen Menschen in Dörfern registriert, 1977 aber dreizehn Millionen, also über drei Viertel der gesamten Bevölkerung Tansanias. ${ }^{69}$ Zumindest ein Teil dieser dreizehn Millionen Menschen wurde mittels Drohungen, Schlägen und niedergebrannten Häusern dazu gebracht, Nyereres Anweisung Folge zu leisten; manche waren aber auch freiwillig migriert bzw. hatten bereits zuvor in Dörfern gelebt, die erst später registriert wurden. ${ }^{70}$

Mothers and the National Family. Ujamaa, Gender and Rural Development in Postcolonial Tanzania, in: Journal of African History 51/1 (2010), S. 1-20.

67 Traci L. Yoder, „Is Use of Cosmetics Anti-Socialist?“ Gendered Consumption and the Fashioning of Urban Womanhood in Dar es Salaam, Tanzania, 1975-1990, MA Thesis, Gainesville 2006, S. 54.

68 Eckert, Herrschen und Verwalten, 256. Zwar hatte es schon zuvor, u.a. in Dodoma, Zwangsumsiedlungen gegeben, die systematische Ausweitung auf fast alle Teile des Landes folgte allerdings dieser Order Nyereres.

69 Kjell J. Havnevik, Tanzania: The Limits to Development from Above, Uppsala 1993, S. 48.

70 Laut Schneider (Government of Development, S. 88-89) haben etwa acht bis neun Millionen Personen tatsächlich eine - freiwillige oder unfreiwillige - Umsiedlung vollzogen. Lal (African Socialism, Kap. 5) diskutiert am Beispiel von drei Dörfern in Mtwara die sehr unterschiedlichen Wege in die Ujamaa-Dörfer und sieht ein Spektrum von freiwilliger und positiv erfahrener Umsiedlung bis hin zum Erfahren verschiedenster Zwangsanwendungen von Drohungen bis hin zu physischer Gewalt. 
Die staatliche Gewaltanwendung erstreckte sich auch auf den urbanen Raum. Bereits in der Kolonialzeit (und der europäischen Geschichte) erprobte Maßnahmen gegen „unproduktive Elemente“ in den Städten wurden wiederbelebt. ${ }^{71}$ In Kampagnen - besonders intensiv etwa 1964, 1976 und 1983 - wurden Personen, die keine Arbeitsbescheinigung vorweisen konnten, in naheliegende Dörfer oder ihre Herkunftsgegenden abtransportiert, um ihre „parasitäre“ Lebensweise zu beenden und sie zur landwirtschaftlichen Nahrungsmittelproduktion zu verpflichten. ${ }^{72}$ Als produktiv galt nur die Arbeit in der Landwirtschaft oder in formalisierten Verhältnissen, nicht der Einkommenserwerb im Rahmen der vorwiegend urbanen informellen Wirtschaft. So waren also auch Schuhputzer, Fischverkäuferinnen und unzählige andere Personen im Kleinhandel ohne Lizenz Ziel staatlicher Repressionsmaßnahmen. ${ }^{73}$ Die während der Kolonialzeit eingeführte Kopfsteuer war 1969 abgeschafft worden und wurde 1982 als „Entwicklungssteuer“ (Development Levy) wieder eingeführt, als der Staat auf jede nur mögliche Einnahmequelle angewiesen war und - wie einst die Kolonialverwaltung - die Steuer als „Anreiz“ zur Arbeit im formellen Lohnsektor bzw. zum Anbau von cash crops instrumentalisierte und daher strikt einzutreiben versuchte. ${ }^{74}$ Wenig überraschend vertrat der Großteil der tansanischen Bevölkerung in den 1980er-Jahren die Meinung, dass weder Regierung noch Partei oder Gewerkschaft ihre Interessen vertraten. ${ }^{75}$

$\mathrm{Zu}$ diesem Zeitpunkt waren Partei und Massenorganisationen in nahezu allen Betrieben, Schulen, Ämtern und Ortschaften präsent. Mittels der 1964 durchgeführten Umorganisation der Partei in „Zellen“, die je zehn nachbarschaftliche Haushalte umfassten, sollte die gesamte Bevölkerung lückenlos in TANU's Strukturen eingebunden werden. Dieses sogenannte 10-Zellen-System übersetzte sich jedoch nur bedingt in eine funktionsfähige Struktur - beschränkt sowohl, was die Durchsetzung von Parteiinteressen von oben und noch mehr, was die

71 Andrew Burton, African Underclass. Urbanisation, Crime \& Colonial Order in Dar es Salaam. London 2005, Kap. 12. Tripp weist auf die lange Geschichte entsprechender Gesetze in Europa hin und die Rolle, die ihre Anwendung während der Industriellen Revolution spielte. Siehe Aili Mari Tripp, Changing the Rules. The Politics of Liberalization and the Urban Informal Economy in Tanzania, Berkeley 1997, S. 140.

72 Tripp, Changing the Rules, S. 140-141; Eckert, Herrschen und Verwalten, S. 225.

73 Tripp, Changing the Rules, S. $140-141$.

74 Das Zahlen der Steuern setzte die Teilnahme an den monetären Wirtschaftskreisläufen voraus, also z. B. cash crop-Anbau statt Subsistenzwirtschaft und Tauschhandel. Tripp, Changing the Rules, S. 154-158; Kapinga, State Control, S. 88.

75 Carol E. Barker u.a., African Industrialisation. Technology and Change in Tanzania, Aldershot, Hants 1986, S. 193-199. 
demokratische Partizipation und Mitbestimmung von unten anging. ${ }^{76}$ Die tansanische Bevölkerung war zu keinem Zeitpunkt, um einen umstrittenen Begriff aus der DDR-Historiografie aufzugreifen, „durchherrscht“. ${ }^{77}$ Die Geschichte der Disziplinierung der Arbeiterschaft etwa ist keinesfalls geradlinig, die Arbeitskämpfe etwa hatten durchaus einen Machtgewinn der Angestellten und ArbeiterInnen gegenüber ihren Vorgesetzten gezeitigt, wie der kanadische Ökonom John Loxley 1979 festhielt: „In the past, efficiency was guaranteed by tight discipline and material incentives. Now, although organization structures remain hierarchical, it is more difficult to enforce discipline or to use the threat of dismissal as a means of ensuring performance." 78 Die Disziplinierungsmaßnahmen wurden keineswegs im ganzen Land einheitlich angewandt; sie waren zudem, gerade was Maßnahmen in den Städten und gegen Personen im informellen Sektor anging, weitgehend ineffektiv, da sie in der Regel Symptome und nicht die strukturellen Ursachen bekämpften. Die aufs Land Deportierten kehrten teils am selben Tag wieder in die Städte zurück. Jugendorganisation und Miliz handelten teils als langer Arm von Partei oder Regierung, in anderen Fällen verfolgten die lokalen Zweigstellen aber auch eigene Interessen. ${ }^{79}$

Während die Umsiedlungskampagne tatsächlich mit Zwangsmaßnahmen umgesetzt wurde, reichten die Macht- und Legitimationsmittel des Staates nicht aus, die neuen Dörfer auch zu gemeinschaftlicher Produktion zu zwingen. Das Vermögen des Staates, Zwang auszuüben - und das übersehen Autoren wie James Scott, die Ujamaa und die Umsiedlungskampagne einzig als Beispiel staatlicher

76 J. H. Proctor, Hg., The Cell System of the Tanganyika African National Union, Dar es Salaam 1971; Bienen, Tanzania, Kap. X. Dass die Struktur „dabei griffige Möglichkeiten [bot] zu kontrollieren wer sich beteiligte oder wer sich immer wieder den öffentlichen Arbeiten entzog“ (Büschel, Hilfe zur Selbsthilfe, S. 189-190) sollte nicht überbewertet werden, wie gerade der Vergleich mit anderen Sozialismen zeigt. Der ehemalige DDR-Botschafter Matthes etwa sah Partei und Massenorganisationen als „politisch nicht genügend wirksam“. Helmut Matthes, Zur Entwicklung der außenpolitischen Grundlagen der Beziehungen zwischen der Deutschen Demokratischen Republik und der Vereinigten Republik Tansania bis Mitte der siebziger Jahre, in: Ulrich van der Heyden/Franziska Benger, Hg., Kalter Krieg in Ostafrika: Die Beziehungen der DDR zu Sansibar und Tansania, Berlin 2009, S. 55-97, hier: S. 77.

77 Jürgen Kocka, Eine durchherrschte Gesellschaft, in: Hartmut Kaelble u.a., Hg., Sozialgeschichte der DDR, Stuttgart 1994, S. 547-553.

78 John Loxley, Monetary Institutions and Class Struggle in Tanzania, in: Bismarck U. Mwansasu/Cranford Pratt, Hg., Towards Socialism in Tanzania, Dar es Salaam 1979, S. 72-92, hier: S. 87. Ähnlich Hydén, Beyond Ujamaa, S. 163-167, S. 222-225.

79 James R. Brennan, Youth, the TANU Youth League and Managed Vigilantism in Dar es Salaam, Tanzania, 1925-73, in: Africa 76/2 (2006), S. 221-246; Lal, African Socialism; Bjerk, Building a Peaceful Nation. 
Repression lesen ${ }^{80}$ - war beschränkt und mit den weitaus wirkungs- und verhängnisvolleren Kollektivierungsmaßnahmen in China oder der Sowjetunion nicht vergleichbar. Die bäuerliche Bevölkerung konnte mittels Subsistenzwirtschaft, Naturalienhandel und Umgehung öffentlicher Vermarktungskanäle überleben. Sie war auf den Staat nicht angewiesen und konnte sich eine gewisse Autonomie gegenüber den öffentlichen Institutionen wahren. ${ }^{81}$ Dem Sozialhistoriker James Giblin zufolge zogen sich TansanierInnen praktisch wie diskursiv in die „familiäre Sphäre“ zurück, um dem Zugriff des Staates zu entkommen. ${ }^{82}$ Dieser breite Raum für Rückzug in vom Staat nicht kontrollierte Sphären, EigenSinn und Obstruktion spiegelt die Machtgrenzen von Staat und Partei. Da nicht genügend Ressourcen auf lokaler Ebene mobilisiert werden konnten, war der Entwicklungsstaat auf Mittel von außen angewiesen - selbst wenn die Strategie der Extraversion im Gegensatz zum self-reliance-Ideal stehen sollte.

\subsection{Abhängigkeit und self-reliance: Extraversion im kapitalistischen Weltsystem}

Es gibt wohl kein besseres Beispiel für das sprichwörtliche entwicklungspolitische „Gesetz der unerwarteten Ergebnisse“ als die tansanische Politik der selfreliance (kujitegemea), die das „Vertrauen in die eigene Kraft“ zum Ausgangspunkt aller Entwicklungsbemühungen machte. Nach anfänglichen Achtungserfolgen mündete sie nämlich statt in Unabhängigkeit in einer vertieften Abhängigkeit, die sich vor allem in wirtschaftlicher Hinsicht offenbarte und auf alle anderen Felder ausstrahlte. Self-reliance war, wie Ujamaa, ein Konzept mit multiplen Wurzeln sowohl in der vorkolonialen als auch kolonialen Vergangenheit. Es überlappte mit globalen Entwicklungsdiskursen und oszillierte in Tansania je nach Akteur und Situation zwischen zahlreichen, teils widersprüchlichen Bedeutungen. ${ }^{83}$ Eine dieser Bedeutungen war, dass Tansania nicht auf externe

80 Scott, Seeing Like a State. Trotz rhetorischer Abgrenzungen zu Scott stehen auch in dieser Tradition: Büschel, Hilfe zur Selbsthilfe, Kap. 7; Schneider, Government of Development.

81 Hydén, Beyond Ujamaa, S. 112, S. 121.

82 James L. Giblin, A History of the Excluded. Making Family a Refuge from State in TwentiethCentury Tanzania, Oxford 2005. Wie Priyal Lal allerdings kritisch anmerkt und nachweist, waren auch private Räume von nationalstaatlichen Kategorien und Erfordernissen durchzogen: Lal, Militants, S. 9, S. 19.

83 Büschel, Hilfe zur Selbsthilfe, S. 206-227; Green, The Development State, 26-29; Priya Lal, Self-Reliance and the State. The Multiple Meanings of Development in Early Post-Colonial Tanzania, in: Africa 82/2 (2012), 212-234. 
„Hilfe“ angewiesen sein und nachhaltiges Wirtschaftswachstum ohne Auslandsinvestitionen erreichen sollte. Dazu brauchte es eine leistungsfähige landwirtschaftliche Produktion, auf deren Basis weiteres Wachstum und Industrialisierung realisiert werden konnten. Eine andere Bedeutung, auf die später noch genauer eingegangen wird, ist die personelle Ebene, also das Auskommen ohne ausländische Fachkräfte (expatriates). Eine dritte Bedeutungsebene zielt auf eine (vor allem in ländlichen Regionen) lokale Entwicklung, die von der Zentralregierung weitgehend unabhängig ist, wobei die Unabhängigkeit vor allem materielle Aspekte betreffen sollte. ${ }^{84}$ Self-reliance bezog sich, je nach Interesse, auf verschiedene räumliche Ebenen oder soziale Einheiten: Der globale Süden, das nationalstaatliche gedachte Tansania, einzelne Regionen und Distrikte, Dörfer, Haushalte und Personen sollten ihr eigenes Potenzial mit Blick auf das Wohl der Allgemeinheit ausschöpfen. Priya Lal zufolge war self-reliance also vieles zugleich: „a mandated developmental strategy or a collective developmental aspiration, a condition of dignity or privation, a hallmark of national citizenship or a reflection of local survivalism, a matter of luxury or necessity “ ${ }^{85}$ Mit der Zeit durchlief das Konzept einen Wandel von der (politikzentrierten) Betonung von Selbstaufopferung für die Entwicklung der Nation zur (wirtschaftszentrierten) Forderung nach Beteiligung der Bevölkerung an Kosten für Dienstleistungen und Appellen an den individuellen Unternehmergeist. ${ }^{86}$

Die Betonung des self-reliance-Aspekts in der Deklaration von Arusha von 1967 war, wie der damalige Finanz- und Wirtschaftsminister Amir Jamal einschätzte, eine Reaktion auf das offensichtliche Scheitern der Wirtschaftspolitik und außenpolitische Krisen in den Jahren direkt nach der Unabhängigkeit. ${ }^{87}$ Die BRD (siehe Kapitel 3), die USA und Großbritannien froren im Zuge diplomatischer Krisen 1964/65 zahlreiche Entwicklungshilfegelder ein. ${ }^{88}$ Auf Ressourcen aus dem Ausland, so die Lektion aus diesen Jahren, konnte Tansania nicht bauen. Selfreliance war die aus dieser Lektion resultierende Strategie Nyereres, die „Kontingenz zu zähmen“ und die Zukunft Tansanias möglichst plan- und vorhersagbar

84 Coulson, Tanzania, S. 347.

85 Lal, Self-Reliance, S. 230.

86 Ebd.

87 A. K. L. J. Mlimuka/P. J. A. M. Kabudi, The State and the Party, in: Issa G. Shivji, Hg., The State and the Working People in Tanzania, Dakar 1986, S. 58-86; Eckert, Herrschen und Verwalten, S. $219-221$.

88 Die Krise mit Großbritannien war das Resultat der prinzipiengeleiteten tansanischen Befreiungspolitik, die auch mit materiellen Opfern verbunden war: Pallotti, Post-Colonial NationBuilding. 
zu gestalten. ${ }^{89}$ Da self-reliance im Sinne der Deklaration von Arusha weder eine internationale „sozialistische Arbeitsteilung“ wie im RGW noch radikale Autarkie, sondern Autonomie als erfolgversprechendsten Weg zur Eigenständigkeit darstellte, blieb externe „Hilfe“ willkommen - solange dadurch die eigene Entscheidungsfähigkeit nicht kompromittiert wurde. Self-reliance war also eine Strategie, die darauf abzielte, die Außenabhängigkeit auch durch Extraversion zu überwinden. Die Diversifizierung der Ressourcenquellen (und Abhängigkeiten) zielte nicht auf die vollständige Abkopplung vom Weltmarkt und von globalen politischen Konstellationen, sondern sollte einen reformartigen, graduellen Strukturwandel ermöglichen.

Der Versuch der Diversifizierung der außenwirtschaftlichen Beziehungen schloss auch die RGW-Länder und China mit ein, die vor 1964 in erster Linie eher als Partner und Waffenlieferanten für die in Tansania ansässigen Befreiungsbewegungen aufgetreten waren und Stipendien vergeben hatten. Die Systemkonkurrenz des Kalten Krieges lieferte generell günstige Voraussetzungen für die Diversifizierung; Handel wie Hilfsbeziehungen mit dem sowjetischen Machtbereich blieben allerdings unbeständig und marginal. Substanziell waren zeitweise die ökonomischen und politischen Beziehungen der DDR und der Sowjetunion zum postrevolutionären Sansibar ab 1964, die u.a. durch die zunehmende Orientierung der tansanischen/sansibarischen Führung auf China 1970/71 zu einem jähen Ende kamen (siehe Kapitel 3 und Kapitel 6.1).

\section{Expatriates und Brüder}

Im Gegensatz zu China, das Tausende Arbeitskräfte entsandte, blieben die RGWLänder zu Tansania und der „kleinbürgerlichen“ Ideologie ${ }^{90}$ Ujamaa auf Distanz und waren zu keinen politisch determinierten Opfern bereit, wie bereits die Entsendung von ExpertInnen zeigt. Die ČSSR, Rumänien und Bulgarien entsandten Personal Anfang der 1970er-Jahre nur, wenn Tansania ein bestimmtes Mindestgehalt deutlich über den regulären tansanischen Bezügen zusicherte. ${ }^{91}$ Der Per-

89 Katrin Bromber u.a., „The Possibilities are Endless“: Progress and the Taming of Contingency, in: ZMO Programmatic Texts 9 (2015). www.zmo.de/publikationen/ProgramaticTexts/pro gress2015.pdf (Zugriff: 31.10.2016).

90 DDR-Perspektiven auf Ujamaa werden in Kapitel 3 genauer diskutiert.

91 Politisches Archiv des Auswärtigen Amtes (PAAA), C 773/74, Zeise (HPA der DDR in Tansania), Gespräch mit dem Handelsattaché der Sozialistischen Republik Rumänien, Dar es Salaam, 17.5. 1972, Fol. 14; ebd., Zeise, Gespräch mit dem Handelsrat der ČSSR, Dar es Salaam, 12.5.1972, Fol. 16; ebd., Zeise, Gespräch mit dem Handelsrat der VR Bulgarien, Dar es Salaam, 11.5.1972, Fol. 18. 
sonaleinsatz in Tansania sollte volkswirtschaftlich möglichst kostenneutral gestaltet werden, im Gegensatz zur DDR zahlten diese Länder ihren Entsandten auch keine Gehaltsaufschläge, was erklärt, warum sich in diesen Ländern zeitweise kaum InteressentInnen für einen Einsatz in Tansania fanden. ${ }^{92}$ Der bulgarische Handelsvertreter sah die Forderung von Mindestgehältern auch als Prestigefrage: ExpertInnen aus sozialistischen Ländern kosteten ohnehin schon zwei bis drei Mal weniger als jene aus westlichen Staaten. Der Eindruck, dass die SpezialistInnen aus sozialistischen Ländern „billig“ seien, sollte unbedingt vermieden werden. ${ }^{93}$ Schon 1964 meinte Landwirtschaftsminister Derek Bryceson, die Anwerbung sowjetischer Veterinäre samt Dolmetschern „sei sehr teuer, aber man habe sich nicht anders zu helfen gewusst“. ${ }^{94}$ Die Abhängigkeit von ausländischem Personal war ohnehin ein politisch sensibles Thema, weil sie dem Ziel personeller self-reliance und nationalistischen Motiven entgegenstand.

Nach der Deklaration von Arusha wurden expatriates von nationalistischer wie marxistischer Seite zu einer Bedrohung des tansanischen Sozialismus stilisiert. John Saul, ein kanadischer Marxist, der an der Universität in Dar es Salaam unterrichtete, warnte (wie einige andere Linke aus westlichen Ländern) 1972 vor den „fremden Experten, die allzu leicht trojanische Pferde im sozialistischen Lager“ werden könnten. ${ }^{95}$ Der Brite John Loxley, überzeugter Sozialist, Finanzexperte und ebenfalls Lehrender an der Universität in Dar es Salaam, legte im selben Jahr in einem dreiteiligen Artikel in der Parteizeitung dar, dass die Fünfjahrespläne von expatriates geschrieben wurden, expatriates nach wie vor Schlüsselfunktionen in vielen Unternehmen und Ministerien besetzten und Tansania sich in einen „Teufelskreis der Unselbstständigkeit“ begebe, weil so die jungen tansanischen AbsolventInnen darin gehindert würden, Erfahrung zu sammeln und Verantwortung $\mathrm{zu}$ übernehmen. ${ }^{96}$ Nyerere legitimierte in einer Ansprache an die TANU-Nationalversammlung im Oktober 1967 die Anwerbung von Fachkräften mit Bezug auf die politische Haltung: „Ideally we [...] need socialists in every job - which is not necessarily the same thing as wanting a citizen

92 Vgl. für das Jahr 1971 auch PAAA, C 928/78, Fol. 60-62..

93 PAAA, C 773/74, Zeise, Gespräch mit dem Handelsrat der Volksrepublik Bulgarien, Dar es Salaam, 11.5.1972, Fol. 19.

94 BArch Koblenz, B 213/7657, BRD-Botschaft an AA, Dar es Salaam, 17.4.1964.

95 John S. Saul, Planning for Socialism in Tanzania: The Socio-Political Context, in: J. F. Rweyemamu u.a., Hg., Towards Socialist Planning, Dar es Salaam 1972, S. 1-29, hier: S. 11, Übersetzung E. B.

96 Aminzade, Race, 178; Werner Dolph, Die ungeliebten Experten, in: Die Zeit, 15.6.1973. Siehe auch den Punkt „Transferieren“ in Kapitel 5.4. 
for every job, because not all Tanzanians are socialists. “97 Im Zusammenhang mit dem oben skizzierten allgemeinen Misstrauen gegenüber „Fremden“ gewann die Rhetorik oft an Schärfe. 1969 prangte eine Drohung von Vizepräsident Kawawa auf der Titelseite des Nationalist: „Tanzania will smoke out any foreigner wherever he may be who tries to sabotage the country's policy of socialism and selfreliance".98

Vorbildcharakter in dieser Hinsicht wurde den chinesischen EntwicklungsarbeiterInnen für ihren Fleiß und ihre frugale, bescheidene Lebensweise verliehen. Sie wurden nicht unter dem Begriff expatriates subsumiert, sondern galten als „Brüder““99 Das Verbundenheitsgefühl, das in dieser Verwandtschaftsmetapher zum Ausdruck kommt, gründete dabei auf einer Idealisierung des chinesischen Entwicklungsweges, wobei die proklamierten Werte von Arbeitsamkeit, Gemeinschaftlichkeit und Genügsamkeit große Schnittmengen mit Ujamaa und insbesondere dem self-reliance-Konzept aufwiesen. Hinzu kam die geteilte Geschichte imperialer Unterdrückung und Ausbeutung durch europäische Kolonialmächte sowie die Nähe der Einsatzbedingungen zu lokalen Standards, was für die tansanische Bevölkerung konkret beobachtbar war. Chinesische EntwicklungsarbeiterInnen lebten wie die Mehrheit der tansanischen Bevölkerung in einfachen Unterkünften, konsumierten genügsam, forderten keinerlei extravagante Freizeitunterhaltung und zeigten eine strikte Arbeitsdisziplin. ${ }^{100}$ Dass in der Praxis die meisten chinesisch-tansanischen Arbeitsverhältnisse sehr hierarchisch waren und private Interaktionen kaum stattfanden, war für die Vorbildrolle unerheblich. ${ }^{101}$

Nach der Verkündung neuer Parteirichtlinien 1971 (Mwongozo, siehe oben) kam es zu zahlreichen Protesten von ArbeiterInnen gegen europäische oder „asiatische“ Manager, die sich selbst bereicherten und rassistische Verhaltensweisen an den Tag legten. ${ }^{102}$ Wiederholt wurden expatriates Ziel von Sabotageund Spionageverdacht (und nicht immer unberechtigt). Nach einem Sprengstoffanschlag 1972 wurden drei westdeutsche Experten festgenommen, was in der

97 Zit. nach Alicia Altorfer-Ong, Old Comrades and New Brothers: A Historical Re-Examination of the Sino-Zanzibari and Sino-Tanzanian Bilateral Relationships in the 1960s, PhD Thesis, London 2014, S. 256; siehe auch Peter E. Temu, The Employment of Foreign Consultants in Tanzania: Its Value and Limitations, in: The African Review 3 (1973), S. 69-84.

98 The Nationalist, „Saboteurs warned“, 21.3.1969, S. 1.

99 BArch Berlin, DC 20/11525, Büttner (DDR-Konsulat Sansibar), Abschlussbericht Juli 1967 - Juni 1970, Berlin, 30.6.1970; Altorfer-Ong, Old Comrades, 261-262.

100 BArch Koblenz, B 213/7672, BRD-Botschaft an AA, Dar es Salaam, 9.8.1969, S. 12; AltorferOng, They Came as Brothers, 73-94.

101 Monson, Africa's Freedom Railway, S. 7.

102 Aminzade, Race, S. 176-177. 
BRD zu einem großen Medienecho über den vermeintlichen „Fremdenhass“ in Tansania führte. ${ }^{103}$ Der Vertreter der Friedrich-Ebert-Stiftung hatte bereits ein Jahr zuvor berichtet, in Tansania würde man „nach Schuldigen für die Wirtschaftskrise suchen“ und diese „zunächst bei der großen Zahl von weißen Ex-Patriots [sic]“ finden. ${ }^{104}$ Europäischen und amerikanischen expatriates schlage Ablehnung entgegen, was auch ihm die Tätigkeit erschwere und nur „Millimeterarbeit“ erlaube. Die Ablehnung in diesen Jahren war aber keinesfalls nur auf „weiße“ oder westliche expatriates beschränkt, wie viele im Westen wahrnahmen. Hinzu kamen Vorbehalte und Maßnahmen gegen „Inder“ und afroamerikanische expatriates. Letztere hatten oft ein Selbstverständnis als „RückkehrerInnen“ und waren daher über die bisweilen kühle Aufnahme in Tansania als ausländische Fachkräfte besonders enttäuscht. Mitunter wurden sie in der Presse bezichtigt, eine „Coca Cola-Haltung“ an den Tag zu legen; 1974 wurden Hunderte von ihnen mit dem Verweis auf Spionageverdacht festgenommen. ${ }^{105}$ Tansania hatte damit den Ruf als Destination für die back to Africa-Bewegung schon nach wenigen Jahren wieder eingebüßt.

Die Regierung experimentierte $\mathrm{zu}$ dieser Zeit mit einer Reihe politischer Maßnahmen, um die Anwesenheit von expatriates aufs Notwendigste zu reduzieren und mit dem Ziel der self-reliance in Einklang zu bringen. Nach einer Phase der kurzfristigen „Afrikanisierung“ 1962/63 und der anschließenden, bis 1980 angelegten „Tansanisierung“ der Beamtenschaft initiierte die Regierung Anfang der 1970er-Jahre weitere Maßnahmen, die auch auf den Wirtschaftssektor abzielten. 1968 verwies Tansania alle Freiwilligen des US-amerikanischen Peace Corps aus Protest gegen die Intervention in Vietnam des Landes. ${ }^{106} 1972$ ordnete Nyerere die Bildung von (ausschließlich mit StaatsbürgerInnen besetzten) Ausschüssen in Ministerien und Betrieben an, die jedem Einsatz einer ausländischen Fachkraft erst zuzustimmen hatten und unnötige Experteneinsätze verhindern

103 Wolfgang Schneider-Barthold, Tanzania. Voraussetzungen und Möglichkeiten der privaten Investition einschließlich der Darstellung des parastaatlichen Sektors, Hamburg 1974, S. 92-93. 104 Roth an FES-Zentrale, Dar es Salaam 1971, zit. nach Volker Vinnai, Die Arbeit der FriedrichEbert-Stiftung in Tansania - 40 Jahre Zusammenarbeit mit Parteien, Gewerkschaften, Zivilgesellschaft und Regierung, in: Norbert von Hofmann u.a., Hg., Die Arbeit der Friedrich-EbertStiftung in Indonesien, Tansania und Zentralamerika seit den 1960er Jahren, Bonn 2010, S. 105202, hier: S. 113-115.

105 Andrew M. Ivaska, Movement Youth in a Global Sixties Hub: The Everyday Lives of Transnational Activists in Postcolonial Dar es Salaam, in: Richard Ivan Jobs/David M. Pomfret, Hg., Transnational Histories of Youth in the Twentieth Century, Hampshire 2015, S. 188-210, hier: S. $203-204$.

106 Cobbs Hoffmann, All You Need Is Love, S. 119. 
sollten. ${ }^{107}$ Hinzu kam eine Sondersteuer von $10 \%$ auf das Gehalt aller expatriates in den Firmen sowie die Regelung, dass maximal ein Drittel der Gehälter ins Ausland transferiert werden durfte. Die 1974 eingeläutete Operation Leapfrog forcierte die Counterpartausbildung und sollte den Anteil von expatriates in den staatlichen Unternehmen reduzieren, insbesondere auf Managerebene. Beide Ziele blieben weitgehend unerreicht; die Programme wurden in den folgenden Jahren eingestellt, weil der Mangel an Fachkräften durch die Wirtschaftskrise noch verschärft wurde.

In direktem Kontakt mit westdeutschen EntwicklungsarbeiterInnen betonten wirtschaftsorientierte Kräfte aus der tansanischen Politik, dass ExpertInnen zwar Respekt an den Tag legen und Tansanias eingeschlagenen Weg unterstützen sollten, sich das Ideal eines „demokratischen Sozialismus“ und die Postulate tansanischer PolitikerInnen aber nicht zu eigen machen müssten. ${ }^{108}$ Diese pragmatische Position vertrat wohl auch Nyerere, wie die Erinnerung eines westdeutschen Ingenieurs an ein persönliches Gespräch mit dem Präsidenten Anfang der 1980er-Jahre nahelegt:

\footnotetext{
Also erst mal hatte er mich gefragt [...]: „Are you a true socialist?“ Er wollte da irgendwie der Sache so ein bisschen nachgehen. Und dann habe ich gesagt, „I am Christian and engineer, is that enough?" Und dann hat er gelacht, hat mich auf die Schulter gehauen und hat gesagt, „It’s okay.“
}

Zusätzlich gab es im tansanischen Staatsapparat offensichtlich Gruppen, die die Rekrutierung von Fachpersonal aus den kommunistischen Ländern Osteuropas zeitweise aktiv behinderten. 1972 bemängelte die DDR-Vertretung die Anstrengungen Tansanias, DDR-Entwicklungspersonal zu rekrutieren. Zwar gehe die Bearbeitung im Falle von LehrerInnen und VeterinärmedizinerInnen, die auf weniger einflussreichen Positionen direkt an der Basis arbeiten sollten, flüssig vonstatten, aber im Falle „hochqualifizierter Kader“ werde „die Bearbeitung verschleppt und die unterschiedlichsten Gründe werden vorgeschoben, um die Entscheidung [...] zu umgehen."109 Das Gleiche galt für Angebote anderer sozialistischer Staaten. Auch eine Entsendeorganisation für afroamerikanische Fachkräfte beklagte sich 1972 über „bürokratische Sabotage“ und ausbleibende Ein-

107 URT, Manpower Report 1972, S. vii-viii.

108 BArch Koblenz, B 213/7675, Dr. Krumbein, Bericht über Projektleitertagung in Dar es Salaam, Bonn, 8.3.1973, S. 2.

109 PAAA, C 773/74, Zeiss (Limex Dar es Salaam) an Thiele (Limex), Dar es Salaam, 13.9.1972; siehe auch ebd., Zeiss an Thiele, Dar es Salaam, 5.10.1972. 
satzbestätigungen. ${ }^{110}$ Letztendlich blieb es, gerade in den entscheidenden Manager- und Consultingpositionen, bei einer Abhängigkeit von ausländischem, insbesondere westlichem und indischem Personal. In der Diversifizierung der wirtschaftlichen Beziehungen war die Regierung bemühter als in der Diversifizierung der Personalquellen, aber zumindest in den RGW-Ländern erfolglos.

\section{Grenzen der Diversifizierung}

Tansanische Offensiven, Ressourcen in den RGW-Ländern zu mobilisieren, waren von nur geringem Erfolg gekrönt. Die erste hochrangig besetzte Regierungsdelegation 1964 nach Osteuropa ${ }^{111}$ bemühte rhetorisch die Notwendigkeit, die neokolonialen Beziehungen zu Großbritannien und den USA durch sozialistische Hilfe bei der Erschließung von Rohstoffvorkommen, bei der Errichtung von Staatsfarmen und beim Bau von Kraftwerken und einer Eisenbahn nach Sambia zu überwinden. Die Ansuchen stießen in Warschau und Prag auf taube Ohren. In Moskau hieß es, jede nach Tansania geschickte Maschine sei eine Maschine weniger in der Sowjetunion. ${ }^{112}$ Die Angebote, die die Sowjetunion für die Investitionsvorhaben unterbreitete, waren näher an Marktkonditionen als an den (westlichen) Entwicklungshilfebedingungen, die Tansania erwartete. So musste Tansania die kompletten Kosten für das sowjetische Personal tragen und im Vergleich zum Westen ungünstige Kreditbedingungen akzeptieren. ${ }^{113}$ Aus tansanischer Sicht schienen die Sowjetunion und ihre Verbündeten nur am profitablen Export ihrer Kapitalgüter, nicht an einer politischen und ökonomischen Intensivierung der Beziehungen interessiert, was sich gerade in den mühsamen Verhandlungen zeigte. Ein internes Urteil der zuständigen CCM-Abteilung ${ }^{114}$ aus den 1980er-Jahren fiel entsprechend kritisch aus:

All these socialist nations like to conduct their relations through a number of agreements like in the field of economic co-operation. These agreements are preceded by long and often

110 Ivaska, Movement Youth, S. 203.

111 Die Delegation wurde geleitet von Vizepräsident Rashidi Kawawa; er wurde begleitet von Politikern, die bereits gute Verbindungen nach Moskau unterhielten, v. a. Minister Hanga. Cranford Pratt, The Critical Phase in Tanzania, 1945-1968. Nyerere and the Emergence of a Socialist Strategy, Cambridge 1976, S. 159.

112 Ebd. Als Quelle diente Pratt ein von Vizepräsident Kawawa angefertigtes Gesprächsprotokoll.

113 Ebd., S. $160-161$.

114 TANU und die Afro-Shirazi Party Sansibars hatten sich 1977 zur Chama cha Mapinduzi (Partei der Revolution, CCM) zusammengeschlossen. 
times cumbersome negotiations before the required assistance is extended. Experience has shown that even after the signing of such agreements there are long delays in full implementation of the projects. ${ }^{115}$

Die tansanische Devise für verhandlungsintensive und materiell begrenzt gewinnbringende Beziehungen dieser Art lautete also ganz pragmatisch: „What we can get [...] without much problem we shall exploit to the maximum. "116 Dieses Maximum war schnell erreicht. Die in Tansania als „Hilfe“ (aid) deklarierten Beiträge aus den kommunistischen Ländern blieben immer hinter jenen aus den westlichen Ländern zurück; zwischen 1969 und 1976 war das Verhältnis mit etwa drei zu eins noch am höchsten, wobei sich hier der Großteil der ausgewiesenen Transfers auf Chinas umfassende Investitionen in die Eisenbahnverbindung zwischen Sambias Kupfergürtel und der Hafenstadt Dar es Salaam 1971-1974 zurückführen lässt (deren Finanzierung erst die Sowjetunion, dann westliche Geber abgelehnt hatten). ${ }^{117}$ Eine Intensivierung von Handel und Investitionstätigkeit auf dem Festland in Zeiten der globalen Détente zwischen den Supermächten scheiterte nicht an einer ideologischen Voreingenommenheit Tansanias, sondern am Desinteresse, der umständlichen Handelspolitik und der mangelhaften Implementierungsfähigkeit der europäischen RGW-Länder. ${ }^{118}$ Osteuropäische Staaten und China schlossen eine Reihe von Investitionsabkommen für den Rohstoffabbau, Technologietransfer und Industrieaufbau mit Tansania ab: Bulgarien investierte in eine Gerberei, Ungarn rüstete Maschinenstationen für die landwirtschaftliche Produktion aus, die UdSSR projektierte auf Nyereres Wunsch ein Zement- und ein Wasserkraftwerk und suchte nach Goldvorkommen; China zog die Ausbeutung von Eisenerz- und Kohlevorräten in Betracht. Tansania zeigte sich allerdings unzufrieden mit den sowjetischen Geologen, die kaum Ergebnisse vorlegten, und kündigte schließlich den Vertrag; China wiederum sah in Tansania

115 CCMA, CMM/OND/183/36, Vol. 1, Foreign Affairs Department of CCM Headquarters, Brief of Socialist Federal Republic of Yugoslavia, o.O., o. J. [ca. 1985], Bl. 20; siehe auch ebd., CMM/OND/ 183/37/Vol. 1, Protokoll des Gesprächs zwischen Stv. Außenminister Ungarns Gábor Nagy und Salim A. Salim (NEC-Sekretär für Int. Beziehungen), Dar es Salaam, 2.12.1988, Bl. 59.

116 CCMA, CMM/OND/183/36 Yugoslavia, Vol. 1, Foreign Affairs Department of CCM Headquarters, Brief of Socialist Federal Republic of Yugoslavia, o.O., o. J. [ca. 1985], Bl. 20.

117 S. S. Mushi, Tanzania, in: Adebayo Adedeji, Hg., Indigenization of African Economies, London 1981, S. 204-237, hier: S. 229. Im Vergleich zum globalen Verhältnis, das David Engerman auf 10:1 schätzt, ist dieses Verhältnis - aufgrund von Transfers aus China - bemerkenswert. Siehe Engerman, Second World's Third World, S. 208-210.

118 So auch die Schlussfolgerung von Green, Tanzanian Political Economy, S. 36. 
die infrastrukturellen Voraussetzungen für einen wirtschaftlich tragfähigen Bergbau nach ausführlichen Studien nicht gegeben. ${ }^{119}$

Blieben substanzielle Transfers aus der kommunistischen Welt also vor allem auf China beschränkt, war die Diversifizierung im Westen um ein Vielfaches ertragreicher. Ende der 1960er und Anfang der 1970er-Jahre hatte Ujamaa nicht nur die ideologische Hegemonie im Inland gewonnen, sondern strahlte weit über die Landesgrenzen hinaus. Wie Michael Jennings festhält, reichte die Begeisterung so weit, dass die westliche Entwicklungshilfe sich bis zum Ende der 1970er Jahre tansanische Werte zu eigen machte:

Far from becoming beholden to the dictates of foreign aid during the 1960s and 1970s and being forced to accept the logic of the Western development paradigm, Tanzania effectively gained compliance from all participants in Tanzanian development for its own set of values. ${ }^{120}$

Die self-reliance-Politik stieß auf internationaler Ebene für etwa eine Dekade auf ein weitgehend positives Echo, nicht zuletzt, weil die Vision nachholender, kapitalistischer Modernisierung im westlichen Diskurs in den 1970er-Jahren angesichts begrenzter Ressourcen zunehmend als Chimäre galt und die Grundbedürfnisstrategie $\mathrm{zu}$ einem wichtigen Paradigma der Weltbank unter Robert McNamara (1968-1981) wurde. ${ }^{121}$ Gerade im linken Spektrum westlicher Intellektueller herrschte eine weitverbreitete Tansaphilie, die sich nicht nur aus der oben diskutierten geostrategisch und regional bedeutenden Rolle Tansanias, politischen Inhalten und dem liberalen Image speiste, sondern wesentlich auf die Begeisterung für den charismatischen und eloquenten Präsidenten zurückging. ${ }^{122}$ Die vollständige Entschädigung westlicher Firmen nach den Nationalisierungen von 1967 stärkte auch das Vertrauen konservativer westlicher Investoren und Regierungen. Die Tansaphilie schlug sich in Ressourcentransfers nieder. Machte

119 Coulson, Tanzania, S. 355; BArch Koblenz, B 213/33046, Döpel, Tätigkeitsbericht Nr. 3, Dar es Salaam, 30.7.1973, S. 2; ebd., Döpel, Tätigkeitsbericht Nr. 5, Dar es Salaam, 4.11.1973; ebd., B 213/ 33056, Africa Bureau Cologne, 3. Quartalsbericht über die Tätigkeit des Beraters P. S. an die GTZ, Köln, Juni 1975, S. 2-3; CCMA, CMM/OND/183/36, Foreign Affairs Department of CCM Headquarters, Brief of Socialist Federal Republic of Yugoslavia, o.O., o. J. [ca. 1985], Bl. 20.

120 Jennings, Surrogates of the State, S. 64.

121 Stephen J. Macekura, Of Limits and Growth. The Rise of Global Sustainable Development in the Twentieth Century, New York 2015; Patrick Allan Sharma, Robert McNamara's Other War: The World Bank and International Development, Philadelphia 2017; Sean Delehanty, From Modernization to Villagization: The World Bank and Ujamaa, in: Diplomatic History 44/2 (2020), S. 289 314.

122 Ali Mazrui, Tanzaphilia, in: Transition 31 (1967), S. 20-26. 
externe Hilfe (assistance) 1967 noch 24 Prozent des Entwicklungshaushalts aus (äquivalent zu 4,7 Prozent der Exporterträge) entwickelte sich Tansania zu einem der Hauptempfänger westlicher - und chinesischer - Entwicklungshilfe in Afrika. 1974/75 stammten 54\% des tansanischen Entwicklungshaushalts aus externen Quellen, darunter insbesondere sozialdemokratisch regierte Länder (Skandinavien, BRD, Niederlande). ${ }^{123}$

\section{Die postkoloniale Aufteilung Tansanias}

Wie das folgende Beispiel der Regionalplanung zeigt, war die Mobilisierung externer Ressourcen durchaus eine bewusste Strategie - die aber trotzdem unbeabsichtigte Folgen zeitigte. Schon der zweite tansanische Fünfjahresplan von 1970 hatte die Einführung von Regionalplanungen ins Auge gefasst und darauf abgezielt, den effizientesten Beitrag jeder Region zur Wirtschaftsleistung des Landes zu identifizieren, die Bevölkerung im Planungsprozess miteinzubeziehen und alle Regionen gleichmäßig mit sozialen Dienstleistungen zu versorgen. ${ }^{124}$ Die praktische Einführung der regionalen integrierten Entwicklungsprogramme (Regional Integrated Development Programmes, RIDEPs) fiel dann mit der Dezentralisierungspolitik im Jahr 1972 zusammen. Die Dezentralisierung stelle den Versuch dar, Verantwortlichkeiten und Kapazitäten auf die regionale Ebene zu delegieren und eine für die Bevölkerung relevantere Planung zu ermöglichen - ohne dabei aber die Autorität der Zentralregierung zu gefährden. ${ }^{125}$ De facto wurde so die Zentralisierung in mancher Hinsicht verstärkt. Die neue Struktur ähnelte nicht zufällig einer großen Firma, in der das „kleine Management“ für die Alltagsaufgaben zuständig war und ein zentrales Management - das neu geschaffene Büro des Premierministers - richtungsweisende Entscheidungen treffen und Planungen vornehmen sollte: Die Dezentralisierung war vollständig vom US-amerikanischen Beratungsunternehmen McKinsey konzeptualisiert worden. ${ }^{126}$

123 Severine M. Rugumamu, Lethal aid. The Illusion of Socialism and Self-reliance in Tanzania, Trenton, NJ 1997, S. 155-156.

124 Klaus Pilgram/Karl-Ludwig Zils, Tanga Integrated Rural Development Programme (TIRDEP): Experience with Regional Planning and Project Implementation in Tanga Region, Tanzania, Tanga, Eschborn 1980, S. 6.

125 Coulson, Tanzania, S. 300 -301; Jennings, Surrogates of the State, S. 61; Tripp, Changing the Rules, S. 155.

126 Lizz Lyle Kleemeier, Integrated Rural Development in Tanzania: The Role of Foreign Assistance, 1972-1982, PhD Thesis, Berkeley 1984, S. 12. Diese politikwissenschaftliche Dissertation wird hier für die Überblicksdarstellung bevorzugt herangezogen, da die Verfasserin exzellenten Zugang zu Dokumenten Tansanias und der Geber hatte, wohl auch weil ihr Dissertationsbetreuer 
Im internationalen entwicklungspolitischen Diskurs erreichte der Trend der Regionalplanung in den frühen 1970er Jahren seinen Höhepunkt. Ähnliche Ansätze hatte es u. a. bereits mit dem Swynnerton Plan im kolonialen Kenia gegeben; die zuständigen englischen Beamten trugen die entsprechenden Konzepte und ihre Erfahrungen im weiteren Karriereverlauf dann in die Weltbank und andere Institutionen. ${ }^{127} \mathrm{Ab}$ Ende der 1950er argumentierten auch Entwicklungsökonomen wie Albert Hirschman und Gunnar Myrdal für Regionalplanungen. ${ }^{128}$ Regionale integrierte Entwicklungsprogramme, die auf eine Produktionssteigerung im kleinbäuerlichen Sektor abzielten, wurden von der Weltbank in den 1960erJahren in Malawi, Äthiopien, Bangladesch und Indonesien umgesetzt. ${ }^{129} 1972$ trafen sich Julius Nyerere und Weltbankpräsident Robert McNamara (der Tansanias Ujamaa und Umsiedlungsprojekten anfänglich äußerst wohlwollend gegenüberstand, weil kleinbäuerliche Produktion und die Erfüllung von Grundbedürfnissen hier ebenfalls im Zentrum standen) um die Finanzierung von integrierten Projekten in mindestens vier Regionen $\mathrm{zu}$ vereinbaren. ${ }^{130}$

Kurz nach dem Treffen zwischen Nyerere und MacNamara begann die Regierung mit der Suche nach Gebern für die Erstellung, Finanzierung und Umsetzung von Entwicklungsplänen für alle Regionen Tansanias. Regeln für die Aufteilung von Territorien wurden festgelegt, dieses Mal allerdings von afrikanischer Seite: Jede Region durfte nur einen Geber haben, aber ein Geber durfte durchaus mehrere Regionen „adoptieren“, was einige TansanierInnen damals scherzhaft und in Anspielung auf die Berliner Kongo-Konferenz 1884/85 als „zweite Aufteilung Afrikas durch den Westen“ bezeichneten. ${ }^{131}$ Tatsächlich war eine solche postkoloniale Einteilung in klar abgesteckte Einflussbereiche von Geberländern nicht gänzlich unüblich, auch Frankreich und Belgien gingen 1965 in Ruanda ähnlich vor. ${ }^{132}$ Auffällig im Falle Tansanias ist jedoch, wie bewusst die Aufteilung im Rahmen der Entwicklungspolitik forciert wurde, um möglichst viele Geber einzubinden. Die Regionalplanung ist somit ein hervorragendes Beispiel für die

selbst als einen Einsatz als Berater für Regionalplanung in Tansania absolviert hatte. Zusätzlich konnte sie auf Interviews mit weiteren involvierten Akteuren zurückgreifen.

127 Hodge, British Colonial Expertise.

128 Kleemeier, Integrated Rural Development, S. 84.

129 Kleemeier, Integrated Rural Development, S. 19, S. 76. Für eine Übersicht von Studien über regionale integrierte Entwicklungsprogrammee, siehe ebd., S. 102. Ein zentrales Werk für die Weltbankperspektive ist Uma J. Lele, The Design of Rural Development. Lessons from Africa, Baltimore 1975.

130 Die Nachricht von flächendeckenden Zwangsumsiedlungen sollte ihn dann allerdings schwer enttäuschen. Siehe Brazinsky, Winning the Third World, S. 293.

131 Kleemeier, Integrated Rural Development, S. 19.

132 Zürcher, Die Schweiz in Ruanda, S. 194-195. 
tansanische Extraversionsstrategie, mit der asymmetrische Verhältnisse über die Landesgrenzen hinweg zum eigenen Vorteil umgestaltet werden sollten. Bis 1972 war das Vorgehen der tansanischen Regierung umgekehrt gewesen. Zuerst wurde der nationale Entwicklungsplan (unter entscheidender Mitwirkung ausländischer Berater) mit einer Liste von Vorhaben formuliert, dann wurden die Vorhaben verschiedenen Gebern in Form eines Wunschzettels vorgelegt. Während im Konzept der Regionalplanung nun die nationale Politik immer noch von der Zentralregierung bestimmt wurde, konnte die „Aufteilung“ das Prestige- und Wettbewerbsdenken unter den Gebernationen anspornen und, so vermutlich die Überlegung von Nyerere und anderen Befürwortern dieses Vorgehens, zu umfassenderen Ressourcentransfers und schlussendlich einer erhöhten Wirtschaftsleistung und verbesserten Lebensstandards führen. ${ }^{133}$

Die nunmehr stark von Gebern beeinflusste Regionalplanung rief allerdings auch Kritik hervor, dass die nationalstaatliche Souveränität und sozialistische Ziele kompromittiert wurden. Bemängelt wurde erstens, dass Tansania keine nationale, übergeordnete Konzeption vorlegte, womit zweitens die Bestimmungsmacht ausgelagert wurde, was drittens die Pläne und Umsetzung von den eigennützigen, neokolonialen Motiven der kapitalistischen Geber abhängig machte. Diese Kritikpunkte - Konzeptlosigkeit, Auslagerung der Entscheidungsmacht, Abhängigkeit von Gebermotiven - wurden insbesondere von der tansanischen Linken vorgebracht. Der tansanische Politikwissenschaftler A. K. Mhina sah in der Adaption der Regionalplanung keine bewusste sozialistische Entwicklungsstrategie: „It was adopted, it seems, because it is ,catchy“ since it implied foreign aid. “134 Ähnlich stellten Studierende der Universität Dar es Salaam im Rahmen einer Demonstration gegen die Privilegien der politischen Elite die regionalen Entwicklungspläne infrage:

The programmes for carrying out our revolution do not reveal that we are really serious about building socialism. We seem to totally throw overboard our aim of building a socialist economy when we assign the various development plans to different capitalist countries, like Kilimanjaro to the Japanese, Dar to the Canadians, Tanga to the West Germans, Coast to the Swedish, etc. Since when have capitalists been able to build socialism? ${ }^{135}$

133 Kleemeier, Integrated Rural Development, S. 86; Coulson, Tanzania, S. 364-368.

134 A. K. Mhina, The Impact of Tirdep Extension Project in Tanga Region, in: Taamuli: A Political Science Forum 11/1 (1982), S. 27-50, hier: S. 31.

135 Zit. nach Issa G. Shivji, The Politics of Liberalization in Tanzania: The Crisis of Ideological Hegemony, in: Horace Campbell/Howard Stein, Hg., Tanzania and the IMF: The Dynamics of Liberalization, Boulder 1992, S. 43-58, hier: S. 50. 
Wie Mhina sahen sie das Grundproblem darin, dass Pläne und Finanzierung von außen kamen und die „kapitalistischen“ Geber den Aufbau des tansanischen Sozialismus qua ihrer Herkunft automatisch unterminieren würden. ${ }^{136}$ Jüngst hat die Historikerin Priya Lal in ähnlicher Stoßrichtung argumentiert, dass die regionalen Entwicklungspläne (,barometers of and catalysts for the attenuation of ujamaa's utopian potential“137) den Abschied vom Prinzip der Souveränität und selbstbestimmten Entwicklung eingeleitet und zu einer nationalen Desintegration geführt hätten: „The rise of the RIDEP model heralded a novel mode of global engagement for Tanzania, both compromising the spatial integrity of the nationstate and challenging its sovereignty by exporting developmental governance to individual foreign donors.“"138

In der Praxis der Regionalplanung offenbarte sich sowohl die institutionelle Schwäche des tansanischen Staates wie auch das Desinteresse der meisten Geber, ihre Maßnahmen untereinander und mit tansanischen Behörden abzustimmen. Das 1972 anlässlich der Dezentralisierung neu gegründete Prime Minister's Office in Dodoma, theoretisch für die geberunterstützen Entwicklungsvorhaben in den Regionen zuständig, war ein innenpolitisches Leichtgewicht ohne jede Durchsetzungsfähigkeit gegenüber anderen Ressorts. ${ }^{139}$ Eine bindende Konzeption zur Regionalplanung fehlte. ${ }^{140}$ Die eigens erlassene Richtlinie war äußerst vage und ließ etwa die zentrale Frage offen, ob sich die geografisch sehr heterogenen Regionen im Sinne einer nationalen Arbeitsteilung und komparativer Vorteile auf die Produktion bestimmter Produkte spezialisieren oder eine jeweilige regionale self-reliance anstreben sollten. Die Koordination unter den verschiedenen inter-

136 Mhina, The Impact of Tirdep, S. 30.

137 Lal, African Socialism in Postcolonial Tanzania, S. 170, S. 218.

138 Ebd.; vgl. auch S. 130, S. 168, S. 218. Die praktische Relevanz dieses postulierten Bruchs in der postkolonialen Geschichte Tansanias bleibt jedoch im Unklaren; Lal selbst hat sich mit der (,finnischen“) Region Mtwara befasst, führt ihre These allerdings nicht genauer aus, da ihr Untersuchungszeitraum 1975 endet. Da es vorerst kaum zu finnischen Aktivitäten in Mtwara kam, wäre sie in diesem Fall auch nur schwerlich belegbar. Das Engagement der BRD in Tanga eignet sich in dieser Hinsicht als Fallstudie deutlich besser.

139 Vonseiten der BRD wurde es nur als technokratische Ausführungsinstitution gesehen. PAAA, ZW 116 859, BRD-Botschaft an AA, Dar es Salaam, 29.8.1977; siehe auch Kleemeier, Integrated Rural Development, S. 55

140 Kleemeier, Integrated Rural Development, 26; BArch Koblenz, B 213/33047, H., Aktennotiz über das Treffen der verschiedenen Regionalplanungsteams in Dar es Salaam am 28. und 29.11. 1974, Tanga, 12.12.1974; Interview \#28, GTZ-Experte. 
nationalen Planungsteams wiederum blieb auf unverbindliche Konferenzen zum Erfahrungsaustausch beschränkt. ${ }^{141}$

Die Ressourcentransfers fielen letztlich in den meisten Regionen deutlich geringer aus als erhofft. Tansania erwartete finanzielle Transfers, aber auch „technische Hilfe“ und Ausbildungen in Regionalplanung für tansanische BeamtInnen. Mit Ausnahme der USA widmete sich anfangs jedoch kein Geber der Ausbildung von Counterparts. ${ }^{142}$ Die Dominanz von expatriates in den Planungsprozessen ist wenig verwunderlich, da erst 1976 die ersten tansanischen BeamtInnen eine Ausbildung in Regionalplanung abgeschlossen hatten. ${ }^{143}$ Selbst danach aber waren es expatriates, die über RIDEP-Konzepte entschieden und das alltägliche Management kontrollierten. Da alle Regionalpläne einen höheren Betrag veranschlagten als den jeweiligen Regionalverwaltungen zur Verfügung stand - im Falle Kilimandscharos war der Betrag gar fünf Mal höher - war externe Finanzierung auch Voraussetzung für jede Umsetzung. Diese Aspekte deuten auf eine Auslagerung der Entscheidungsmacht und eine Verstärkung der Abhängigkeit von außen. Tansanische Akteure versuchten diese Abhängigkeit allerdings zu gestalten und zu verringern, etwa indem sie auf nationale Präferenzen pochten. Pläne, in denen nur geringe Investitionen vorgesehen waren und wo zusätzlich politische Spannungen mit den Planungsteams bestanden, wurden abgelehnt. ${ }^{144}$

Die Strategie der Extraversion durch Regionalpläne stieß auch in anderer Hinsicht an Grenzen. Nur wenige Regionen fanden über die Planungsphase hinaus einen interessierten „Entwicklungspaten“ (Tabelle 2.1). Entgegen der Erwartung, dass die Geber eher bereit sein würden, einen Plan zu finanzieren, den sie selbst erstellt hatten, fristeten die meisten Pläne ein Schubladendasein. ${ }^{145}$ Staaten des sowjetischen Lagers wurden anscheinend nicht angefragt. Die Blockfreienorientierung Tansania schlug sich darin nieder, dass auch Indien und Jugoslawien Pläne für je eine Region erstellten; beide trugen aber letztlich nicht zur Umsetzung bei. Selbst für die meisten westlichen Geber waren multisektorale Vorhaben zu kostspielig, sie konzentrierten sich weiterhin auf klar abgegrenzte

141 Laut D. G. R. Belshaw, 1975 Berater für Regionalplanung im Prime Minister's Office, wurden von ihm initiierte Koordinationstreffen von tansanischer Seite neun Mal verschoben. Siehe Kleemeier, Integrated Rural Development, S. 27.

142 Kleemeier, Integrated Rural Development, S. 19, S. 53.

143 Interview \#84, Tansanischer Entwicklungsplaner.

144 Planungsteams aus skandinavischen Ländern hatten Politikempfehlungen abgegeben, die den Regionalbehörden zu weit gingen; Schweden etwa durfte trotz starken Interesses kein RIDEP umsetzen. Kleemeier, Integrated Rural Development, S. 35, S. 40 - 41.

$145 \mathrm{Zu}$ den geplanten Kosten der einzelnen Pläne siehe Kleemeier, Integrated Rural Development, S. 54-55. 
Bereiche wie etwa die Wasserversorgung. Im Falle der BRD ging die tansanische Hoffnung, durch die Planung ein langfristiges Engagement zu stimulieren, jedoch auf (siehe Kapitel 8).

Ein weiterer Kritikpunkt von Mhina und anderen war, dass die entwicklungspolitischen Aktivitäten der Geberländer durch außenpolitische und -wirtschaftliche Interessen überformt waren; gerade kapitalintensive Vorhaben im Straßenbau oder der Wasserversorgung würden erlauben, Gelder durch Technologieexporte und die Beauftragung privater Firmen aus dem eigenen Land wieder zurückfließen zu lassen. Nicht zufällig hätten zudem ausgerechnet Tansanias wichtigste cash crop-Regionen langfristig engagierte Geberpatrone bekommen: Tanga mit Sisal und Tee, Kilimandscharo mit Kaffee, Tabora mit Tabak. ${ }^{146}$ Tatsächlich spielten Lieferbindungen und etablierte Handelsstrukturen eine Rolle. Die Europäische Kommission (in der Region Iringa) und Japan, das Traktoren nach Kilimanjaro lieferte, machten keinen Hehl daraus, dass die „Hilfe“ an den Export eigener Industriegüter, Maschinen und Dienstleistungen gebunden war. ${ }^{147}$ Die Niederlande wählten Morogoro im Zusammenhang mit bereits laufenden Investitionen im Zuckerrohranbau und der Wasserversorgung. ${ }^{148}$ Die für Tanga bedeutende Sisalindustrie befand sich infolge der Verstaatlichung in einer Krise; westdeutsche Firmen investierten (mit zusätzlichen DEG-Geldern) in Sisal-Spinnereien und waren auch an anderen Vorhaben beteiligt. ${ }^{149}$ Als Infrastrukturhilfe finanzierten deutsche Entwicklungshilfekredite den Ausbau der Hafenanlage und einer Verladerampe in Tanga für die umstrittene staatliche Düngemittelfabrik (siehe Kapitel 3), die auf deutsches Management und teure Rohstoffimporte angewiesen war. ${ }^{150}$ In keinem dieser Fälle lässt sich von einer Förderung von selfreliance sprechen.

Ab Mitte der 1970er-Jahre kippte die Haltung westlicher Geber von einer begeisterten Tansaphilie in eine Ermüdung und insbesondere beim Wechsel zu konservativen Regierungsparteien gar in eine Tansaphobie. Die wirtschaftlichen Schwierigkeiten wurden als schlagendster Beleg für die Reformbedüftigkeit wenngleich nicht zwingend Perspektivlosigkeit - von Ujamaa angeführt. Die landwirtschaftliche Produktion brach kurzfristig ein und stagnierte in den Jahren

146 Faustin Peter Maganga, Emerging Trends in Foreign-Aided Rural Development Programmes in Tanzania: The Case of Tanga Integrated Rural Development Programme (TIRDEP) and Rukwa Integrated Rural Development Programme (RUDEP), MA Thesis, Dar es Salaam 1990, S. 10.

147 Kleemeier, Integrated Rural Development, S. 102.

148 Ebd., S. 31, 40.

149 Wirth, Aspekte, S. 131-132.

150 Gerd Röhnelt, Die bundesdeutsche Entwicklungshilfe für Tansania seit 1961: Regionale Bedeutung und gesamtwirtschaftlicher Nutzen, Frankfurt/Main 1980, S. 151. 


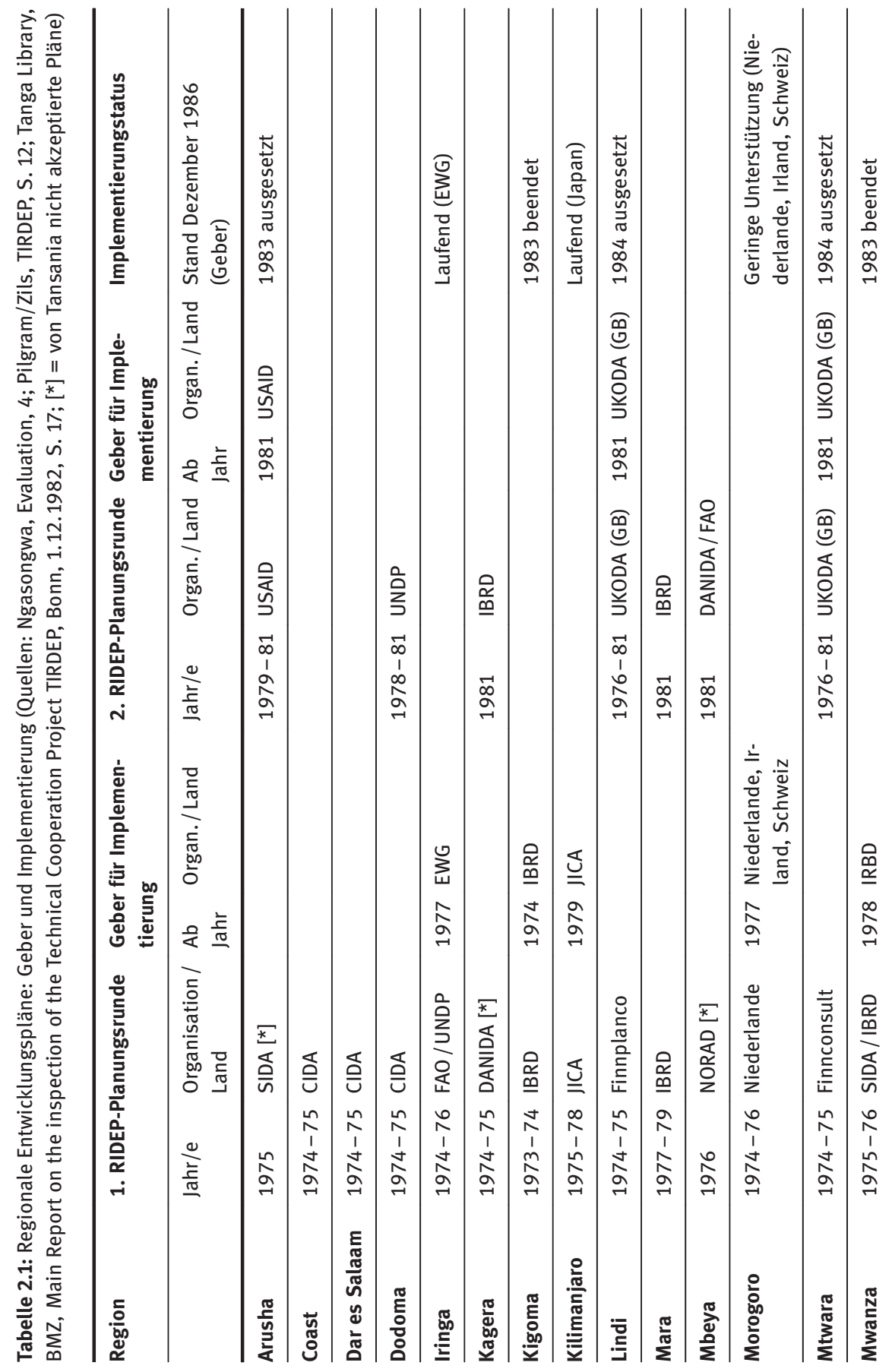




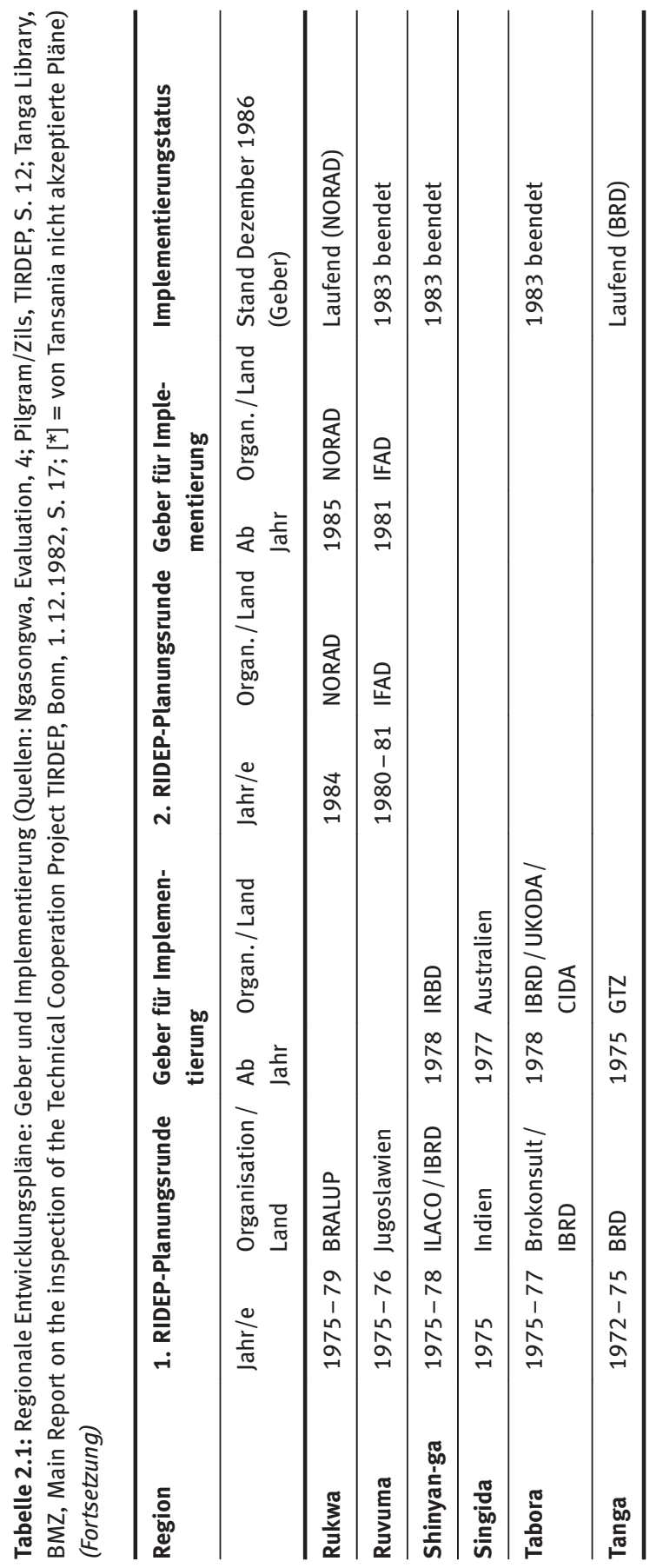


1977-1986, während die Industrieproduktion im selben Zeitraum sogar zurückging. ${ }^{151}$ Versorgungskrisen und Nahrungsmittelknappheit, zum Teil durch Dürren in den Jahren 1973-1974 und 1981-1984 hervorgerufen, zwangen die Regierung zum Import von Getreide. Das Umsiedlungsprogramm (1969-1975/76), das u.a. darauf abgezielt hatte, die verstreute ländliche Bevölkerung zur effizienteren Bewirtschaftung von Gemeinschaftsfeldern in Dörfern zu vereinen, um mehr cash crops exportieren und so dem Zahlungsbilanzdefizit entgegenwirken zu können, zeitigte nicht die gewünschten Erfolge. Im Zuge der fortschreitenden Inflation des tansanischen Schillings umging die bäuerliche Bevölkerung zunehmend die staatlichen Vermarktungskanäle. Auch die auf Importsubstitution und zunehmend auf teure Technologieimporte setzende Industrialisierungsstrategie (Basic Industry Strategy) brachte keine nennenswerten Produktivitätsgewinne. Die im Gefolge der Deklaration von Arusha nationalisierten Unternehmen, die jedoch in den meisten Fällen joint ventures mit westlichen Firmen blieben, operierten nach anfänglichen Erfolgen ${ }^{152}$ zunehmend auf Verlustbasis. Hier spielten Ineffizienz und Korruption aber wie im Fall der Düngemittelfabrik auch kostspielige Importe von Technologien und Grundstoffen eine Rolle, deren Mangel (z. B. bei steigenden Importpreisen) zu Produktionsausfällen und Unrentabilität führte. Zwischen den verschiedenen Industrieprojekten - deren Realisierung fast immer von externen Investoren abhing - ergaben sich keine Synergieeffekte. ${ }^{153}$ Insgesamt blieb die Wirtschaftsstruktur in Kontinuität zur Kolonialzeit auf den Export von Primärgütern in kapitalistische Länder ausgerichtet, nicht zuletzt, um an dringend benötigte Devisen zu kommen.

Diese Probleme wurden aufgrund Tansanias peripherer Position im kapitalistischen Weltsystem durch eine Reihe externer Faktoren mit ausgelöst oder verschärft. VerfechterInnen von Ujamaa im In- und Ausland verwiesen vor allem auf diese äußeren Einflüsse und historisch gewachsene Widersprüche, um die Misere zu erklären. Die von Anfang der 1970er Jahre bis 1990 im Schnitt deutlich fallenden terms of trade bedeuteten geringere Exporterlöse und teurere Importe, was den Druck auf die Zahlungsbilanz verstärkte. Die Ölkrisen 1973/74 und 1979/

151 T. L. Maliyamkono/M. S. D. Bagachwa, The Second Economy in Tanzania, London 1990, S. 6. 152 So waren 1974 ca. $75 \%$ aller in Tansania konsumierten Verbrauchsgüter (broad-market consumer manufactured goods) im Inland hergestellt worden, im Vergleich zu ca. 25\% zur Unabhängigkeit. Der Anstieg ist allerdings nicht allein auf Produktionsgewinne zurückzuführen; Importbeschränkungen spielten ebenfalls eine Rolle. Reginald H. Green, Tanzanian Political Economy Goals, Strategies, and Results, 1967-1974: Notes Towards an Interim Assessment, in: Bismarck U. Mwansasu/Cranford Pratt, Hg., Towards Socialism in Tanzania, Dar es Salaam 1979, S. 15 - 41, hier: S. 33.

153 Barker, African Industrialisation, S. 193-199; Green, Tanzanian Political Economy, S. 40. 
80, der Zusammenbruch der East African Community 1977 (wodurch nicht nur der Handel einbrach, sondern Tansania auch in den Aufbau der zuvor gemeinschaftlichen Sektoren wie Telekommunikation oder Luftfahrt investieren musste) sowie der etwa 500 Millionen US-Dollar kostende Krieg gegen Uganda nach der Invasion durch Idi Amin 1979 trieben die Auslandsverschuldung weiter in die Höhe, bis der Devisenmangel selbst viele der notwendigsten Importe unmöglich machte. ${ }^{154}$ Die Bedeutung der informellen Ökonomie wuchs nicht nur rasant, weil Arbeitsplätze knapp waren, sondern auch, weil die Reallöhne in den 1980erJahren zum Überleben völlig unzureichend waren und durch legale wie illegale Nebentätigkeiten aufgebessert werden mussten. ${ }^{155}$ Klientelismus und Korruption durchzogen nunmehr alle Bereiche der Gesellschaft. Beinah die gesamte Bevölkerung partizipierte notgedrungen an Schwarzmarktgeschäften, insbesondere in den Städten war es „buchstäblich unmöglich zu überleben [...], wenn man dem Gesetz folgte“. 156

1979 forderte der Internationale Währungsfonds (IWF) erstmals die Abwertung des tansanischen Schillings und weitere makroökonomische Reformen. Gegen den Rat seines Finanzministers, der daraufhin zurücktrat ${ }^{157}$, weigerte sich Nyerere diese Bedingungen für eine weitere Kreditvergabe anzunehmen, wies die IWF-Delegation kurzerhand außer Landes und ersuchte die Bevölkerung, den Gürtel enger zu schnallen. Westliche Gebernationen schlossen sich dem IWF nach und nach an und machten Reformen zur Bedingung für weitere entwicklungspolitische Transfers. Die externen Mittel, bisher unter entwicklungspolitischen Prämissen im Bildungssektor, der ländlichen oder Industrieentwicklung eingesetzt, benötigte Tansania nun zunehmend zum Ausgleich des Zahlungsbilanzdefizits. ${ }^{158}$ Die noch unter eigener Regie initiierten Reformen zwischen 1982 und 1985 - auch später waren keineswegs alle Umstrukturierungsmaßnahmen von

154 Diskussionen über die Ursachen der wirtschaftlichen Krise finden sich u. a. in C. G. Kahama/ T. L. Maliyamkono/Stuart Wells, The Challenge for Tanzania's Economy, London 1986; Michael F. Lofchie, The Political Economy of Tanzania. Decline and Recovery, Philadelphia 2014; Tripp, Changing the Rules, S. 62-67.

155 Die ökonomischen Überlebensstrategien bilden das Hauptthema von Maliyamkono/Bagachwa, Second Economy; Tripp, Changing the Rules. Siehe auch Andrew S. Z. Kiondo, The Second Economy in Tanzania: its Emergence and Strategies of Control, in: Maria Łoś, Hg., The Second Economy in Marxist States, Basingstoke 1990, S. 175-192.

156 Emily Callaci, Street Archives and City Life. Popular Intellectuals in Postcolonial Tanzania, Durham, London 2017, S. 197.

157 Mtei, From Goatherd to Governor.

158 Andrew Kiondo, The Nature of Economic Reforms in Tanzania, in: Horace Campbell/Howard Stein, Hg., Tanzania and the IMF: The Dynamics of Liberalization, Boulder 1992, S. 21-42, hier: S. 22. 
außen diktiert - konnten keinen Trendwechsel einleiten. Bemühungen, das Wegbrechen westlicher Hilfs- und Investitionsgelder durch ein stärkeres Engagement aus kommunistischen Staaten zu kompensieren, blieben erfolglos (detailliert zur DDR siehe Kapitel 3). Der breiteren Dynamik globaler Nord-Süd-Beziehungen entsprechend verengte sich der Handlungsspielraum Tansanias angesichts von globaler Rezession, Kapitalismuskrise und erhöhten Zinssätzen für den Schuldendienst. ${ }^{159}$

Als die westlichen Geber 1985 schließlich eine Einheitsfront bildeten, war ein Ausweichen auf alternative Ressourcenquellen nicht mehr möglich. Abbildung 2.3 zeigt den Anstieg (1970 - 1979) und dramatischen Rückgang (1979-1985) westlicher Nettotransfers mit dem Jahr 1979 als klar erkennbarem Wendepunkt. 1985 machten auch die skandinavischen Länder und die Niederlande, die letzten treuen Unterstützer eines eigenständigen tansanischen Weges, grundlegende makroökonomische Reformen zur Bedingung von „Hilfe“. Nyerere trat vom Präsidentenamt zurück und überließ dem reformorientierten Ali Hassan Mwinyi das Feld, der 1986 das Abkommen mit dem IWF unterzeichnete und - gegen Widerstände der alten Parteigarde - eine partielle Liberalisierung, Deregulierung und Privatisierung der Wirtschaft einleitete. Verschuldung und Geberabhängigkeit

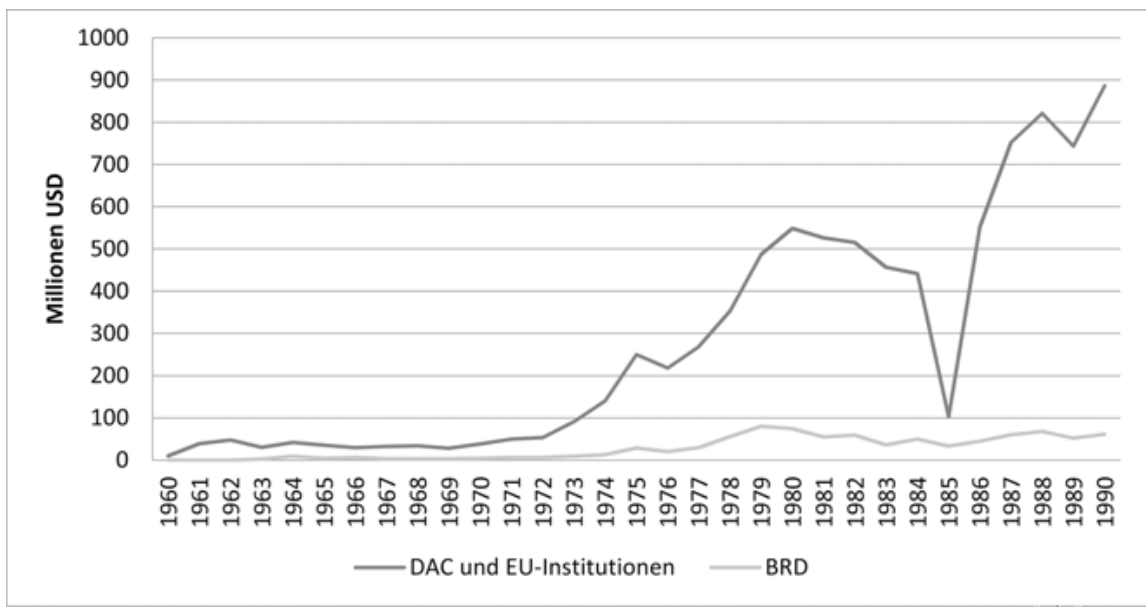

Abbildung 2.3: Ujamaa und Entwicklungshilfe: Nettotransfers aller DAC-Geber an Tansania in Millionen US-Dollar, 1960-1990.

Der Anteil der BRD ist zusätzlich separat angegeben. (Quelle: Edwards, Toxic Aid, 57-59; Darstellung und Berechnung: E.B.)

159 Havnevik, Tanzania, S. 22-23. 
nahmen danach noch größere, unter Ujamaa ungekannte Dimensionen an. Kommunistische Staaten hatten entweder kein Interesse mehr oder operierten wie China mittlerweile selbst nach Kriterien der Profitabilität. So kam auch die zweite Säule von Ujamaa - self-reliance - zum Einsturz, bevor sie überhaupt errichtet war.

\subsection{Egalitarismus und Elitenbildung: Ungleichheit in der sozialistischen moralischen ökonomie}

Eine dritte Säule von Ujamaa neben der öffentlichen Kontrolle der Wirtschaft und self-reliance war der Egalitarismus. Hier bestand ein Dilemma, denn zur Erreichung der vollen Unabhängigkeit brauchte es eigene Fachkräfte, von denen aber aufgrund begrenzter Ressourcen nur wenige ausgebildet werden konnten. Als Erbe der Kolonialzeit stellten Abschlüsse von Bildungsinstitutionen westlichen Modells die conditio sine qua non für berufliche Karrieren dar. Nur das symbolische Kapital von Bildungsabschlüssen qualifizierte für eine Tätigkeit für mittlere und höhere Posten in Verwaltung und halbstaatlichen Unternehmen. Da sich in Tansania keine ökonomischen Klassen herausgebildet hatten (bzw. die Nationalisierungen ab 1967 manche der bestehenden Unterschiede tendenziell einebneten) und eine egalitaristische Lohnpolitik die Einkommensungleichheit reduzierte, stellte das hochselektive Bildungssystem in Kontinuität zur Kolonialzeit einen zentralen Mechanismus sozialer Stratifizierung dar. In einem Entwicklungsstaat hat das weitreichende Folgen, wie die Anthropologin Kristin Philips festhält: „Education is not only a major objective of development but it serves to distinguish those who will be the ,minds' of development, from those who will be its ,hands.' It functions [...] as a ,principle of selection' [...] of those who are ,entrusted' and those who will ,trust.““160 1970 brachte ein junger Mann sein elitäres Sendungsbewusstsein in einem Leserbrief an den Nationalist deutlich zum Ausdruck:

The pride, the status of being the group upon which the future of this young nation of Tanzania largely and exclusively depends! It is not an individual person, place, town or region that will depend on us, but the whole nation at large. Fellow youths, we are the cream, the echelons of this society. ${ }^{161}$

160 Kristin Philips, Dividing the Labor of Development: Education and Participation in Rural Tanzania, in: Comparative Education Review $57 / 4$ (2013), S. 637-661, hier: S. 655.

161 Leserbrief von D. Philly, Future of Tanzania lies with her youth, in: The Nationalist, 9.11. 1970, zit. nach Ivaska, Cultured States, S. 124. 
In mancher Hinsicht hatte der Verfasser dieses Briefes gute Gründe, die gebildete, junge Generation zu einer raren Ressource zu stilisieren. Da sich die Bildungspolitik während des britischen Mandats nicht nur durch die zur Aufrechterhaltung kolonialer Herrschaft übliche Ausgrenzung bzw. Segregierung aufgrund „rassischer“ Kriterien, sondern auch durch eine beispiellose Investitionsarmut auszeichnet hatte, galt Tanganjika zum Zeitpunkt der Unabhängigkeit als Extrembeispiel für Fachkräftemangel und insbesondere die fehlende Qualifikation der „rassischen“ Bevölkerungsmehrheit. Von 184 ÄrztInnen in Tanganjika waren nur 16 afrikanischer Herkunft, von 57 AnwältInnen zwei und von 84 Ingenieuren ein einziger. Nur zwei Prozent der Jugendlichen im entsprechenden Alter besuchten die Sekundarschule. ${ }^{162}$ Höhere Abschlüsse konnten an der 1922 gegründeten Verwaltungs- und späteren Hochschule in Makerere in Uganda erlangt werden, die für alle ostafrikanischen Territorien unter britischer Herrschaft zuständig war. ${ }^{163}$ Da die Regierung in Dar es Salaam die Sekundarschulbildung in Tanganjika bewusst vernachlässigte und fürchtete, dass StudentInnen während eines Aufenthalts in Makerere zur politischen Agitation angestiftet werden könnten, wurden die ohnehin niedrigen Quoten, die Tanganjika zustanden, oft nicht ausgeschöpft. ${ }^{164}$ Während bereits in den 1930er-Jahren größere Zahlen von Studierenden aus Westafrika an britischen und französischen Universitäten anzutreffen waren, konnten nur vereinzelt junge Männer aus Tanganjika ein Studium - meist ein missionsfinanziertes Theologiestudium - in den USA oder Europa absolvieren. ${ }^{165}$ Lediglich materiell bessergestellte Familien und einige Organisationen auf religiöser, regionaler oder ethnischer Basis waren in der Lage, Mitgliedern der eigenen Gemeinschaft Ausbildungen und Studien im Ausland unabhängig von Regierungsstipendien zu ermöglichen. ${ }^{166}$

\section{Afrikanisierung und Dekolonisierung}

Im nationalistischen Diskurs der 1950er-Jahre war jeder Studienabschluss ein politisches Argument. Der Mangel an ausgebildeten afrikanischen Verwaltungs-

162 Iliffe, Modern History, S. 573.

163 Carol Sicherman, Becoming an African University. Makerere, 1922-2000, Trenton 2005.

164 Judith Listowel, The Making of Tanganyika, London 1965, S.179-180; Eckert, Herrschen und Verwalten, S. 69.

165 Eckert, Herrschen und Verwalten, S. 70. Zu Großbritannien und Frankreich siehe Hakim Adi, West Africans in Britain, 1900-1960. Nationalism, Pan-Africanism, and Communism, London 1998; Fabienne Guimont, Les étudiants africains en France, 1950 -1965, Paris 1997.

166 Iliffe, Modern History, S. 446-447. 
kräften wurde von der TANU als Beleg für die unzureichende Umsetzung der kolonialen Entwicklungsversprechen gesehen, von britischer Seite jedoch wiederholt als Legitimation für die Fortführung der Kolonialherrschaft ins Feld geführt. Gouverneur Richard Turnbull ging noch 1959 davon aus, dass Tanganjika mindestens zwei weitere Jahrzehnte auf externe Kräfte angewiesen bleiben würde. ${ }^{167}$ Erst in diesem Jahr, nach drei Jahrzehnten deutscher und vier Jahrzehnten britischer Herrschaft, wurden die ersten sieben Afrikaner in höheren Beamtenpositionen zugelassen, von denen es insgesamt 299 gab. ${ }^{168}$ Die TANU forderte daher schon 1954 ein eigenes University College und mehr Investitionen in höhere Bildung. Parteimitglieder profitierten von Stipendien, die die TANU von diversen Institutionen meist in Übersee erhielt.

Um die Abhängigkeit von den noch im Land verbliebenen britischen Beamten und weiterem ausländischem Personal zu verringern, investierte die postkoloniale Regierung in Sekundär- und Tertiärbildung und „afrikanisierte“ und nationalisierte die Beamtenschaft. Die kurze Phase der „Afrikanisierung“ bis 1963 ging insbesondere auf politischen Druck aus Partei- und Gewerkschaftskreisen zurück und zielte auf die möglichst schnelle Ersetzung von europäischen und asiatischen durch afrikanische Beamte, insbesondere in den höheren Positionen. ${ }^{169}$ Nyerere, der ein explizit nicht-rassialisiertes Bild der Staatsbürgerschaft vertrat und die Effizienz der Verwaltung durch überhastete Afrikanisierungsmaßnahmen gefährdet sah, konnte aber schon 1963 de jure die Nationalisierung ohne Rücksicht auf „rassische“ Kriterien - als Leitprinzip der Rekrutierungspolitik durchsetzen. ${ }^{170}$ In der Praxis wirkte die Idee der „Afrikanisierung“ jedoch fort. Tansanische StaatsbürgerInnen asiatischer Herkunft wurden bei Beförderungen und Bewerbungen regelmäßig übergangen. Teils aufgrund historisch gewachsener Privilegien und Besitzstrukturen, teils durch gezielte Angriffe war diese Bevölkerungsgruppe auch überproportional von Nationalisierungsmaßnahmen betroffen. ${ }^{171}$ Rund die Hälfte der etwa 40.000 „InderInnen“ (wahindi)

167 Sebastian Edwards, Toxic Aid. Economic Collapse and Recovery in Tanzania, Oxford 2014, S. 66. Diese Begründung wurde von manchen afrikanischen SekundarschülerInnen auch geteilt: siehe Edwin Mtei, From Goatherd to Governor. The Autobiography of Edwin Mtei, Dar es Salaam 2009, S. 32-33.

168 Pratt, The Critical Phase, S. 92

169 Pratt, The Critical Phase, S. 124-125.

170 Es kam jedoch auch später noch zu Ausnahmen, z. B. nach der Armeemeuterei 1964, die sich u.a. gegen die britischen Offiziere richtete. Timothy Parsons, The 1964 Army Mutinies and the Making of Modern East Africa, Westport, CT 2003.

171 Detailliert hierzu siehe Aminzade, Race; James R. Brennan, Taifa. Making Nation and Race in Urban Tanzania, Athens 2012; Eric Burton, „...What Tribe Should We Call Him?“ The Indian Diaspora, the State and the Nation in Tanzania since ca. 1850, in: Stichproben. Wiener Zeitschrift 
wanderte Ende der 1960er und Anfang der 1970er-Jahre aus, was einen herben Rückschlag für die Bemühungen bedeutete, bis 1980 alle Posten im öffentlichen Dienst mit tansanischen StaatsbürgerInnen zu besetzen. ${ }^{172} \mathrm{Hinzu} \mathrm{kam}$, dass Großbritannien 1968 sämtliche Personalverträge auslaufen ließ, da Tansania sich geweigert hatte, weiterhin die Pensions- und Entschädigungszahlungen für ehemalige Kolonialbeamte $\mathrm{zu}$ begleichen. Von über 1.000 ehemaligen britischen Kolonialbeamten Anfang der 1960er-Jahre waren 1970 aber immer noch 340 in Diensten des tansanischen Staates. Neun Jahre nach der Unabhängigkeit galt zahlreichen Beobachtern, darunter auch die Bonner Vertretung, noch immer das „Personalproblem [als] Haupthindernis für die Erreichung der Planziele des Zweiten Fünfjahresplans““. ${ }^{173}$

In rein quantitativer Hinsicht war die Nationalisierung durchaus erfolgreich. Der Anteil von StaatsbürgerInnen im Verwaltungsapparat stieg von 26,2\% (1961) auf 85,6\% (1970) und 99,5\% (Durchschnitt 1981-85); die Rekrutierung von expatriates wurde in erster Linie für Posten mit technischen und naturwissenschaftlichen Qualifikationsprofilen weiterhin durchgeführt. ${ }^{174}$ Der Erfolg war in einer technokratischen, bedarfsorientierten Heranbildung von Fachkräften begründet, die zeitweise von einem eigenständigen Ministerium für manpower development gesteuert wurde: Das Bildungssystem sollte exakt die Art und Anzahl von Fachkräften „produzieren“, die der Staat benötigte. Den theoretischen Hintergrund dieser Praxis, in der der Fachkraftbedarf aller nicht-staatlichen Sektoren inklusive der Privatwirtschaft ausgeblendet blieb, bildete die Verbindung von Humankapitaltheorie, Planungsdenken und Modernisierungstheorie. ${ }^{175}$ Bildung galt in erster Linie als ökonomische Investition in die Produktionssteigerung, als Voraussetzung von Wachstum und „Entwicklung“.

für kritische Afrikastudien 13/25 (2013), S. 1-28; Dharam P. Ghai/Yash P. Ghai, Asians in Tanzania, in: Knud Erik Svendsen/Merete Teisen, Hg., Self Reliant Tanzania, Dar es Salaam 1969, S. 90 -110. Zur Geschichte von race mit einem Fokus auf sansibarische Diskursstränge siehe auch Jonathon Glassman, War of Words, War of Stones. Racial Thought and Violence in Colonial Zanzibar, Bloomington 2011.

172 Ghai/Ghai, Asians in Tanzania. Der hierzu verwendete Begriff war self-sufficiency. Siehe URT, Manpower Report 1976, S. 109; URT, Annual Manpower Report to the President 1982, Dar es Salaam 1984, S. 119

173 BArch Koblenz, B 213/7673, BRD-Botschaft an AA, Dar es Salaam, 4.2.1970.

174 Außerdem wurde eine Vielzahl von Stellen als vakant gelistet, von denen allerdings ein großer Teil eher Planstellen denn tatsächlichen Fachkraftmangel betraf. Pratt, The Critical Phase, S. 129-130; URT, Annual Manpower Report to the President 1976, Dar es Salaam 1978, S. 9-10; URT, Annual Manpower Report to the President 1985, Dar es Salaam 1988, S. viii.

175 Lene Buchert, Education in the Development of Tanzania, 1919-90, London u.a. 1994, S. 93-34. 


\section{Entwicklungsstaat und soziale Mobilität}

Die Biografien tansanischer InterviewpartnerInnen waren von Momenten und Strukturen dieses technokratischen manpower development geprägt. Noch vor dem Erlangen der Hochschulreife mussten SchülerInnen ein Formular ausfüllen, auf dem sie ihre Präferenzen für eine Studienrichtung angaben. Sie wurden dann vom Bildungsministerium den höheren Bildungsinstitutionen im In- und Ausland zugewiesen; mit Ausbildungsende folgte die Zuteilung zu staatlichen Arbeitgebern. Jene, die ein Regierungsstipendium erhalten hatten - was auf den Großteil der StudentInnen zutraf - mussten sich verpflichten, nach dem Studienabschluss fünf Jahre für staatliche Stellen zu arbeiten. Diese Pflicht, die es für bestimmte Stipendien bereits zur Kolonialzeit gegeben hatte, war anfangs zugleich auch eine Jobgarantie. In den 1960er und 1970er Jahren - dem „goldenen Zeitalter“ des öffentlichen Dienstes in Tansania - bedeutete eine Stelle in der Verwaltung wie zur Kolonialzeit Prestige, Sicherheit, Weiterbildungs- und Aufstiegsmöglichkeiten. ${ }^{176}$ Die Ansicht, dass zwischen der Entwicklung des Landes und der eigenen Laufbahn eine symbiotische und reziproke Beziehung bestehe, war in gebildeten Kreisen Konsens: Schon 1946 hatte Shaaban Robert, einer der bedeutendsten tansanischen Schriftsteller und selbst in Diensten der Kolonialverwaltung, in diesem Sinne geschrieben: „Das Leben eines Menschen ist die Grundlage für die Entwicklung des Landes. “177 Auch nach der Unabhängigkeit richteten sich Entwicklungserwartungen gleichermaßen auf die Entität des Nationalstaats wie auch auf den persönlichen (und familiären) Bildungs- und Lebensstandard; höhere Bildung sollte vor allem zu einer vergrößerten existenziellen Sicherheit beitragen. ${ }^{178}$ „Wenn du das Land aufbaust“, so ein Baufachmann im Interview 2014, „baust du dich dann nicht auch selbst auf? Ich als Arbeiter und meine Familie sollten auch profitieren, und genauso habe ich meinen Beitrag für das Land zu leisten." ${ }^{179}$ Der persönliche Aufstieg und die Mechanismen des Entwicklungsstaats waren so eng miteinander verflochten.

176 Eckert, We Must Run, S. 217.

177 Shaaban Robert, Maisha Yangu na Baada ya Miaka Hamsini, Dar es Salaam, 2013, S. 4. Im Original: „Maisha ya mtu ni msingi wa maendeleo ya nchi.“

178 Green, The Development State, S. 38, S. 50 -51; Joel D. Barkan, An African Dilemma. University Students, Development and Politics in Ghana, Tanzania and Uganda, Nairobi 1975, S. $40-44$.

179 Interview \#57, Tansanischer Baufachmann. Im Original: „Lakini unapojenga nchi na wewe mwenyewe si unajijenga kwa sababu unajenga nchi, mi nafanyakazi ninufaike na familia yangu na vile vile nitoe mchango wangu kwa nchi.“ 
Dieser Lebensentwurf war allerdings nur für eine Minderheit realisierbar, denn der „koloniale[n] Bildungspyramide“ ${ }^{180}$ konnte schon aus ökonomischen Gründen keine wirkliche Alternative entgegensetzt werden. Das Bildungssystem hatte auch nach der Unabhängigkeit weiterhin eine stark stratifizierende Wirkung. Der Zugang zu höherer Bildung stand nur einer kleinen Minderheit offen, die dann die Funktionärsschicht bildete. Nyerere legte großen Wert darauf, gerade dieser gebildeten Elite eine sozialistische Haltung anzuerziehen. Das 1967 von ihm formulierte Pamphlet Education for Self-reliance stellte bis in die 1980er-Jahre die ideologische Grundlage der Bildungspolitik dar. Ihm zufolge sollte Bildung eine sozialistische, gemeinwohlorientierte Haltung und Respekt für den Wert körperlicher Arbeit vermitteln. Eine praxisorientierte, für landwirtschaftliche und handwerkliche Tätigkeiten relevante Grundbildung sollte die SchulabgängerInnen „self-reliant“ machen, statt sie mit rein theoretischen Inhalten auf eine Bildungs- und Bürokarriere hinzuführen, die der Mehrheit verwehrt blieb. Die durch höhere Bildungsabschlüsse privilegierte Minderheit wiederum sollte sich mit den arbeitenden Massen identifizieren und sich ganz in ihren Dienst stellen. ${ }^{181}$

Eine erste Maßnahme zur Erziehung der gebildeten Eliten war - bereits vor der Umsetzung der Education for Self-reliance - die Verpflichtung für alle AbsolventInnen höherer Bildung, den paramilitärischen National Service zu absolvieren (siehe auch Kapitel 4). Der heftige Protest von StudentInnen gegen diese 1966 eingeführte Regelung ließ und der politischen Elite die Umorientierung des Bildungssystems umso notwendiger erscheinen. Es folgte die Umgestaltung von Lehrplänen und die beschleunigte Nationalisierung des Lehrkörpers, der noch zu einem guten Teil aus expatriates (gerade aus westlichen Freiwilligenorganisationen, aber auch aus den kommunistischen Ländern) bestand. Die neue Bildungspolitik sollte auch verhindern, dass Bildung vererbt wurde und so auf die wirtschaftsstarken Areale und bereits privilegierten Gruppen beschränkt blieb. Quotenregelungen und andere Maßnahmen, um bestehende Ungleichheiten in Bezug auf Geschlecht, Klasse, regionale Herkunft und ethnische Identität zu verringern, zeigten durchaus Wirkung. ${ }^{182}$ Der Anteil von Frauen in Institutionen höherer Bildung und im formellen Sektor stieg bis etwa Mitte der 1970er Jahre kontinuierlich (fiel jedoch wieder mit der Verschärfung der Wirtschaftskrise, weil überwiegend Frauen und Mädchen die Arbeit im Haushalt und zur Einkommensgenerierung im informellen Sektor verrichteten). ${ }^{183}$ Auch Kindern aus nicht-

180 Gudrun Kolodzig, Das Erziehungswesen in Tanzania. Historische Entwicklung und Emanzipation von der kolonialen Vergangenheit, Saarbrücken 1978, S. 147-148.

181 Ivaska, Cultured States, S. 148.

182 Buchert, Education, S. 93-94; Ivaska, Cultured States, S. 114.

183 Tripp, Changing the Rules, S. 108. 
privilegierten Familien gelang so zeitweise der Aufstieg bis an die Universität (siehe auch Kapitel 4). Regierungsstipendien eröffneten anderweitig versperrte Aufstiegschancen, Alphabetisierungskampagnen und die ab 1974 kostenlose Bildung von der Grundschule an ermöglichten auch Ärmeren einen gewissen Grad an Teilhabe. Die 1974 beschlossene und bis 1984 angewendete Musoma Resolution verfügte, dass nur noch Personen, die sich bereits in der Arbeitswelt „bewährt“ hatten und eine Empfehlung von der lokalen Parteistelle vorweisen konnten, studieren durften (und dann wieder $\mathrm{zu}$ ihrem alten Arbeitgeber zurückkehren sollten). Diese Regelung, die sich gegen technokratische Selektionskriterien wandte und eine weitere Disziplinierung der Bildungselite verfolgte ${ }^{184}$, erwies sich angesichts des fortbestehenden Fachkräftemangels schnell als impraktikabel, führte zu Auseinandersetzungen mit Gebern im Bildungsbereich wie der BRD (siehe Kapitel 7) und wurde 1984 wieder außer Kraft gesetzt.

Egalitaristische Prinzipien prägten auch die Wirtschafts- und Sozialpolitik. Nach der Deklaration von Arusha agierte der Staat zunehmend interventionistisch und zog weitere wirtschaftliche und soziale Funktionen an sich. Der Staat kontrollierte nunmehr den Großteil der Produktionsmittel im Land, stellte soziale Dienstleistungen zur Verfügung und glich die Einkommen an. ${ }^{185}$ Die Verstaatlichung von Schlüsselsektoren der Wirtschaft, Außenhandelshäusern, Banken und Versicherungen (1967) sowie die Nationalisierung aller Häuser, die von den EigentümerInnen nicht selbst bewohnt wurden (1971), schränkten private Aneignungsmöglichkeiten ein. Einzig im Kleinhandel, in kleineren Betrieben und - vor allem in Regionen mit cash crop-Anbau - im landwirtschaftlichen Bereich waren private Initiativen wirtschaftlich noch von Bedeutung. ${ }^{186}$ Schon vor 1967 hatte die Regierung - vor allem in Person von Nyerere, hierin unterstützt vom radikaleren Flügel der TANU - Schritte unternommen, die Gehälter der höchsten Staatsbediensteten herabzusetzen. Im öffentlichen Sektor verringerte sich das Verhältnis vom höchstem zum niedrigsten Gehalt von 20:1 (1967) auf 5:1 (1985). ${ }^{187}$ Die Kaufkraft der höchsten Beamtengehälter (nach Steuern) sank im Verhältnis zur Kaufkraft des Mindestlohns von 80:1 (1960) auf 11:1 (1974), während auch die

184 Diese Maßnahme ist üblicherweise als Disziplinierungsmaßnahme interpretiert worden, um radikalen politischen Aktivismus an Sekundarschulen und an der Universität zu schwächen. Siehe Arnold Temu/Bonaventure Swai, Historians and Africanist History: A Critique, London 1981, S. 168; Buluda Itandala, University of Dar es Salaam's Immediate Response to Musoma Resolution, in: Isaria N. Kimambo u.a., Hg., In Search of Relevance: A History of the University of Dar es Salaam, Dar es Salaam 2008, S. 193-205, hier: S. 201.

185 Eckert, Herrschen und Verwalten, S. 217.

186 Green, Tanzanian Political Economy, S. 31.

187 Tripp, Changing the Rules, S. 40. 
absolute Kaufkraft abnahm. ${ }^{188}$ Die tansanischen BeamtInnen gehörten zu den schlechtbezahltesten auf dem Kontinent, aber bis in die 1970er-Jahre hinein waren viele aufgrund eines politischen, Ujamaa zugewandten Bewusstseins zeitweise bereit, materielle Einschränkungen zu akzeptieren. ${ }^{189} \mathrm{Zu}$ diesen Einschränkungen zählte der leadership code, der einen zentralen Teil der Deklaration von Arusha 1967 darstellte.

\section{Ungleichheit im Egalitarismus}

Im engeren Sinne handelte es sich beim leadership code um den Versuch, die staatliche Elite zu disziplinieren und ihre Aneignungsmöglichkeiten $\mathrm{zu}$ begrenzen. Im weiteren Sinne war er Teil der (auch in anderen sozialistischen Ländern erprobten) Strategie, den Einfluss der ökonomischen Machtträger auf die politische Sphäre zurückzudrängen und die Spielregeln politischen Handelns zu ändern. ${ }^{190}$ Die Richtlinie zielte darauf ab, die Möglichkeiten des Amtsmissbrauchs sowie die Verfilzung von ökonomischen und politischen Machtpositionen zu verhindern. ${ }^{191}$ Sie regelte die Beziehung zu produktivem Eigentum und untersagte Angehörigen von Regierung, Partei und Verwaltungsapparat dabei nicht nur die gleichzeitige Tätigkeit in Privatunternehmen oder das Halten von Aktien, sondern sogar das Vermieten von Häusern und Wohnungen. ${ }^{192}$ Der leadership code war der kontroverseste und parteiintern mit Abstand am meisten diskutierte Teil der Deklaration von Arusha. Ein Rundschreiben an alle Parlamentsmitglieder sowie die hochrangigen Partei- und Regierungsangehörigen stellte sie vor die Wahl, ob sie weiter ihre öffentliche Führungsfunktion ausüben oder ökonomisch attraktiveren Tätigkeiten nachgehen wollten. Nur wenige entschieden sich für Letzteres, der Großteil optierte für die Beibehaltung des Postens im Staats- oder Parteiapparat. Die Umsetzung wurde konsequent durchgeführt, allerdings hatten die GegnerInnen der neuen Bedingungen Nyerere den Kompromiss abgerungen, die Übertragung des Eigentums an Familienmitglieder zu legalisieren. ${ }^{193}$

188 Pratt, The Critical Phase, S. 247-248.

189 Loxley, Monetary Institutions, S. 73-74.

190 Das kann als typisches Merkmal sozialistischer Machtsysteme gelten, vgl. Bourdieu, Praktische Vernunft, S. 30.

191 Pratt, The Critical Phase, S. 238.

192 Siehe den Abdruck der Erklärung in Julius Nyerere, Freedom and Socialim / Uhuru na Ujamaa. A Selection from Writings and Speeches 1965-1968, Dar es Salaam 1968.

193 Außerdem war die Einstellung saisonaler Arbeitskraft, was besonders für jene mit landwirtschaftlichen Besitzungen bedeutend war, erlaubt. Hauspersonal wiederum galt nicht als 
Das öffnete Schlupflöcher, die in der Meinung überzeugter Ujamaa-AnhängerInnen nicht der neuen moralischen Ökonomie eines sozialistischen Tansanias entsprachen. In formal-rechtlicher Hinsicht wurden diese Schlupflöcher jedoch nicht gestopft. In einem (anscheinend unveröffentlicht gebliebenen) Brief vom April 1969 an die parteieigene Tageszeitung The Nationalist fragte ein anonymer Schreiber empört, ob es rechtens sei, dass die Ehefrauen einiger „hoher Tiere“ (big shots) Geflügelzucht betrieben und für die tägliche Produktion von Hunderten Eiern sogar Personal einstellten. ${ }^{194}$ Der für die Implementierung des leadership code zuständige TANU-Generalsekretär Pius Msekwa antwortete, dass in rechtlicher Hinsicht kein Vergehen vorliege. Die TANU werde diese Tätigkeiten, die den „Geist“ der Deklaration von Arusha brachen, jedoch nicht lange tatenlos tolerieren, wie Msekwa hinzufügte: „People must choose between exploitation and leadership“, anderenfalls müssten sie schon bald die Folgen in Kauf nehmen. ${ }^{195}$ Die Konsequenzen blieben zumindest für die höchsten „leaders“ aus. Der westdeutsche Botschafter berichtete 1974, dass einige Eliteangehörige - darunter der Staatsbank-Präsident und mehrere Parteichefs in den Regionen (Regional Commissioner) - mehr mit ihren illegalen Hühnerfarmen als der Ausübung ihrer Ämter befasst seien. ${ }^{196}$

Die rechtliche Anwendung des Begriffs leader weitete sich mit den Jahren auf einen immer größeren Personenkreis aus. Wurde er anfangs noch über die Funktion definiert, so war in späteren Jahren die Höhe des Einkommens ausschlaggebend. Da die nunmehr finanzielle „Trennlinie“ zwischen führenden und nicht führenden Positionen trotz Inflation und Gehaltsanpassungen nicht nach oben korrigiert wurde, betrafen die einschränkenden Bedingungen 1991 schließlich Staatsbedienstete aller Ebenen - von denen aber längst die große Mehrzahl die Richtlinien übertreten hatte, weil ein Überleben im urbanen Raum ohne Nebeneinkünfte nicht mehr zu bewerkstelligen war. ${ }^{197}$ Aili Mari Tripp zitiert einen jungen Straßenverkäufer, der mit Zigarettenverkauf in der informellen Ökonomie ein Vielfaches dessen als Einkommen erzielte, was Regierungsangestellte bekamen: „Only the rich can enjoy life. For others, especially for govern-

„ausgebeutete Arbeitskraft“ und fiel ebenfalls nicht unter diese Regelung. Interview mit Pius Msekwa, Dar es Salaam, 21.11.2014; Pratt, The Critical Phase, S. 239.

194 CCMA, THQ/A.25/7, „Very Concerned“ an The Nationalist, o.O., 8.4.1969.

195 CCMA, THQ/A.25/7, Pius Msekwa, Answer, o.O., 9.4.1969. Die Antwort überrascht insofern, als dass es im leadership code selbst heißt: „[...] ,leader‘ means a man, or a man and his wife; a woman, or a woman and her husband." Die uneindeutige Formulierung wurde dann offensichtlich in der Anwendung auf das Individuum zurechtgestutzt.

196 BArch Koblenz, B 213/7679, Müllenheim (BRD-Botschaft) an AA, 5.12.1974, S. 2.

197 Tripp, Changing the Rules, S. 171-172. 
ment civil servants, life is very difficult." ${ }^{198}$ Von 1974 bis 1988 fiel der durchschnittliche Reallohn um 83 Prozent. ${ }^{199}$ Die egalitaristische Ideologie, Hoffnungen auf eine bessere Zukunft und Verweise auf kollektive Opfer, die angesichts des Befreiungskampfes oder des Krieges gegen Uganda erbracht werden mussten, legitimierten Versorgungslücken und andere wirtschaftliche Krisenerscheinungen. Für den Zusammenbruch der sozialistischen moralischen Ökonomie sorgte aber, dass Last und Knappheit zunehmend ungleich verteilt waren und nicht alle im gleichen Maße zurückstecken mussten. ${ }^{200}$ Hinzu kamen die immer trüberen Zukunftsaussichten für diejenigen, die gerade Schule und Universität verlassen hatten.

Nach eineinhalb Dekaden stetigen Wachstums erreichte die Größe des Verwaltungsapparates um 1975 den Plafond; über 300 Stellen wurden in diesem Jahr sogar gestrichen. ${ }^{201}$ Für AbsolventInnen der Sekundarschulen wurden selbst schlecht bezahlte Arbeitsplätze knapp. Ab Mitte der 1970er Jahre äußerten UniversitätsabsolventInnen Unmut über die egalitaristische Lohnpolitik und geschrumpfte Aufstiegsmöglichkeiten. ${ }^{202}$ Die Sprache egalitaristischer Prinzipien wurde nun gegen die Regierung gewendet. Auf einem Protestmarsch in die Stadt 1978 protestierten StudentInnen gegen die geplante Diätenerhöhung im Parlament und die geplante Ausweitung der Privilegien der „bürokratischen Bourgeoisie“ (zu diesem Begriff von Issa Shivji siehe Kap. 2.4 und 7.2). Ihr Protestmarsch wurde von der Polizei gestoppt, 400 Personen wurden in ihre Herkunftsregionen abtransportiert und 350 von ihnen ihrer jeweiligen Bildungsinstitutionen verwiesen. ${ }^{203}$ Obwohl diese Proteste aufgrund ihrer Solidarisierung mit der Arbeiter- und Bauernschaft mitunter als Beleg für eine erfolgreiche sozialistische Sozialisierung und für die Überwindung des selbstzentrierten Karrieredenkens - wie in den Protesten nach der Einführung der Pflicht zum National Service 1966 - interpretiert worden sind, kann die große Teilnehmerzahl von etwa 1.500 ebenso als Ausdruck getrübter Zukunftsaussichten gedeutet werden. ${ }^{204}$

Durch die veränderte Lage internationalisierten sich Karrierestrategien nun auch über die Studienzeit hinaus. In den 1970er-Jahren setzten sich tansanische

\footnotetext{
198 Ebd., S. 133.

199 Ebd., S. 40.

200 Lal, African Socialism in Postcolonial Tanzania, S. 5.

201 URT, Manpower Report 1976, S. 97-101.

202 Green, Tanzanian Political Economy, S. 30.

203 Chris Peter/Sengondo Mvungi, The State and the Student Struggles, in: Issa G. Shivji, Hg., The State and the Working People in Tanzania, Dakar 1986, S. 155-194, hier: S. 187-191.

204 Coulson, Tanzania, S. 275-276; vgl. zur Motivation bei Protesten auch Barkan, An African Dilemma, Kap. 4.
} 
Fachkräfte, vor allem Ingenieure und ÄrztInnen, zunehmend ins Ausland ab oder kamen erst gar nicht von ihren Studienaufenthalten zurück. 1974 etwa waren laut einer öffentlichen Erklärung 60 AbsolventInnen „nicht zur Arbeitsaufnahme erschienen, sondern spurlos verschwunden“. ${ }^{205}$ Selbst wenn aus Übersee zurückgekehrte hoch qualifizierte Fachkräfte bereit waren, die Fünfjahresklausel zu akzeptieren und ohne nennenswerte materielle Anreize zu arbeiten, monierten manche von ihnen, dass sie ständig zur Teilnahme an Partei- und Gewerkschaftstreffen gedrängt würden und so die eigentliche Arbeit vernachlässigen müssten, wie die Bonner Vertretung berichtete. ${ }^{206}$ Es war aber keinesfalls nur die technokratisch-akademische Elite, die sich von den politischen Strukturen und den sozialistischen Diskursen entfremdete. Für einfache Angestellte, ArbeiterInnen und BeamtInnen (von der ländlichen und ärmeren Bevölkerung in den Städten ganz zu schweigen) verloren die Durchhalteparolen zunehmend an Überzeugungskraft. Nationalstolz und eine durchaus verbreite Bereitschaft zur Aufopferung für sozialistische Ziele wichen politischen Witzen, Zynismus und Desillusionierung. ${ }^{207}$

Dahinter standen die zeitweise ausgeglicheneren, ab Mitte der 1970er Jahre aber wieder zunehmend auseinanderklaffenden Opportunitätsstrukturen. Von der Mangelwirtschaft profitieren konnten vor allem private wie öffentliche Akteure, die sich an Knotenpunkten zwischen Produktion, Großhandel, Warendistribution und Finanzströmen befanden und so privilegierten Zugang zu Importwaren und Devisen besaßen. ${ }^{208}$ Die Umgehung staatlicher Regulierungen war Ende der 1970er Jahre längst eine weitverbreitete Strategie, sodass im legalistischen Sinn fast alle Kriminelle waren, aber nur die Elite keine Sanktionen zu fürchten hatte. ${ }^{209}$ Populäre Forderungen, dass die Regierung konsequent gegen Korruption vorgehen sollte, führten zu Alibimaßnahmen und Schauprozessen gegen Kader mittlerer Ebene, während die entscheidenden Personen auf den oberen Ebenen sich schadlos halten konnten. ${ }^{210}$ Regierungsmaßnahmen wie der „Krieg gegen Wirtschaftssabotage“ 1983 waren verzweifelte moralistische Akte gegen Korruption, Schmuggel (magendo) und die Verlagerung ökonomischer Aktivitäten in die

205 BArch Koblenz, B 213/7679, Müllenheim (BRD-Botschaft) an AA, 5.12.1974, S. 2.

206 Ebd., S. 3.

207 Loxley, Monetary Institutions, S. 87-88.

208 Bourdieu, Praktische Vernunft, S. 30.

209 Callaci, Street Archives, S. 199; Tripp, Changing the Rules, S. 138.

210 Issa G. Shivji, Introduction: The Transformation of the State and the Working People, in: Issa G. Shivji, Hg., The State and the Working People in Tanzania, Dakar 1986, S. 1-15. 
informelle Sphäre. ${ }^{211}$ Sie verkürzten aber nicht die stundenlange Wartezeit beim Anstehen für Zucker oder Seife, noch brachten sie LehrerInnen, Tische und Stühle zurück in die Klassenzimmer. Die sozialen Errungenschaften des tansanischen Entwicklungsweges, darunter kostenlose gesundheitliche Grundversorgung, die Abschaffung der Steuern für die Ärmsten und ein Bildungssystem, das - zumindest bis zu einem gewissen Grad - alle einbezog und eine im regionalen Vergleich beachtliche Alphabetisierungsrate beschert hatte, erodierten durch die Wirtschaftskrise und den sukzessiven Rückzug des Wohlfahrtsstaates. Die Wiedereinführung von Schulgebühren und die (Teil-)Privatisierung von Gesundheitsund Bildungssystem erhöhten zwar die „Servicequalität“ in einzelnen Institutionen, verstärkten aber Ungleichheits- und Exklusionseffekte. Von 1986 bis 1990 stiegen die Lebenshaltungskosten im urbanen Raum um 250 Prozent. ${ }^{212}$ Schon lange ging es nicht mehr um „Entwicklung“, sondern um Krisenbewältigung und einfaches Überleben. In der Wahrnehmung vieler TansanierInnen waren die 1980er-Jahre das Jahrzehnt des Rückschritts (kurudi nyuma), in dem sich Tansania und das eigene Leben nicht (mehr) vorwärts, sondern rückwarts entwickelten. ${ }^{213}$ Nichtsdestoweniger hatte der Ujamaa-Diskurs bis zu diesem Zeitpunkt eine hegemoniale Stellung - wenngleich sich dahinter stets Stellungs- und Deutungskämpfe abspielten.

\subsection{Einheit und Antagonismen: Die umkämpfte Hegemonie von Ujamaa}

In den späten 1960er-Jahren hatte sich Ujamaa durch erfolgreiche Bildungsmaßnahmen sowie die Marginalisierung politischer GegnerInnen als nationalstaatliche Ideologie etabliert. Die Hegemonie von Ujamaa war jedoch - wie bereits die obigen Hinweise auf die wiederholte Anwendung von Zwang zeigen ungleichmäßig, unvollständig und auch in der Partei umkämpft, wozu nicht zuletzt die konzeptuelle Unschärfe beitrug. Mit der Verschärfung der wirtschaftlichen Krise, die alle Gesellschaftsschichten erfasste, wurde die ideologische Hegemonie von Ujamaa von „rechts“ und „links“, von „innen“ und „außen“, von „oben“ und „unten“ aber nicht nur verschieden interpretiert, sondern auch immer offener angefochten. Die Positionen, die Akteure bei diesen Spannungen ein-

211 Die Maßnahmen sind anschaulich beschrieben in Maliyamkono/Bagachwa, Second Economy, S. ix-xix.

212 Aminzade, Race, S. 325.

213 Robert M. Ahearne, Development and Progress as Historical Phenomena in Tanzania: „Maendeleo? We Had That in the Past“, in: African Studies Review 59/1 (2016), S. 77-96. 
nahmen, waren dabei von jeher auch mit spezifischen Strategien der Modell-, Ressourcen- und Allianzsuche über die Landesgrenzen hinaus verbunden.

\section{Der triadische Einparteienstaat: Regierung, Partei und Verwaltung}

Die Entscheidung, welche politischen und gesellschaftlichen Spannungen als zentral erachtet werden, war und ist in erster Linie eine Frage der theoretischen Position. Neo-marxistische Stimmen an der Universität Dar es Salaam wie auch in der BRD bezeichneten den spätsozialistischen tansanischen Staat der 1980erJahre ohne Umschweife nicht nur als „autoritär“, sondern auch als „,neokolonial“ und „staatskapitalistisch“. ${ }^{214}$ Der zentrale Antagonismus besteht in dieser Perspektive, hier aus Platzgründen nur stark vereinfacht wiedergegeben, zwischen der „bürokratischen Bourgeoisie“ (Issa Shivji) oder „Staatsklasse“ (Rainer Tetzlaff) einerseits und der im formellen wie informellen Sektor arbeitenden Bevölkerung andererseits. ${ }^{215}$ Politik wird dabei verstanden als Strategie der Selbstbereicherung und Klassenreproduktion, deren treibender Faktor das materielle Interesse ist. $\mathrm{Zu}$ Recht ist an diesen materialistischen Interpretationen kritisiert worden, dass z. B. der leadership code kaum das richtige Instrument für die Etablierung einer „bürokratischen Bourgeoisie“ sein könne. ${ }^{216}$ Ebenso sind verschiedene Positionen in der Politik und der „bürokratischen Bourgeoisie“ damit nicht gänzlich erklärbar.

214 Issa G. Shivji, Hg., The State and the Working People in Tanzania, Dakar 1986, S. 2, S. 59. 215 Shivji, Class Struggles; Rainer Tetzlaff, Der begrenzte Handlungsspielraum der tansanischen Staatsklasse zur Überwindung von Abhängigkeit und Unterentwicklung: Zum Verhältnis von Bürokraten und Bauern, in: Werner Pfennig u. a., Hg., Entwicklungsmodell Tansania, Sozialismus in Afrika: Geschichte, Ökonomie, Politik, Erziehung, Frankfurt/Main, New York 1980, S. 42-68; Michaela von Freyhold, The Post-Colonial State and Its Tanzanian Version, in: Review of African Political Economy 8 (1977), S. 75-89. Besonders auf das Verhältnis von „Staatsklasse“ und bäuerlicher Bevölkerung verweisen Hydén, Beyond Ujamaa; Rainer Tetzlaff, Der begrenzte Handlungsspielraum der tansanischen Staatsklasse zur Überwindung von Abhängigkeit und Unterentwicklung: Zum Verhältnis von Bürokraten und Bauern, in: Werner Pfennig u.a., Hg., Entwicklungsmodell Tansania, Sozialismus in Afrika: Geschichte, Ökonomie, Politik, Erziehung, Frankfurt/Main, New York 1980, S. 42-68. Siehe auch Mushi, Tanzania, S. 214-218. Arbeiten der New Political Economy, die ebenfalls mit Blick auf materialistisches Eigeninteresse von Eliten argumentieren, aber sich vom Postulat des Klassenkampfes entfernen, sind Lofchie, Political Economy; Robert H. Bates, Markets and States in Tropical Africa: The Political Basis of Agricultural Policies; Berkeley 1981.

216 Paul Nugent, Africa since Independence. A Comparative History, 2. Aufl., Basingstoke 2012, S. 149 . 
Eine zweite Interpretation stellt Klassenverhältnisse nicht in Abrede, rückt aber ideologische Positionierungen in den Vordergrund. Der Soziologe Ronald Aminzade unterscheidet „marxistisch-leninistische“ und „sozialdemokratische“ Haltungen in der politischen Elite, ähnlich wie auch DDR-Analysen regelmäßig Trennlinien zwischen „reaktionären“ und „fortschrittlichen Kräften“ zogen. ${ }^{217}$ Eine entsprechend aufgeladene Rhetorik findet sich auch in den Selbstbezeichnungen; es ist aber fraglich, inwieweit derartige Begriffe analytisch greifen, da marxistische oder maoistische Rhetorik oft ein Vehikel für Nationalismus und bisweilen eher Ausdruck von Protest denn Grundlage politischen Handelns waren. ${ }^{218}$ Die politischen Positionen und Auseinandersetzungen sind mit dem eurozentrischen politischen Koordinatensystem von „rechts“ und „links“ schwerlich zu fassen, wie schon William Tordoff und Ali A. Mazrui gewarnt haben und als Alternative ein Spektrum von gemäßigten und radikalen Positionen (siasa ya pole und siasa ya kali) vorschlagen. ${ }^{219}$ Ähnlich identifiziert Dean McHenry in Tansania nur zwei politische Typen, nämlich „pragmatische“ und „ideologische“ Sozialisten. 220

Tatsächlich war mit den Begriffen „radikal“ oder „ideologisch“ oft ein marxistisch geprägter Zugang gemeint. Nach der Interpretation von Jeannette Hartmann war auch die Deklaration von Arusha kein Alleingang Nyereres, sondern ein Konsens: Nyerere setzte sich vor allem für den leadership code ein, während marxistische Parteiangehörige die Nationalisierungen in der Wirtschaft hineinreklamierten. ${ }^{221}$ Wie die marxistische Terminologie und die Betonung der avantgardistischen Rolle der Partei nahelegen, wurden die Parteirichtlinien (der bereits erwähnte Mwongozo) von 1971 nicht von Nyerere, sondern hauptsächlich von Kingunge Ngombale-Mwiru, dem damaligen Generalsekretär der TANU Youth League, und anderen Politikern wie Rashidi Kawawa und A. M. Babu verfasst, die zum Teil aus der Gewerkschaftsbewegung kamen und explizit marxistische Positionen wie das von Nyerere nicht geteilte Konzept des Klassenkampfs vertraten. ${ }^{222}$ Die Verabschiedung des Mwongozo sollte der größte Erfolg des „linken“ Parteiflügels bleiben. Durch Festnahmen (u.a. von Babu 1972 infolge der Ermordung des sansibarischen Präsidenten Abeid Amani Karumes) und Flucht ins Exil dezimiert, blieb der Einfluss marxistischer Akteure in den folgenden Jahren

217 Aminzade, Race, S. 145-154.

218 Roberts, Politics, S. 91.

219 Tordoff/Mazrui, Left and Super-Left in Tanzania; ebenso Roberts, Politics, S. 91.

220 Dean E. McHenry, Limited Choices. The Political Struggle for Socialism in Tanzania, Boulder 1994.

221 Jeanette Hartmann, The Arusha Declaration Revisited, in: African Review 12 (1985), S. 1-11.

222 Roberts, Politics, S. 180; Shivji, Class Struggles, S. 125. 
weitgehend auf Jugend- und Gewerkschaftsorganisationen, zu denen die DDR gute Kontakte unterhielt, sowie die Parteikaderschmiede Kivukoni College beschränkt. Am Kivukoni College fungierte Ngombale-Mwiru, in vielerlei Hinsicht der Chefideologe der Partei, bis 1973 als Direktor. In einer Rede am Kivukoni College, wo auch die historischen Erfahrungen anderer sozialistischer Länder auf dem Lehrplan standen, betonte Nyerere 1973, dass sich „diejenigen, die sagen, dass man Ujamaa nicht aufbauen kann, ohne dem Marxismus-Leninismus zu folgen, auf dem Irrweg befinden“. ${ }^{223}$ TANU sei keine Avantgardepartei und werde auch keine werden; aber trotzdem brauche sie eigene „Kader“ (makada) zur Propagierung und Durchsetzung von Ujamaa. Nyerere selbst ging auf internationaler Bühne wie auch in Tansania rhetorisch immer wieder auf Distanz zu marxistischen Ansätzen und insbesondere dem Marxismus-Leninismus und erteilte Forderungen nach einem „wissenschaftlichen Sozialismus“, den er mit einem religiösen Dogma verglich, eine Absage. ${ }^{224}$

Diese Abgrenzung gegenüber marxistischen Analyse- und Politikentwürfen verdeutlicht einerseits die Bemühungen, die Hegemonie von Ujamaa zu stabilisieren. Andererseits ist bei einer grenzübergreifenden Analyse auch zu beachten, dass ideologische Positionierungen nicht nur im Hinblick auf interne politische Auseinandersetzungen vorgenommen wurden, sondern auch eine zentrale Strategie zur Ressourcenmobilisierung und Allianzbildung über Tansania hinaus darstellten. Diese Bezugnahmen auf das „Außen“ wiederum waren immer auch Argumente für Auseinandersetzungen im „Inneren“. Radikale Stimmen in der Partei, der Jugendorganisation und der Gewerkschaft forderten wiederholt die Umwandlung der Partei in eine Avantgardepartei Lenin'schen Typus und den Ausschluss von Mitgliedern mit kapitalistischen Verbindungen und Haltungen oder zumindest die Umwandlung der Parteielite in eine Avantgarde. ${ }^{225}$ Offensichtliche Bezugnahmen auf den Marxismus, der wiederholt als „fremde“ Ideologie diskreditiert wurde, waren jedoch im Zeitalter des Nationalismus und der Afrikanisierung inopportun und daher oft nur verdeckt möglich.

Eine dritte Möglichkeit, Antagonismen in Tansania greifbar zu machen, besteht darin, strukturelle und diskursive Aspekte miteinander zu verknüpfen und

223 THQ/C/E.20/2/Vol. III, Ufunguzi wa Chuo cha TANU Kivukoni Tarehe 2/7/73, o.O., o.D. [1973], S. 3. Im Original: „Watu wasemao kuwa huwezi kujenga Ujamaa bila kufuata Marxism-Leninism ni wapotovu."

224 Julius Nyerere, The Varied Paths to Socialism. Address to Cairo University, 10 April 1967. In: Ujamaa. Essays on Socialism, Dar es Salaam 1968, S. 77.

225 Bismarck U. Mwansasu, The Changing Role of the Tanganyika African National Union, in: Bismarck U. Mwansasu/Cranford Pratt, Hg., Towards Socialism in Tanzania, Dar es Salaam 1979, S. 169-192, hier: S. 169-170. 
auf die verschiedenen Positionen im sozialen Feld zu verweisen, die mit spezifischen Ressourcen, Strategien zur Kapitalakkumulation und Untermauerung der politischen Legitimität einhergehen. Drei Positionen können an dieser Stelle unterschieden werden: Verwaltung, Partei und Regierung. ${ }^{226}$ Die Trennlinien zwischen diesen drei Gruppen sind zwangsläufig unscharf, zumal die Beamtenschaft 1964 zum Eintritt in die Partei gedrängt wurde (und schon zehn Tage nach der Aufforderung durch Vizepräsident Kawawa 90\% der BeamtInnen als Mitglieder registriert waren). ${ }^{227}$ Die Verschmelzung blieb aber unvollständig, es kam zur Genese eines dualistischen Systems mit eigenen Modi der Entscheidungsfindung und spezifischen Karrierewegen. ${ }^{228}$

Verwaltungskräfte hatten sich an administrative Spielregeln zu halten. Sie betrachteten sich im nationalen Kontext als „Entwicklungsavantgarde“ mit der Aufgabe, Wirtschaftswachstum und Steueraufkommen zu garantieren. Regierungsangehörige wiederum hatten häufiger die Möglichkeit zur Mobilisierung von Ressourcen auch über die nationalen Grenzen hinaus. Durch ihre höhere Bildung und zahlreiche internationale Kontakterfahrungen waren sie sprachgewandter und verfügten über eine Reihe von Möglichkeiten, Ressourcenengpässe zu überwinden. ParteifunktionärInnen schließlich waren näher an der Basis positioniert. Auf die Gnade der Parteiführung ebenso wie auf Wählerstimmen angewiesen, folgten sie einer Mischung aus Obrigkeitshörigkeit und populistischer Handlungslogik. Ihre Hauptstrategien zur Kapitalakkumulation waren politische Mobilisierung und Umverteilung von Ressourcen, $\mathrm{zu}$ denen sie vor allem durch Kontakte im Inland Zugang gewannen. Die Ressourcen des entwicklungspolitischen Feldes, die für Regierungsangehörige und Verwaltungskräfte in verschiedenen Graden zugänglich waren, blieben für Parteikader - von einigen Weiterbildungen in Übersee abgesehen - meist außer Reichweite.

Das schwächste Glied in der Dreiecksbeziehung von Regierung, Verwaltung und Partei war die Partei, die zwar auf symbolisches und politisches Kapital zurückgreifen konnte, aber ökonomisch konstant anämisch und fachlich schwach besetzt war. Zwischen Partei- und Verwaltungsangehörigen kam es daher immer wieder zu Spannungen. Die Partei bestimmte zwar 1967 die vage politische Grundausrichtung und konnte die obligatorische Teilnahme an Sitzungen in den verschiedensten Gremien erwirken, hatte aber weder direkten Zugriff auf materielle Ressourcen noch die Kapazitäten, die Umsetzung zu steuern und zu überwachen. Die schwache Position der Partei wird auch daran deutlich, dass eine

226 Hier und im Folgenden folge ich: Aminzade, Race, S. 158-161.

227 Eckert, Herrschen und Verwalten, S. 235.

228 Lofchie, Political Economy, S. 145. 
politische Karriere oder eine Anstellung bei der TANU für die gebildete Elite keineswegs ein Karriereziel war. Der Politiker John Chiligati, in den 1980er-Jahren persönlicher Assistent Nyereres und zeitweise Kabinettsmitglied, erinnerte sich daran, dass seine Entscheidung, nach dem Studium 1975 eine Parteilaufbahn anzustreben, mit Erstaunen aufgenommen wurde:

Some of our friends called us crazy to go to TANU, a political party. Working for a Ministry, you get respect, a good salary, car, a good environment. At TANU, there was no good salary, no security, it was unsure what was to happen in future. ${ }^{229}$

Erst mit der Formalisierung der „führenden Rolle der Partei“ (party supremacy) 1977 seien Prestige, Einfluss („Ministers came trembling to the party“) und Gehälter in der Partei gestiegen. ${ }^{230}$ Zwar wurden Vorrechte der Partei 1965 und 1975 (gegenüber dem Parlament) sowie 1977 (über den Staat) wiederholt formell bestätigt. ${ }^{231}$ Es fehlte der Partei aber immer an Ressourcen, Expertise und Verwaltungskapazitäten, um ihrer proklamierten Rolle als watchdog gerecht zu werden. ${ }^{232}$ Laut einem Fragebogen, den die TANU für das Manpower-Ministerium beantwortet hatte, hatten von 2.700 Parteiangestellten gerade einmal 18 einen Universitätsabschluss; der zuständige Parteifunktionär beklagte sich darüber, dass der Partei zu wenige UniversitätsabsolventInnen zugewiesen wurden, vor allem ökonomische Expertise werde dringend benötigt. ${ }^{233}$ Gut ausgebildete Führungskader waren zudem oft nur von der Regierung an die Partei „sekundiert“ und wurden bei Bedarf umgehend wieder abgezogen, sodass es im Hauptquartier wie in den regionalen Zweigstellen an Kompetenz und Erfahrung fehlte. ${ }^{234}$ Eine gegenläufige Orientierung zwischen Partei und Regierung offenbarte sich auch in den Extraversionsstrategien, insbesondere den Entsende- und Ausbildungspraktiken. Partei und Massenorganisationen sendeten ihre Kader in den 1970er und 1980er Jahren vorwiegend zu Fortbildungen an das Kivukoni College oder die „sozialistischen Länder“ (wozu jedoch bisweilen auch skandinavische Länder

229 Interview mit John Chiligati, Dodoma, 19.11.2014. Zum Karriereziel (materieller) "Sicherheit” vgl. Barkan, African Dilemma, S. 40-44.

230 Interview mit John Chiligati, Dodoma, 19.11.2014.

231 Tripp, Changing the Rules, S. 83; Aminzade, Race, S. 89-90.

232 Aminzade, Race, S. 156-161; Mwansasu, Changing Role of TANU, 174-175.

233 CCMA, THQ/C/E.20/7, Employers Questionnaire - TANU, o.O., o.D. [ca. 1975].

234 CCMA, THQ/C/E.20/7 T. Mweri (TANU-Generalsekretär) an A. B. Mwasongwe (Secretary of National High Level Manpower Allocation Committee), o.0., 5.11.1973. 
zählten), während Regierungsmitglieder und Unternehmensmanager in erster Linie Seminare und Universitätsstudien in westlichen Staaten absolvierten. ${ }^{235}$

\section{Globale Modellsuche}

Schon seit den späten 1950er-Jahren waren die Antagonismen im „Inneren“ mit solchen Außenbeziehungen verflochten. Wenngleich Nyerere sich insbesondere vom Kommunismus sowjetischen Typs abgrenzte, hielt er doch auch immer die Forderung aufrecht, von Erfahrungen anderer sozialistischer Länder zu lernen. Bereits vor der Unabhängigkeit hatten führende Mitglieder der TANU und politischer Parteien in Sansibar sich auf der Suche nach passenden Entwicklungsmodellen in der Welt umgeschaut. Ein besonders wichtiger Modus des „Lernens“ waren Delegationsreisen. Obwohl diese in der Regel immer zu einer Verbesserung von Beziehungen führen sollten, waren die „Lerneffekte“ keineswegs vorhersehbar; sie reichten von Abschreckung und Entfremdung bis zu kopierfreudiger Begeisterung. Der Bericht des TANU-Mitbegründers Dennis Phombeah von seiner Reise nach Nordkorea und China im Jahr 1959 etwa sollte den kommunismusskeptischen Nyerere überzeugen, Entwicklungsstrategien nicht nur im Westen zu suchen. Zu diesem Zweck stellte Phombeah sich selbst ostentativ als wirtschaftsorientierten Pragmatiker dar, der keinerlei Interesse hatte, im Ost-WestKonflikt Partei zu ergreifen:

Of course you will realize that I am not interested in the ideological differences between East and West. My main interest has always been to try and isolate important economic developments from the ideology of the countries concerned and try and find out for myself how such schemes could be applied in under-developed countries such as those we have in Africa. ${ }^{236}$

Phombeah wurde 1968 als einer der radikalen, „linken“ Kritiker von Ujamaa aus dem Staatsdienst entfernt; Nyereres Haltung gegenüber China hatte sich zu diesem Zeitpunkt bereits ins Positive gewandelt. Selbst in seinem engsten Umkreis bestand jedoch kein Konsens über das chinesische Modell. Thematisiert wurde dabei insbesondere der Zugriff auf die Gesellschaft. Nyereres jüngerer Bruder Joseph, 1964 Vorsitzender der Jugendorganisation der Partei, war schockiert von der Überwachung und Uniformität in China und mochte sich einen derartig to-

235 BArch Berlin, DR 3/2. Schicht/1514, Staatl. Leiter der Univ.-Gruppe K., Jahresanalyse 1986/87, Dar es Salaam, 20.7.1987.

236 CCMA, NP/008/A, Dennis Phombeah an Julius Nyerere, o.O., 11.2.1959. 
talitären Sozialismus in Tansania nicht vorstellen, während sich andere Delegationsreisende von der Ordnung und Einheitlichkeit in den Massenorganisationen in China, der Sowjetunion oder in der DDR beeindruckt zeigten. ${ }^{237}$ Der führende TANU-Politiker und Außenminister Ibrahim Kaduma war von Vietnam, das von einer marxistisch-leninistischen Partei regiert wurde, angetan und lobte nach einer Reise 1975 die Einbeziehung aller gesellschaftlichen Gruppen. ${ }^{238}$ Straffe Organisation, Disziplin, Geschlossenheit und die lückenlose Einbindung aller Bevölkerungsgruppen in Ujamaa waren weitverbreitete, aber nicht universal geteilte Ideale in den mittleren und oberen Rängen der Partei.

Weitere weit verbreitete Ideale betrafen die staatliche Wohlfahrtsfunktion und gleichmäßige Verteilung von Ressourcen. Diese Aspekte wurden auch als Maßstab zur Bewertung anderer sozialistischer Länder herangezogen. Kuba etwa hätte einen nicht allzu hohen Lebensstand, aber doch ein gutes Bildungssystem für alle gehabt; in Albanien hingegen seien die Parteifunktionäre einen Mercedes Benz gefahren, während alle anderen auf Eselskarren angewiesen seien - so die Erinnerungen des sansibarischen Politikers Seif Sharif Hamad. ${ }^{239}$ John Chiligati erinnerte sich im Interview an eine Delegationsreise im Jahr 1983 durch die DDR, Kuba, die UdSSR, Bulgarien, Ungarn und die Tschechoslowakei. Er hob die öffentlichen und für alle leistbaren Dienstleistungen hervor - Bildung, Gesundheit, Verkehrswesen - und meinte, genau diesen „Zugang zum modernen Leben“ für die gesamte Bevölkerung habe auch Tansania angestrebt. Im Westen hingegen würden nach wie vor manche an Hunger sterben und andere, weil sie sich „überfraßen“. ${ }^{240}$ Bernadette Kunambi, Kreiskommissarin der Frauenorganisation der CCM und 1988 Teil einer Delegation in die DDR, wurde in einem ostdeutschen Bericht mit den Worten zitiert, dass sie zwar schon viele (kapitalistische) Länder bereist habe,

[a]ber ich habe noch kein Land erlebt, in dem der soziale Wohlstand so gleichmäßig auf alle Teile der Bevölkerung verteilt ist. Mich hat besonders beeindruckt: die Ordnung, die Disziplin und die moralische Haltung der Jugend. Solche Erscheinungen des Westens, wie: Drogenabhängigkeit, Gammelei und Pornographie habe ich bei Euch nicht gesehen. ${ }^{241}$

237 Bjerk, Building a Peaceful Nation, S. 230; Burgess, To Differentiate Rice from Grass, S. 223 226; BArch Berlin, DR 2/25494, Baier an MfVobi, Dar es Salaam, 13.8.1971, S. 7.

238 CCMA, THQ/C/E.20/7, Ibrahim Kaduma, Report from journey to Vietnam, 18.9.1975.

239 Burgess, Race, S. 243.

240 Interview mit John Chiligati, Dodoma, 19.11.2014; Übersetzung E. B.

241 BArch Berlin, DK 1/26764, Glemnitz (Direktor des Instituts für die Weiterbildung von Kadern für das Ausland beim Ministerium für Land-, Forst- und Nahrungsgüterwirtschaft der DDR), Erster Zwischenbericht über die Durchführung des 2. Kurses für CCM-Kader vom 18.6.-19.7.1986, Berichtszeitraum 18.6.-30.6.1986, Zschortau, o.D. [1986], S. 4. 
In derartigen Äußerungen tansanischer FunktionärInnen tauchen damals global verbreitete Argumente für sozialistische Gesellschaftsordnungen auf, denen die vermeintlichen Pathologien des Kapitalismus als Kontrastbild gegenübergestellt werden. Die eng miteinander verflochtenen Ideale von Ordnung, Disziplin, Wohlfahrtsstaatlichkeit und Egalitarismus beeinflussten auch die Art und Weise, wie die Welt aus tansanischen Perspektiven wahrgenommen wurde. Ob „Modelle“ aus anderen sozialistischen oder kapitalistischen Ländern auf Tansania übertragbar waren, darüber gingen die Meinungen jedoch auseinander - insbesondere in den 1980er Jahren, als der Glaube an die Realisierbarkeit eines gänzlich eigenständigen tansanischen Modells schwand.

\section{Lokale Sackgassen und globale Auswege im Spätsozialismus}

Mit dem Ende der Zwangsphase der Umsiedlungskampagne 1975 war Ujamaa in eine Sackgasse gelangt, aus der ein Ausweg gefunden werden musste. Die Etablierung einer ländlichen Produktionsbasis für den Entwicklungsstaat war gescheitert, die Kräfte im Inland zur intellektuellen Erneuerung fehlten, wurden marginalisiert oder nicht angehört. In den 1980er-Jahren richtete sich der Blick daher wieder stärker nach außen, um transferierbare Modelle zur Bearbeitung der Wirtschaftskrise ausfindig zu identifizieren. Paradigmatisch dafür steht das Kapitel Learning from Others im 1986 herausgegebenen Buch The Challenge for Tanzania's Economy, in dem die Entwicklungswege von Brasilien, China, Ungarn, Japan, Kenya, Mexiko, der Elfenbeinküste und Jugoslawien und ihre Übertragbarkeit auf tansanische Verhältnisse diskutiert werden. ${ }^{242}$ Offensichtlich hatten die Autoren - zwei Wirtschaftswissenschaftler und ein Diplomat - bewusst Länder der Peripherie oder Semiperipherie ausgewählt, von denen einige mit verschiedenen Mixturen von Markt- und Planwirtschaft experimentierten. Sie suchten dabei insbesondere nach Möglichkeiten, die Wirtschaftspolitik zu reformieren, ohne an den sozialistischen Prinzipien Tansanias zu rühren. ${ }^{243}$ An der Universität - gerade in den Wirtschaftswissenschaften - gewann die Liberalisierungsfraktion an Zustrom, während in der stark marxistisch geprägten Studentenzeitschrift Maji Maji noch 1988 die Meinung vertreten wurde, dass Tansania von Kuba, Nordkorea und sogar Albanien lernen könne, um einen semiautarken Entwicklungsweg zu gehen. ${ }^{244}$

242 Kahama/Maliyamkono/Wells, Challenge for Tanzania's Economy.

243 Ebd., S. 320.

244 Mwesiga Baregu, The Arusha Declaration Paradox or How a Self-Reliance Policy Reinforced Tanzania’s Dependency, in: Maji Maji 46 (1988), S. 1-13, hier: S. 12. 
In der Partei versuchte man, Anknüpfungspunkte in Osteuropa zu finden und schloss ab Mitte der 1980er-Jahre auch die von der Führung zuvor im Sinne der Blockfreiheit vermiedenen Abkommen mit den kommunistischen Parteien aus dem sowjetischen Machtbereich ab. ${ }^{245}$ Damit verbunden war fraglos auch die Hoffnung auf materielle Transfers. Der Leiter einer 1988 in die DDR entsandten Delegation wurde vom Gastgeber folgendermaßen zitiert:

Unsere Aufgabe: Die Kleinbauern fördern, die Bauern in Dörfern zusammenfassen, Staatsfarmen für Tier- und Pflanzenzucht aufbauen und allmählich den Weg zu Genossenschaften beschreiten. Das können wir nicht allein, von Kapitalisten angebotene Hilfe möchten wir nicht nehmen, weil wir dann abhängig werden. Wir hoffen auf Hilfe und Unterstützung der sozialistischen Länder. ${ }^{246}$

Auch im Archiv der CCM finden sich Belege für die Überzeugung hochrangiger Parteimitglieder wie Salmin Amour, dass Tansania z. B. in Fragen der Planwirtschaft noch in den späten 1980ern Jahren von Jugoslawien oder Ungarn lernen solle. ${ }^{247}$ Teil der alten Garde der CCM setzte noch Zukunftshoffnungen in den Sozialismus; Amour hatte kurz zuvor an der SED-Parteihochschule in Ost-Berlin in Politischer Ökonomie promoviert. ${ }^{248}$

Die alte Garde ebenso wie der Flügel der Wirtschaftsreformer registrierten ab Mitte der 1980er Jahre aber auch aufmerksam die Entwicklungen im Rahmen von perestroika und die Auseinandersetzungen in den osteuropäischen kommunistischen Parteien. ${ }^{249}$ Die meisten FunktionärInnen hatten jedoch nicht nur das Vertrauen in die Durchsetzungsfähigkeit ihres Staates und ihrer Partei verloren, sondern auch den Glauben daran, dass staatliche Zwangsausübung eine in Tansania gangbare Mobilisierungs- und Transformationsstrategie sein könnte wie er zur Zeit der Umsiedlungskampagne noch bestanden hatte. Das zeigte sich

245 SAPMO BArch Berlin, DY 30/15206, Bericht der Leitung an die Wahlberichtsversammlung der GO der SED DSM, 25.11.1985.

246 BArch Berlin, DK 1/26764, Glemnitz, Abschlußbericht für den 3. Kurs für Kader der CCM Tansanias (7.9.-2.10.1988), Zschortau, 30.9.1988, S. 6.

247 CCMA, CMM/OND/183/36, Protokoll des Gesprächs zwischen Lukovac (Botschafter Jugoslawiens) und Salmin Amour (NEC-Sekretär für Wirtschaft und Planung) am 7.4.1989, Dar es Salaam, 24.4.1989, Bl. 103; CCMA, CMM/OND/183/37/Vol. 1, Important Areas of Interest for Discussion in the Hungarian People's Republic by the CCM Delegation led by Dr. Salmin Amour, o.O., o.D. [ca. 1989/90], Bl.71; CCMA, CMM/OND/183/37/Vol. 2, Areas for Discussion during Visit in Hungary, o.O., o.D. [ca. 1989], Bl. 3.

248 Als Betreuer fungierte Alfred Kurtz, der auch am Institute of Development Studies in Dar es Salaam unterrichtete; siehe Kapitel 7.

$249 \mathrm{Zu}$ Polen siehe etwa CCMA/CMM/OND/183/46/Vol. I, Telegramm von [unleserlich] an CCMGeneralsekretär, 27.5.1986, Bl. 6. 
etwa bei Delegationen in die DDR in den Jahren 1985, 1986 und 1988, die mit hochrangigen und mittleren ParteifunktionärInnen sowie vereinzelten MinisteriumsbeamtInnen, UniversitätsprofessorInnen und DozentInnen verschiedener Institute besetzt waren.

Seitens der DDR versuchte man den tansanischen Kadern innerhalb eines Monats „mit Erfahrungen der Entwicklung unserer Landwirtschaft im Zeitraum von der demokratischen Bodenreform bis zur Herausbildung und Festigung der durch den freiwilligen Zusammenschluss von Bauern entstandenen Landwirtschaftlichen Produktionsgenossenschaften vertraut $\mathrm{zu}$ machen“.250 Die entscheidende Rolle von Partei und Staat in der Durchsetzung der Agrarpolitik und der Gedanke, dass die Vergenossenschaftlichung „die einzig wahre Lösung für den Fortschritt der Bauern“251 sei, wurden jedoch auf tansanischer Seite nicht einmütig hingenommen. Während einige Delegationsmitglieder davon überzeugt waren (oder sich überzeugen ließen), dass auch Tansania Staatsfarmen aufbauen und die Vergenossenschaftlichung im Agrarsektor vorantreiben sollte, äußerten andere Zweifel daran, dass eine derartige Agrarpolitik allein mit Mitteln der Überzeugung umsetzbar wäre. ${ }^{252}$ Die Erfahrungen der Ujamaa-Umsiedlungskampagne galten vielen als Beweis, dass eine Transformationsstrategie auf Basis von Vergenossenschaftlichung und Kollektivierung in Tansania nicht funktionieren könne. ${ }^{253}$ In ideologischer Hinsicht bekannten sich vor allem die jüngsten unter den mitgereisten Kadern zu einem nicht näher spezifizierten Sozialismus oder sogar zur „uneingeschränkte[n] Orientierung auf den Marxismus-Leninismus“, während die älteren sich mit entsprechenden Äußerungen zurückhielten. ${ }^{254}$ Mehrere TeilnehmerInnen meinten, dass weder der Staat noch die Partei in Tansania schlagkräftig organisiert und konsequent genug wäre, eine Politik, wie sie die DDR propagierte, durchsetzen zu können. ${ }^{255}$ Wie die DDR-Berichterstatter festhielten, herrschte bei den meisten älteren DelegationsteilnehmerInnen die Ansicht vor, dass staatliche und wirtschaftliche Interessen schwer vereinbar seien und staatliche Wirtschaftskontrolle in einer Bevormundung der Betriebe münde.

250 BArch Berlin, DK 1/26764, Semmelmann an Glemnitz, Berlin, 5.8.1988.

251 BArch Berlin, DK 1/26764, Glemnitz, Abschlußbericht über die Durchführung des 2. Kurses für Kader der CCM, Tanzania vom 18.6.86 bis 19.7.86, Zschortau, 18.7.1986, S. 4.

252 BArch Berlin, DK 1/26764, Glemnitz, Abschlußbericht für den 3. Kurs für Kader der CCM Tansanias (7.9.-2.10.1988), Zschortau, 30.9.1988, S. 5.

253 BArch Berlin, DK 1/26764, Glemnitz, Abschlußbericht über die Durchführung des 2. Kurses für Kader der CCM, Tanzania vom 18.6.86 bis 19.7.86, Zschortau, 18.7.1986, S. 4.

254 BArch Berlin, DK 1/26764, Glemnitz, Abschlussbericht über den Studienaufenthalt für leitende Kader der Partei der Revolution Tansania vom 25.4.-24.5.1985, o.O., o.D. [1985], S. 4.

255 Ebd., S. 5. 
Es sei „natürlicher, dass staatliche und betriebliche Interessen auseinanderfallen“, während „die Übereinstimmung der allgemein gesellschaftlichen mit den betrieblichen und persönlichen Interessen die Ausnahme“ darstelle. ${ }^{256}$

Diese Position fand in Tansania immer breitere Zustimmung. Seit Ende der 1970er-Jahre hatte sich ein Flügel formiert, der für wirtschaftliche Reformen plädierte. Finanzminister Edward Mtei nahm 1979 seinen Hut, nachdem er Nyerere ohne Erfolg geraten hatte, auf die Forderungen des IWF einzugehen; andere folgten ihm. Während der reformorientierten Präsidentschaft Ali Hassan Mwinyis kam es zu Spannungen zwischen Partei und Regierung, die sich auf entgegengesetzte Ansichten zur Reformpolitik und divergierende Biografieverläufe zurückführen lassen. In personeller Hinsicht äußerte sich die Spannung darin, dass der am Fernziel Sozialismus festhaltende Nyerere 1987 - für viele überraschend als Parteivorsitzender wiedergewählt wurde. Außerdem waren 1990 mit Präsident Mwinyi und Premierminister Warioba nur noch zwei Kabinettsmitglieder gleichzeitig im Zentralkomitee der CCM vertreten, während Anfang der 1980er Jahre noch elf von achtzehn Mitgliedern des Zentralkomitees auch der Regierung angehört hatten. ${ }^{257}$ Die in den 1970er-Jahren eng verquickten Entscheidungskreise von Regierung und Partei entflechteten sich im Zuge einer Polarisierung zwischen wirtschaftsliberalen Reform- und sozialpolitisch orientierten Anti-Reformkräften, die sich gegenseitig blockierten. Dementsprechend war die von westlichen Gebern geforderte „Strukturanpassung“ auch nach 1986 keinesfalls ein geradliniger Prozess. Bis zu seinem Rücktritt vom Parteivorsitz im August 1990 bremste Nyerere Reformen immer wieder aus. Gegen den vom Finanzminister vorgelegten Fünfjahresplan für die Jahre 1988-1993 legte die CCM ein Veto ein, weil er zu weit von der Parteilinie abweiche; Parteimitglieder und auch vereinzelte Minister pochten wiederholt auf egalitaristische Prinzipien, verhinderten die Durchsetzung von Reformen und stellten sich gegen die Deregulierung und Privatisierung der Wirtschaft. ${ }^{258}$ Erst mit der Verabschiedung der Zanzibar Declaration 1991 - die offiziell nur „Nachbesserungen“ an der Deklaration von Arusha 24 Jahre zuvor

256 BArch Berlin, DK 1/26764, Glemnitz, Zweiter Zwischenbericht über die Durchführung des 2. Kurses für Kader der CCM Tansania vom 18.6.-19.7.86, o.O., o.D. [1986], S. 2; ebd., Glemnitz, Erster Zwischenbericht über die Durchführung des 2. Kurses für CCM-Kader vom 18.6.--19.7.1986, Berichtszeitraum 18.6.-30.6.1986, Zschortau, o.D. [1986], S. 3.

257 Auslöser der Entzweiung waren die Reformen: Erst entfernte die alte Parteigarde die Unterstützer der Abkommensunterzeichnung mit dem IWF aus dem CCM-Zentralkomitee. Mwinyi revanchierte sich, indem er reformkritische Parteimitglieder wie Ngombale-Mwiru und Gertrude Mongella aus dem Kabinett verbannte. Aminzade, Race, S. 246; Tripp, Changing the Rules, S. $186-$ 189; Mlimuka/Kabudi, The State and the Party, S. 81.

258 Tripp, Changing the Rules, S. 162, 167. 
vornahm, deren Positionen aber in vielen Punkten unterwanderte und konterkarierte - war die sozialistische Fraktion, die self-reliance und Egalitarismus predigte, endgültig auf verlorenem Posten. Die Außerkraftsetzung des leadership code gab PolitikerInnen und höheren Staatsbediensteten nunmehr die Möglichkeit, weitere Einkommen zu beziehen und Zusatzgeschäfte in aller Offenheit zu betreiben. ${ }^{259}$ Politischer und (privat-)wirtschaftlicher Einfluss konnten fortan wieder in Personalunion ausgeübt werden.

\section{Fazit}

Der Liberalisierung der Wirtschaft folgte die Liberalisierung auf dem politischen Markt: 1992 wurde die Gründung neuer politischer Parteien zugelassen, die der CCM die Regierungsmacht aber bis dato nicht streitig machen konnten. Wie der Frelimo in Mosambik oder der MPLA in Angola, beide ehemalige Befreiungsbewegungen, die auch von Tansania unterstützt worden waren, gelang der CCM der Übergang in die postsozialistische Ära, ohne die Macht abgeben zu müssen. Die CCM ist damit die am längsten ohne Unterbrechung regierende Partei auf dem Kontinent, was ein beeindruckendes Zeugnis von Stabilität und Machterhaltungsstrategien darstellt. Drei Jahrzehnte vor der Wiedereinführung der Mehrparteiendemokratie hatte sich Tanganjika in den frühen 1960er-Jahren als unabhängiger Staat konstituiert und interne und externe Souveränität bis zu einem Grad hergestellt, der sogar erlaubte, das panafrikanische Ideal der Befreiung des Kontinents in die Praxis umzusetzen und Befreiungsbewegungen bis zum Ende der Apartheid zu unterstützen. Die politische Stabilität gab dem Staat auch nach innen Möglichkeiten, ein umfangreiches Entwicklungsprogramm $\mathrm{zu}$ initiieren und stärker in Wirtschaft und Gesellschaft zu intervenieren, um eine Transformation zu einer sozialistischen, egalitaristischen und auf eigenen Kräften basierenden Gesellschaft einzuleiten, was zur Überwindung kolonialer Abhängigkeiten und der Hebung des Lebensstandards der Bevölkerung führen sollte. Der Schwerpunkt dieser Bemühungen verlagerte sich Anfang der 1970er Jahre von Wohlfahrt, Teilhabe und politischer Mobilisierung auf Produktion, rigiden Bürokratismus und die Ausübung von Zwang, wobei sich Macht wie Ohnmacht des (keinesfalls einheitlichen) Einparteien-Entwicklungsstaates gleichermaßen manifestierten. Maßnahmen zur Disziplinierung von Arbeitskräften und die Umsiedlungskampagne waren Interventionen in die Gesellschaft, die nicht zu den gewünschten Produktionssteigerungen und Verhaltensänderungen führten.

259 Aminzade, Race, S. 247. 
Das Hauptproblem der Transformationsstrategien von oben war die Diskrepanz zwischen der Ressourcenbasis und den Ambitionen. Der Wandel vom global viel beachteten und hoffnungsvollen Experiment zur Krise betraf aber nicht nur das sozialistische Tansania, sondern auch marktwirtschaftlich orientierte Staaten wie Kenia oder die zeitweise als Vorzeigeland wirtschaftlicher Entwicklung gepriesene Côte d'Ivoire. ${ }^{260}$ Das ist ein deutlicher Hinweis darauf, dass nationale Faktoren und divergierende politische Strategien zur Erklärung der Enttäuschungen postkolonialer Jahrzehnte nicht genügen und auch strukturelle, historisch gewachsene Abhängigkeiten und globale Prozesse Beachtung finden müssen, wenn die Entwicklungsprojekte eine adäquate Beurteilung erfahren sollen.

Ujamaa war spätestens ab 1975 ein degenerierendes Projekt, wenngleich sowohl in Tansania wie auch über die Ländergrenzen hinweg das Experiment zwar als krisengeschüttelt, aber noch keineswegs als beendet galt. Im Gegenteil: Erst in den kommenden Jahren entfalteten sich die Widersprüche zwischen self-reliance und Abhängigkeit sowie Egalitarismus und Elitenbildung (also in der Verfolgung jener Ziele, die Tansania spezifisch sozialistisch machen sollten) zur Gänze. Die zeitweise wirksame Ideologie und Dominanz des politischen Feldes verlor ebenso wie die Vision einer egalitären Gesellschaft zunehmend an gesellschaftlichem Rückhalt, weil die faktisch bestehenden Ungleichheiten offensichtlicher und die Lebensbedingungen schlechter wurden. Lange bevor sich der Staat „zurückgezogen“ hatte, war nicht nur die ländliche, sondern auch die urbane Bevölkerung längst selbst dazu übergegangen, Überlebensstrategien fern staatlicher Einmischung und Patronage zu verfolgen.

Während des tansanischen Entwicklungsstaats mit Ujamaa das nation-building auf diskursiver und kultureller Ebene weitgehend gelang (sichtbar etwa in der Verankerung von Swahili als supraethnischer Nationalsprache und einer geteilten tansanischen Identität), blieb die Einbeziehung der Bevölkerung in die wirtschaftlichen Transformationsstrategien insbesondere im landwirtschaftlichen Sektor fragmentarisch - die „Durchstaatlichung“ der agrarischen Produktion scheiterte. ${ }^{261}$ Die Misserfolge führten zu einer Hinterfragung der Transformationsstrategien. Wie gezeigt waren in den 1980er-Jahren weite Teile der tansanischen Elite überzeugt, dass staatliche Autoritätsausübung für Tansania keinen geeigneten Weg darstellte - einerseits, weil Staat und Partei nicht über die notwendigen Ressourcen verfügten, um die Autorität durchzusetzen, bzw. in

260 Bamba, African Miracle.

261 Zur These der misslungenen „capture“ der Bevölkerung siehe u.a. Hydén, Beyond Ujamaa; Ivaska, Cultured States, S. 20, S. 210 -214, Walter Schicho, Ujamaa: Sozialismus und/oder Entwicklung, in: Joachim Becker/Rudy Weissenbacher, Hg., Sozialismen: Entwicklungsmodelle von Lenin bis Nyerere, Wien 2009, S. 175-188. 
produktive Ergebnisse zu überführen; andererseits, weil vorherige Versuche der Zwangsanwendung kontraproduktive Ergebnisse gezeitigt hatten. Die paternalistische Haltung, wie sie in der technokratischen Bürokratie und den Parteischaltstellen in den 1960er und 1970er-Jahren weithin anzutreffen war, erodierte ebenfalls. Der Höhepunkt der Wirtschaftskrise und die Liberalisierung in den 1980er Jahren gaben schließlich der Entfaltung „neuer“ wirtschaftlicher und politischer Eliten Raum - der aber durch die Vorgaben westlicher Geber, die mit dem Abdrehen des Geldhahns drohten, mitbestimmt wurde. Den Spielraum, wie 1965, eigene politische Prinzipien durchzusetzen und damit auf materielle Ressourcen zu verzichten (bzw. darauf setzen zu können, dass sich neue Ressourcenquellen eröffneten), hatte die Regierung in den 1980er Jahren nicht mehr.

Die vier Widersprüche zwischen Befreiung und Autoritarismus, Abhängigkeit und self-reliance, Egalitarismus und Elitenbildung sowie Einheit und Antagonismen, die Ujamaa kennzeichneten, wandelten sich mit diesen Konjunkturen. Sie prägten auch die Kooperation mit den beiden deutschen Staaten sowie die Handlungsorientierungen der Akteure der Entwicklungspolitik. Theoretisch konnten internationale Interventionen und Kooperationen auf allen diesen Ebenen in beide Richtungen wirken. Historisch konkret trugen sie aber meist zur Stärkung staatlicher Autorität gegenüber der Bevölkerung bei, förderten Elitenbildung statt Egalitarismus und vertieften die Abhängigkeit von externen Ressourcen. Das verdeutlichen auch die wechselhaften Beziehungen zu den beiden deutschen Staaten. 